\title{
2 Rhetorische Streitkultur, Polemik und ihre kommunikativen Situationen
}

Mit dem sogenannten ,Anschlag' (I5I7) und insbesondere mit der Veröffentlichung der Übersetzung der 95 Thesen (I 5 I 8$)^{42}$ sowie mit etlichen seiner folgenden Schriften rückte Martin Luther den unterschwellig vorhandenen Willen zur Kirchenreform ins Licht der damaligen Öffentlichkeit. ${ }^{43}$ Im Gegensatz zu den zahlreichen gescheiterten spätmittelalterlichen Reformversuchen konnten Luthers Reformbestrebungen nicht erneut in den Untergrund gedrängt werden. ${ }^{44}$ Sie erhielten innerhalb kürzester Zeit große Aufmerksamkeit in

${ }^{42}$ Pettegree, Andrew (2005): Reformation and the Culture of Persuasion. Cambridge: Cambridge University Press, S. I64.

${ }^{43}$ Das Verständnis von ,Öffentlichkeit' ist hier kein modernes (nach Jürgen Habermas), sondern das einer spätmittelalterlich-frühneuzeitlichen bzw. sogenannten „reformatorischen Öffentlichkeit“ und knüpft nach Rainer Wohlfeil „nicht an das Substantiv ,Öffentlichkeit‘ an, das seit der zweiten Hälfte des I 8. Jahrhunderts aufkam, sondern an das Adjektiv ,öffentlich', das um I 500 noch nicht die spätere Bedeutung von ,staatlich“ besaß, vielmehr ,klar', ,offensichtlich' bzw. , bekannt sein bezeichnete. Darüber hinaus begann sich die Wortbedeutung um den intendierten Aspekt zu erweitern, d. h. daß etwas dazu bestimmt ist, allgemein bekannt zu werden oder daß sein Bekanntsein nicht verhindert werde." Wohlfeil, Rainer (I984): „Reformatorische Öffentlichkeit“. In: Grenzmann, Ludger \& Karl Stackmann (Hg.): Literatur und Laienbildung im Spätmittelalter und in der Reformationszeit. Stuttgart: Metzlersche Verlagsbuchhandlung, S. 4I-52, hier S. 47. Betont werden soll außerdem Wohlfeils Feststellung, dass es sich um ein „System [handelt], in das der gemeine Mann bewußt dadurch einbezogen wurde und war, daß mündliche, visuelle und literarische Medien jedermann zugänglich waren, bzw. von jedermann benutzt oder zumindest zur Kenntnis genommen werden konnten." Ebd.

${ }_{44}$ Vgl. dazu: „Das seit dem Hochmittelalter bestehende Streben nach einer dem reinen Evangelium treuen Kirche hatte zu wiederholten Protestbewegungen gegen den Reichtum der Kleriker und die Verknüpfung der geistlichen mit der weltlichen

How to cite this book chapter:

Lundström, Kerstin. 2015. Rhetorische Streitkultur, Polemik und ihre kommunikativen Situationen. In: Lundström, Kerstin. Polemik in den Schriften Melchior Hoffmans: Inszenierungen rhetorischer Streitkultur in der Reformationszeit, Pp. 23-117. Stockholm: Stockholm University Press. DOI: http://dx.doi.org/10.16993/bae.b. License: CC-BY 
der Bevölkerung und Luthers Schriften erlangten - obwohl sie I 520 verboten wurden - eine Popularität, die einzigartig zu dieser Zeit war. In den Schriften fanden sich prägnant und anschaulich formulierte Überzeugungen, Kritikpunkte und Thesen, die mittels Buchdruck und Übersetzungen in die Volkssprache einem großen Kreis der Bevölkerung zugänglich gemacht wurden. Infolgedessen entstanden neue Positionen der öffentlichen Meinung, ${ }^{45}$ die die bisherigen Grenzen der geltenden religiösen, aber auch kulturellen und sozialen Normen und Regeln in Frage stellten und den Glaubensstreit ${ }^{46}$ der Reformation initiierten.

Macht geführt. Gegen die daraus hervorgehenden, als ketzerisch gebrandmarkten Gemeinschaften wehrte sich die Institution, ohne sie jedoch ausmerzen zu können. Die Krise, die das Schisma hervorgerufen hatte, lieferte dem Protest gegen die Papstkirche neue Argumente. Die im Untergrund nie ganz versiegte Strömung tauchte in England und in Böhmen wieder auf; Wyclifs Anlauf versandete zwar rasch, aber die hussitische Revolution kann durchaus als Vorspiel der Reformation angesehen werden. Mühsam wurde auch diese Häresie bezwungen. [...] Martin Luther verlieh der bis dahin sukzessiv verlaufenden Verwandlung des Abendlandes plötzlich einen ganz anderen Rhythmus. Es gelang ihm, das Erbe der mittelalterlichen Theologie in eine neue Form zu gießen und weiter zu entwickeln. Mit einer genialen Sprachbegabung formulierte er seine Überzeugungen derart zugespitzt, dass der Zündfunke seiner Thesen einen Flächenbrand auslöste - eine geistige Verwandtschaft verband ihn mit einem Großteil des deutschen Volkes." Rapp, Francis (2006): Christentum IV. Zwischen Mittelalter und Neuzeit (1378-I552). Stuttgart: Kohlhammer, S. 7.

45 „Die ,öffentliche Meinung“ ist ,nicht die Summe individueller Meinungen, sondern die als herrschende Meinung akzeptierte', die Meinung, die sich im öffentlichen Widerstreit von Meinungen als herrschende durchgesetzt oder herauskristallisiert hat.“ Wolf, Norbert Richard (I996): „Das Entstehen einer öffentlichen Streitkultur in deutscher Sprache“. In: Große, Rudolf \& Hans Wellmann (Hg.): Textarten im Sprachwandel - nach der Erfindung des Buchdrucks. Heidelberg: Universitätsverlag Winter, S. I35-I46, hier S. I37 (Binnenzitat nach „Kurt Koszyk: Öffentliche Meinung. In: Handbuch Massenkommunikation. Hg. von Kurt Koszyk und Karl Hugo Pruys. München I98I [dtv 4370], S. 214-217, hier S. 21 5“). Wolf spricht hier lediglich von einer herrschenden Meinung, es ist jedoch sinnvoller, davon auszugehen, dass mehrere dominierende Meinungen oder Meinungstendenzen gleichzeitig in der Öffentlichkeit existieren, die nicht miteinander konform sein müssen. Gerade ein öffentlicher Streit, wie z. B. die Reformation, ist Ausdruck einer solchen öffentlichen Meinungspluralität, die durchaus auch oppositionelle Positionen mit einschließt. Die Lösung des Streits kann dann die von Wolf beschriebene Situation die Dominanz einer Meinung - herstellen, muss sie aber nicht zwangsläufig zur Folge haben.

${ }^{46}$ Um sich einerseits dem zeitgenössischen Sprachgebrauch anzupassen (es wird zumeist um den rechten Glauben gestritten, ,Religion' wird in den früheren Schriften weitaus seltener genannt) und andererseits zu verdeutlichen, dass es sich noch nicht um einen Streit um Konfessionen bzw. die Spaltung einer Religion handelt, ist die Rede hier vom ,Glaubensstreit' und nicht ,Religionsstreit‘. Siehe auch das Deutsche 
Die Zeit der Reformation - hier sind hauptsächlich die I 5 2oer und zoer Jahre gemeint - umspannt insofern einen kulturellen Prozess, für den Streit eine zentrale Rolle spielt. In dieser von Streit geprägten Kultur und Zeit wirkten, wie bereits erwähnt, auch Laienprediger wie Melchior Hoffman bei Prozessen der Meinungsbildung aktiv mit sie sind Teil der ,Streitkultur' ihrer Zeit. Inwiefern sich die Schriften Melchior Hoffmans in dieser ,Streitkultur' der Reformationszeit verorten lassen, wird im Folgenden noch erörtert.

Zunächst ist jedoch zu klären, was unter dem Begriff ,Streitkultur ${ }^{6} \mathrm{zu}$ verstehen ist. Wie die Streitkultur der frühen Reformationszeit in ihrer Rekonstruktion sichtbar gemacht werden kann und inwiefern gerade die Reformation ein Zeitraum ist, in dem es naheliegt, eine Streitkultur in Abgrenzung zu Zeitspannen vor und nach diesem zeitlich begrenzten Rahmen zu verorten, sind ebenfalls Fragen, die als Ausgangspunkt für weitere Überlegungen dienen. Im Zuge dessen wird die Nuancierung der Streitkultur als eine, rhetorische Streitkultur' vorgeschlagen und eine Definition des Konzepts erarbeitet. Dieses Vorgehen rückt die Erscheinungsformen der Polemik und die Schriften, in denen Polemik zur Anwendung kommt, ins Zentrum der Untersuchung. Entlang dieser Fragestellungen wird im Folgenden in drei Schritten ein Abriss des theoretischen Hintergrunds der ,rhetorischen Streitkultur' in der Reformationszeit gegeben. Die theoretischen Überlegungen zu dominanten Mustern und generellen Tendenzen sowie die Definitionen der wichtigen Begriffe und erarbeiteten Untersuchungskriterien sind das

Wörterbuch von Jacob und Wilhelm Grimm, das eine der zwei Bedeutungen als „streit um die glaubenslehren“ definiert. Deutsches Wörterbuch von Jacob und Wilhelm Grimm (= DWB). I 6 Bde. in 32 Teilbänden. Leipzig I 854-I96I, Quellenverzeichnis Leipzig I97I, hier „GLAUBENSSTREIT“, Bd. 7, Sp. 7877 f. Für die Recherchen im Zuge dieser Arbeit wurde der Online-Zugang vom Kompetenzzentrum für elektronische Erschließungs- und Publikationsverfahren in den Geisteswissenschaften an der Universität Trier genutzt. URL: http://woerterbuchnetz.de/cgi-bin/WBNetz/ wbgui_py sigle=DWB\&mainmode= (I8.I0.20I5). Im Folgenden werden die bibliographischen Angaben verkürzt angegeben und beschränken sich auf Angaben des Bandes und der Spalte.

In den folgenden Kapitelüberschriften verbirgt sich hinter dem Wort ,Streit' immer der Glaubensstreit (oftmals im Plural auch mit ,Streitigkeiten' bezeichnet, wenn es um die Betonung einzelner Auseinandersetzungen geht), der sinnstiftend dem Verständnis von ,Reformation` zugrunde liegt. Die Verkürzung der untergeordneten Überschriften dient der Prägnanz und Vermeidung von Redundanzen. Eine detaillierte Begriffsdefinition und Erörterung des semantischen Wandels von ,Streit wird in diesem Kapitel an anderer Stelle (siehe Abschnitt Bedeutungsgeschichtliche Aspekte von ,Streit' im I6. Jahrhundert) vorgenommen. 
Fundament, auf dem die Untersuchung der Polemik Melchior Hoffmans aufbaut.

In einem ersten Schritt wird herausgearbeitet, wie die Kultur des Streits in der Reformationszeit entsteht, sich manifestiert und ausprägt. Mithilfe der Bestimmung und Erklärung der Konzepte ,Streit" und ,Streitkultur' werden die Prozesse der Entwicklung und Veränderung kultureller Regeln und Normen des Streitens beleuchtet. Zudem wird diskutiert, was die Bestimmung einer ,rhetorischen Streitkultur' leisten kann und wie der Begriff auf die Reformationszeit anzuwenden ist. Ziel in dem ersten Teilkapitel (2.I) ist es, das Konzept der ,rhetorischen Streitkultur ${ }^{6}$ auf Basis der Forschungsdiskussion zur ,Streitkultur ${ }^{6}$ zu entwickeln. Dabei spielt der Begriff der ,Streitinszenierung' eine zentrale Rolle. Anhand des Konzepts der ,rhetorischen Streitkultur' lassen sich die kulturellen Prozesse des Streits (mit denen die Schriften Melchior Hoffmans interagieren) schließlich veranschaulichen.

Im zweiten Teil des Kapitels (2.2) wird der Fokus auf die Mittel der ,Streitinszenierung' gesetzt. Dabei steht die Polemik als Methode der Streitinszenierung im Zentrum.Zunächst wird in der Auseinandersetzung mit verschiedenen Definitionsansätzen eine für die Arbeit grundlegende Definition dessen erörtert, was unter ,Polemik ${ }^{\mathbf{}}$ zu verstehen ist. In einem zweiten Schritt werden polemische Strategien erklärt und diskutiert, die zur „strukturellen Performativität" ${ }^{\text {"47 }}$ des Textes beitragen und insofern für die Inszenierung relevant sind.

Zuletzt wird im Kapitel (2.3) über die kommunikativen Situationen des Polemisierens reflektiert. Dabei steht die Vermittlung der Polemik im Vordergrund. Auf der Basis von Jürgen Stenzels Modell der „polemischen Situation" ${ }^{48}$ werden die Kommunikationsverhältnisse näher untersucht - und zwar sowohl auf der Text- als auch auf der Kontextebene. Entsprechend werden mittels dieser zwei Ebenen und ihrem Verhältnis zueinander jeweils zwei Grundformen der polemischen Kommunikationssituation identifiziert. Zum einen wird auf der Ebene der Text-Kontext-Beziehung eine Einteilung in offenes und

47 Häsner, Bernd, Henning S. Hufnagel, Irmgard Maassen \& Anita Traninger (20I I): „Text und Performativität“. In: Hempfer, Klaus W. \& Jörg Volbers (Hg.): Theorien des Performativen. Sprache - Wissen - Praxis. Eine kritische Bestandsaufnahme. Bielefeld: transcript, S. 69-96, hier S. 82.

${ }^{4}$ Stenzel, Jürgen (I986): „Rhetorischer Manichäismus. Vorschläge zu einer Theorie der Polemik“. In: Worstbrock, Franz Josef \& Helmut Koopmann (Hg.): Formen und Formgeschichte des Streitens. Bd. 2. Der Literaturstreit. Tübingen: Niemeyer, S. 3-II, hier S. 4 (Hervorhebung im Original). 
verdecktes Polemisieren vorgenommen, zum anderen wird auf der Textebene zwischen direktem und indirektem Polemisieren unterschieden. Die so herausgearbeiteten Formen des Polemisierens dienen bei den Untersuchungen der Polemik in Melchior Hoffmans Schriften als zentrales Analysewerkzeug.

\subsection{Die Kultur des Streits (in der Reformationszeit)}

Innerhalb der letzten zwei Jahrzehnte hat der Begriff ,Streitkultur' in verschiedenen Disziplinen Fuß fassen können, so dass es zahlreiche Untersuchungen zu diesem Thema z. B. in der Sozialwissenschaft, Politikwissenschaft, Geschichtswissenschaft, Psychologie, Bildungswissenschaften, Linguistik und anderen Wissenschaftszweigen gibt. ${ }^{49}$ Insbesondere auch in der (historischen) Kultur- und Literaturwissenschaft ist das Thema Streitkultur(en) vermehrt zu einem Untersuchungsgegenstand avanciert und hat eine Vielzahl von Publikationen, vor allem Konferenz- und Sammelbände, hervorgebracht, die sich sowohl mit dem Terminus als auch mit den verschiedenen Formen von Streit und Streitkultur befassen. ${ }^{50}$

Bei den Abgrenzungen des Begriffs ,Streitkultur' fällt jedoch auf, dass von unterschiedlichen Definitionen ausgegangen wird, die im Allgemeinen auf einem differierenden Verständnis von ,Streit` beruhen.

${ }^{49}$ Hier seien chronologisch nur einige Publikationen genannt, die den Begriff ,Streitkultur' bereits im Titel tragen: Sarcinelli, Ulrich (I990): Demokratische Streitkultur: Theoretische Grundpositionen und Handlungsalternativen in Politikfeldern. Bonn: Westdeutscher Verlag. Wagner, Peter (I997): Streitkultur: Vom Ende der Rechthaberei. Produktiver Streit als Grundlage. Wien: expert verlag/ Linde Verlag. Geißler, Peter \& Klaus Rückert (Hg.) (2000): Mediation, die neue Streitkultur. Gießen: Psychosozial-Verlag. Haack, Julia (2008): Der vergällte Alltag: zur Streitkultur im I 8. Jahrhundert. Köln u. a.: Böhlau.

5o Auch hier sei nur eine kleine Auswahl wiedergegeben: Mauser, Wolfram \& Günter Saße (Hg.) (1993): Streitkultur: Strategien des Überzeugens im Werk Lessings. Tübingen: Niemeyer. Monteath, Peter \& Reinhard Alter (Hg.) (I996): Kulturstreit - Streitkultur: German Literature Since the Wall (= German Monitor). Amsterdam: Rodopi. Eriksson, Magnus \& Barbara Krug-Richter (Hg.) (2003a): Streitkulturen. Gewalt, Konflikt und Kommunikation in der ländlichen Gesellschaft ( I 6.-I9. Jahrhundert). Köln u. a.: Böhlau. Baumann, Uwe, Arnold Becker \& Astrid Steiner-Weber (Hg.) (2008a): Streitkultur - Okzidentale Traditionen des Streitens in Literatur, Geschichte und Kunst (= Super alta perennis. Studien zur Wirkung der Klassischen Antike 2). Göttingen: V\&R unipress. Gebhard, Gunther, Oliver Geisler \& Steffen Schröter (Hg.) (2008a): StreitKulturen: Polemische und antagonistische Konstellationen in Geschichte und Gegenwart. Bielefeld: transcript. Laureys, Marc \& Roswitha Simons (Hg.) (20Iоa): Die Kunst des Streitens. Inszenierung, Formen und Funktionen öffentlichen Streits in historischer Perspektive. Göttingen: V\&R unipress. 
Im Folgenden sollen daher die Entstehung und Entwicklung, also die konkrete Manifestation des Streits im frühen I6. Jahrhundert, in Grundzügen dargestellt werden, wobei der Blick aber immer wieder auf die übergreifenden Konzepte von ,Streit' und ,Streitkultur' gerichtet wird. Ziel ist es, die Ausformung des Streits der Reformation zu ergründen und die Prozesse seiner Kultivierung - das Entstehen und Ausformen der volkssprachlichen ,rhetorischen Streitkultur ${ }^{6}$ - zu veranschaulichen.

\subsubsection{Verständnis von ,Streit' und ,Streitkultur`}

Auseinandersetzungen und Konflikte sind für das gemeinschaftliche Dasein der Menschen nichts Außergewöhnliches, sondern gehören zum alltäglichen sozialen Leben. Sie können jedoch auf verschiedenen Ebenen stattfinden und haben dementsprechend Einfluss auf das gesellschaftliche Leben: Auf einer privaten Ebene bleiben sie zumeist ohne gesellschaftliche oder kulturelle Breitenwirkung, wenn sie jedoch öffentliche Formen ${ }^{51}$ annehmen und medial ausgetragen oder repräsentiert werden, können sie zu historischen Ereignissen werden..$^{52}$

Der Glaubensstreit der Reformation und die darunter fallenden verschiedenen individuellen Streitigkeiten bzw. Streitakte ${ }^{53}$ sind als solche Praktiken zu betrachten, die erst durch die Manifestation in den gedruckten Flugblättern und Flugschriften entstehen, sich formieren und sich verändern. Die Publikationsflut von gedruckten Schriften, die sich mit dem Streit befassen oder direkt bzw. indirekt in Verbindung mit ihm stehen, war die Folge und nahm sowohl quantitativ als auch

${ }^{51}$ Hierunter sind zum Beispiel politische Auseinandersetzungen bis hin zum Krieg zu verstehen sowie politische, soziale und kulturelle Konflikte, Rechtsstreitigkeiten etc., die eine größere Menschenmenge betreffen und öffentliches Interesse wecken.

${ }_{52}$ Nicht jede gesellschaftliche Handlung kann als ,Ereignis' bezeichnet werden. Frank Bösch unterscheidet zwischen ,Geschehen' und ,Ereignis' anhand des Kriteriums der medialen Vermittlung: „Die notwendige breite Kommunikation vollzieht sich in der Neuzeit in überregionalen Räumen wiederum medial, ebenso die öffentliche Sinnbildung - sei es durch Boten, Flugblätter oder das Fernsehen, deren und dessen Zuschreibungen erst ein Geschehen zu einem Ereignis machen.“ Bösch, Frank (20Iо): „Europäische Medienereignisse“. In: Europäische Geschichte Online (EGO). Hg. vom Institut für Europäische Geschichte (IEG), Mainz 2010-I2-03. URL: http://www.ieg-ego.eu/boeschf-20IO-de (I 8.I0.20I 5).

${ }_{53}$ Nachfolgend soll ,Streit' in diesem Zusammenhang immer als Oberbegriff verstanden werden, der die einzelnen ,Streitigkeiten“ oder ,Streitakte' in sich zusammenfasst und gleichzeitig abstrahiert repräsentiert. Der Begriff ,Streitakt` geht zurück auf Gierl, Martin (I997): Pietismus und Aufklärung. Theologische Polemik und die Kommunikationsreform der Wissenschaft am Ende des 17. Jahrhunderts. Göttingen: Vandenhoeck \& Ruprecht. 
in ihrer Wirkmächtigkeit zu, wie es für diese Zeit einzigartig war. Erstmals kam es zu einer verdichteten Kommunikation in erster Linie durch Druckerzeugnisse, ${ }^{54}$ die die Glaubensfrage ins Zentrum des Interesses einer breiteren Öffentlichkeit rückten ${ }^{55}$ und die reformatorischen Glaubensstreitigkeiten zum „erste[n] veritable[n] Medienereignis machten ". ${ }^{56}$ Die Kombination von Gutenbergs Drucktechnik und dem Bedürfnis nach Reform der Kirche ermöglichte, dass die Reformation, die in engerem Sinne als Synonym für den Streit um den rechten Glauben stehen kann, zu einem einschneidenden und medialen Ereignis wurde. ${ }^{57}$

${ }_{54}$ Bernd Balzer spricht in diesem Zusammenhang auch von der Entstehung einer ,Öffentlichkeit':,[W]eit über die phänomenologische Analogie hinaus ist die Frühreformation das erste Beispiel einer politisch fungierenden Öffentlichkeit bürgerlichen Zuschnitts. Konstituens und Forum dieser Öffentlichkeit zugleich sind die Flugschriften. “ Balzer, Bernd (I973): Bürgerliche Reformationspropaganda. Die Flugschriften des Hans Sachs in den Jahren I 523-I 525. Stuttgart: J.B. Metzlersche Verlagsbuchhandlung, S. I3.

55 Der von Wolfgang Stammler verwendete Ausdruck „Lutherische Pause“ (Überschrift des vierten Abschnitts) ist zwar kritisch zu betrachten, da ihm ein eingeschränkter Literaturbegriff zugrunde liegt und die Bezeichnung „Pause“ der Fülle der Publikationen nicht gerecht wird, er impliziert aber zumindest die wichtige Stellung von Luthers Schriften und Ideen sowie die Rolle der damit verbundenen Agitationsliteratur überhaupt. Stammler, Wolfgang (I950): Von der Mystik zum Barock. I400-I600 (= Epochen der deutschen Literatur II: I). Stuttgart: Metzlersche Verlagsbuchhandlung. Vgl. dazu auch Müller, Jan-Dirk (20I I): „Die Frühe Neuzeit in der Literaturgeschichtsschreibung“. In: Lepper, Marcel \& Dirk Werle (Hg.): Entdeckung der frühen Neuzeit. Konstruktionen einer Epoche der Literatur- und Sprachgeschichte seit I 750 . Stuttgart: Hirzel Verlag, S. I 5-38.

${ }_{56}$ Würgler, Andreas (2009): Medien in der frühen Neuzeit (= Enzyklopädie deutscher Geschichte 85). München: Oldenbourg, S. I6. Nick Couldry und Andreas Hepp fassen den Begriff des Medienereignisses folgendermaßen zusammen: „[M]edia events are certain situated, thickened, centering performances of mediated communication that are focused on a specific thematic core, cross different media products and reach a wide and diverse multiplicity of audiences and participants." Couldry, Nick \& Andreas Hepp (2009): „Introduction: media events in globalized media cultures“. In: Dies. \& Friedrich Krotz (Hg.): Media Events in a Global Age. New York: Routlegde, S. I-20, hier S. I2. Trotz zeitlicher Festlegung auf das ,Zeitalter der Globalisierung، ist dieses Verständnis auch für die Reformationszeit zutreffend. Ebenfalls rekurriert das Verständnis von ,Medienereignis‘ in der vorliegenden Arbeit auf den Aufsatz ,Europäische Medienereignisse' von Frank Bösch (2010). Vgl. auch Hamm, Berndt (I996): „Die Reformation als Medienereignis“. In: Jahrbuch für Biblische Theologie. Bd. II. Neukirchen-Vluyn: Neukirchener Verlag, S. I37-166 und Nieden, Marcel (2012): „Die Wittenberger Reformation als Medienereignis“. In: Europäische Geschichte Online (EGO). Hg. vom Institut für Europäische Geschichte (IEG), Mainz. URL: http://www.ieg-ego.eu/niedenm20I2-de (I8.10.20I5).

57 Vgl. Bösch (2010). Vgl. dazu auch Roelker, Nancy L. (I980): „The Impact of the Reformation Era on Communication and Propaganda“. In: Lasswell, Harold D., 
Neben den durch die neue Drucktechnik florierenden Printmedien war die Volkssprache ein wichtiger Faktor für die Verbreitung und Durchschlagskraft der reformatorischen Botschaft. Sie und die Reformation standen in einem engen Verhältnis zueinander: Einerseits lieferte die Volkssprache das Fundament für den Erfolg der Reformation in der Öffentlichkeit, da durch sie ein Publikum erschlossen werden konnte, das sich nicht nur auf die lateinkundigen Gelehrten beschränkte, andererseits war die Reformation die Triebfeder, die das volkssprachliche Schrifttum vorantrieb, neue literarische Formen sowie eine große Anzahl von neuen Autortypen generierte. ${ }^{5}{ }^{8}$ Besonders die volkssprachliche Vermittlung von Luthers Lehre vom ,Priestertum aller Gläubigen' und dem Prinzip des sola scriptura schaffte die Voraussetzung dafür, dass auch Nicht-Kleriker und Nicht-Studierte aktiv am Streit über den Glauben im Allgemeinen und bestimmte religiöse Fragen im Besonderen (z. B. der Liturgie) teilnehmen konnten. ${ }^{59}$ Durch die lutherischen Maximen und die Desakralisierung der Priester erfuhr der Laienstand eine Aufwertung. Die den Laien bis dahin zugedachte passive Empfängerrolle wurde in Frage gestellt. Laien bekamen eine Stimme und verschafften sich Gehör innerhalb eines Diskurses, der ihnen zuvor nur unter eingeschränkten Bedingungen offenstand. Infolge der quantitativen sowie qualitativen Erweiterung der Beteiligten und weiterentwickelter Kommunikationsweisen veränderte sich auch der Diskurs. Bernd Moeller spricht in dem Zusammenhang von einem

Daniel Lerner \& Hans Speier (Hg.): Propaganda and Communication in World History. Volume II: Emergence of Public Opinion in the West. Honululu: University Press of Hawaii, S. 4I-84, insbesondere S. $78 \mathrm{f}$.

${ }^{8} \mathrm{Vgl}$. dazu: „Unstrittig ist, dass nicht nur die neuen Medien die Reformation prägten, sondern dass auch die Medienlandschaft durch die Reformation expandierte, volkssprachlicher wurde und neue Formate ausbildete. Sowohl der quantitative Anstieg an Drucken als auch die qualitative Veränderung der Texte mit ihrem mobilisierenden Gehalt ist evident." Bösch (20IO). Vgl. auch Bösch, Frank (20II): Mediengeschichte. Vom asiatischen Buchdruck zum Fernsehen. Frankfurt/Main \& New York: Campus Verlag, S. $53 \mathrm{f}$.

59 Vgl. dazu: „The doctrine of Scripture alone [...] was powerful not only because of its radical rhetorical simplification, but because it was reinforced in virtually every medium: through preaching, through the pamphlets on the streets, and finally of course through the publication of the Bible itself. The appearance of the September Testament in I 522 was an instantaneous publishing sensation." Pettegree (2005), S. 169 . 
„,Kommunikationsprozeß‘[, der] die deutlichste Manifestation der frühen Reformation überhaupt gewesen sein dürfte" .60

Dieser Kommunikationsprozess ist größtenteils Resultat dessen, was Streit an Eigenschaften und Prozessen mit sich bringt. Auf den ersten Blick ist ,Streit' als Begriff negativ besetzt, er entzweit und verursacht Disharmonie, ein Zustand, der auf sämtlichen Ebenen des gesellschaftlichen Lebens als nicht erstrebenswert bewertet wird. Bei seiner Initiierung bricht Streit den Konsens und die Einförmigkeit auf und manifestiert neue Positionen. In diesem Prozess, der aus einer Position zwei oder mehrere macht bzw. einer von der aktuellen oder dominierenden Position abweichenden Meinung Relevanz einräumt, ${ }^{6 \mathrm{I}}$ übernimmt Streit die Funktion der (Neu-)Verhandlung gesellschaftlicher und kultureller Fragen und trägt damit zum ständigen Wandel der Strukturen sozialer Kommunikation bei:

[...] Streit schafft [...] Kultur, und zwar in dem Sinne, dass Streit kulturelle und gesellschaftliche Bindungen in Formen hervorbringt und konstituiert. Mit Georg Simmel kann Streit als eine Form der Vergesellschaftung konzipiert werden. ${ }^{62}$

Streit ist demnach ein Motor von sozialen Prozessen, die die Kultur einer Gesellschaft strukturieren, und zu den „kulturellen Praktiken, die für den dauerhaften Bestand und die Entwicklung menschlicher Gemeinschaften notwendig sind ", ${ }^{63}$ zu zählen.

Einen positiven, produktiven Effekt von Streit - wenn auch auf eine andere Weise als Simmel es auffasst - beschreibt Melchior Hoffman selbst schon ${ }_{52} 28$ in seiner ersten Streitschrift gegen Nikolaus von

${ }^{60}$ Moeller, Bernd (I994): „Die frühe Reformation als Kommunikationsprozeß“. In: Boockmann, Hartmut (Hg.): Kirche und Gesellschaft im Heiligen Römischen Reich des I5. und I6. Jahrhunderts. Göttingen: Vandenhoeck \& Ruprecht, S. I48-164, hier S. I 53 .

${ }^{61}$ Das bedeutet nicht, dass abweichende Positionen vor dem Streitbeginn nicht vorhanden sind. Dennoch gibt erst die sprachliche Formulierung, die den Streit ins Leben ruft, dieser Position Ausdruck und macht sie für andere als solche wahrnehmbar.

${ }^{62}$ Baumann, Uwe, Arnold Becker \& Astrid Steiner-Weber (2008b): „Vorwort“. In: Dies. (Hg.): Streitkultur - Okzidentale Traditionen des Streitens in Literatur, Geschichte und Kunst. Göttingen: V\&R unipress, S. I-V, hier S. II. Vgl. dazu auch Bremers detaillierte Auseinandersetzung mit Georg Simmel und der „,kollektivierende[n] Wirkung des Streites““ in Bremer (2005) S. 2I3-22I.

${ }_{63}$ Laureys, Marc \& Roswitha Simons (20Iob): „Einleitung“. In: Dies. (Hg.): Die Kunst des Streitens. Inszenierung, Formen und Funktionen öffentlichen Streits in historischer Perspektive. Göttingen: V\&R unipress, S. 9-1 5, hier S. 9. 
Amsdorf. Das Wort an sein Publikum, die „vtherwelden Christen vnde Gades hyligen “, ${ }^{64}$ richtend erklärt er:

ergert iuw nicht am kyue der Lerer / [...] Wente wennèr also ein donder ys in den geistliken wolcken / welcker de Lerer synt / so regent denn dat lutter Gades wort mit frowden / v $\bar{n}$ mit rechter krafft / dat denn de geistliken fruchtbarheit vp erden bringet. ${ }^{65}$

Mit der Metapher eines Gewitters erklärt Hoffman seine Auffassung des positiven Effekts von Streit und schreibt der geistlich-gelehrten Auseinandersetzung - ähnlich dem Prinzip des platonischen Dialogs eine dialektische Funktion zu, denn das Gotteswort tritt aus ihr reiner, klarer und gestärkt hervor und trägt auf diese Weise zur christlichen Wahrheitsfindung bei. Als Zusatz äußert Hoffman zudem das Vertrauen darauf, dass "de důuvel vnde dat kaff / vnde de valsche bueckknecht“ von selbst entlarvt werden. ${ }^{66}$ Dass Streit den Falschen, den Unrechten, nutzen könnte, negiert er durch das Vertrauen auf Gott. Streit wird von Hoffman als natürlicher Prozess dargestellt, der dem Hervortreten der göttlichen Wahrheit dient.

Im Unterschied zu Simmels Überlegungen und dem postmodernen kulturwissenschaftlichen Denken sind Hoffmans Vorstellungen teleologisch aufgeladen: Bei ihm führt der Streit zur Wahrheitsfindung. Im Sinne eines konstruktivistischen Kulturbegriffs spricht man nicht mehr vom Auffinden präexistentieller objektiver Wahrheiten, sondern von Kulturproduktion, die kulturelle Konventionen, Erscheinungsformen und Prozesse generiert.

${ }^{64}$ Hoffman, Melchior (I 528): Dat Nicolaus Amsdorff, A4r. Übersetzung: „[die] auserwählten Christen und Gottesheiligen“. Diese und sämtliche nachfolgende Übersetzungen aus mittelniederdeutschen und mittelniederländischen Originalen in heutiges Deutsch sind zur Verständnissicherung von der Verfasserin der vorliegenden Arbeit erstellt worden. Verwendetes Hilfsmittel für diese und folgende Übersetzungen: Schiller, Karl \& August Lübben (I 875-I88I): Mittelniederdeutsches Wörterbuch. 6 Bde. Bremen: Kühtmann [u. a.]. Digitalisat: URL: http://www. rzuser.uni-heidelberg.de/ cd2/drw/s/Sa-schm.htm\#Schiller-Lubben (I8.IO.20I 5). Im Folgenden wiedergegeben als Schiller-Lübben.

${ }^{65}$ „Ärgert euch nicht über den Streit der Lehrer/Gelehrten, denn wenn solch ein Donner in den geistlichen Wolken ist, welche die Lehrer/Gelehrten sind, so regnet dann das klare Gotteswort mit Freuden und mit rechter Kraft nieder, das dann die geistliche Fruchtbarkeit auf Erden bringt." Hoffman (I 528 ): Dat Nicolaus Amsdorff, A4r.

${ }^{66}$ „die Teufel und die Spreu und die falschen Bauchknechte“. Hoffman (I 528 ): Dat Nicolaus Amsdorff, A4r. 
,Kultur' wird im Zusammenhang der gemachten Ausführungen zum produktiven Potential des Streits als ein diskursives Konstrukt, ${ }^{67}$ „als der von Menschen erzeugte Gesamtkomplex von Vorstellungen, Denkformen, Empfindungsweisen, Werten und Bedeutungen aufgefasst, der sich in Symbolsystemen materialisiert" ". ${ }^{68}$ In dieser weitgefassten Auffassung beinhaltet Kultur einerseits die mentale Grundlage für das menschliche Zusammenleben in den verschiedenen Lebensbereichen, andererseits die daraus resultierenden materiellen (Re)Präsentationen. ${ }^{69}$ In der Funktion einer kulturellen Praktik - einer Handlung, die Kultur(en) reproduziert und mit konstruiert - ist Streit ein Motivator, die materiellen und mentalen Strukturen herauszufordern und zu modifizieren. ${ }^{\circ}$

${ }^{67}$ Vgl. dazu Keller, der bei seiner Definition von „Kultur als Diskursfeld“ (Beitragstitel) indirekt auf den Stellenwert von Streit rekurriert: „Kultur als Diskursfeld zu begreifen, impliziert, auf Auseinandersetzungen um Reproduktion und Veränderung von Deutungsweisen und Handlungspraktiken hinzuweisen, die vielgestaltige Strukturiertheit, (Re-)Produktion, Heterogenität und Wandelbarkeit soziokultureller Ein- oder besser: ,Vielheiten', die Bedeutung der diskursiven Artikulationskämpfe für die Erzeugung, Identitätsstabilisierung und Transformation solcher DiskursKollektive zu betonen.“ Keller, Reiner (2003): „Kultur als Diskursfeld“. In: Geideck, Susan \& Wolf-Andreas Liebert (Hg.): Sinnformeln. Linguistische und soziologische Analysen von Leitbildern, Metaphern und anderen kollektiven Orientierungsmustern. Berlin \& New York: De Gruyter, S. 283-305, hier S. 285.

${ }^{68}$ Nünning, Ansgar (2009): „Vielfalt der Kulturbegriffe“. Bundeszentrale für politische Bildung (Hg.). URL: http://www.bpb.de/themen/IXSSWE.html ( I 8.I0.20 I 5). Vgl. dazu auch: „Kultur ist dann als dynamisches, konflikthaftes ,Diskursfeld“ (Schiffauer I995) zu begreifen, d. h. als permanenter Aushandlungsprozess von symbolischen Ordnungen, Artefakten und angemessenen Praktiken, der in unterschiedlichen sozialen Arenen, auf verschiedenen gesellschaftlichen Ebenen, unter Beteiligung heterogener gesellschaftlicher Akteure geführt wird und nur vorübergehend sozial-räumlich feste Muster oder Strukturen kristallisiert. “ Keller (2003), S. 284.

${ }^{69} \mathrm{Vgl}$. Nünning (2009).

70 Max Ohrlich sieht in Anlehnung an Wolfgang Eßbach (1996) Kultur als eine Grenzfrage und Streit als Grenzen verhandelndes Element: „Die Grenzfrage als Kernelement von Kultur manifestiert sich im Streit darüber, was Kultur ist oder sein kann. Streit macht Grenzen sichtbar und führt so ein selbstreflexives Element ein. Im Streit wird der abstrakte Möglichkeitsraum des Außen transformiert in das konkrete Aufeinandertreffen verschiedener Ziele und Mittel, um deren Umsetzung und Verwirklichung im Inneren gerungen wird. [...] Nur dadurch, dass etwas anderes als Kultur aufgefaßt wird, nur durch den Blick über die Grenze, ist es möglich, auch das Eigene als Kultur zu konzipieren. “ Ohrlich, Max (2008): „,Don’t be nice it's the kiss of death'. Streitlust und Streitkultur der Avantgarden“. In: Gebhard, Gunther, Oliver Geisler \& Steffen Schröter (Hg.): StreitKulturen: Polemische und antagonistische Konstellationen in Geschichte und Gegenwart. Bielefeld: transcript, S. 97-I24, hier S. 97 f. 
Streit (als kulturelle Praktik) und andere kulturelle Erscheinungsformen stehen folglich in einer wechselseitigen Beziehung zueinander und bedingen gegenseitig ihre Erscheinungsformen. Gleichzeitig generiert und erneuert Streit auf einer Metaebene seine eigenen, ihm zugrunde liegenden Konfliktaustragungsstrukturen. Streit muss folglich kein negatives Phänomen sein, sondern zeigt sich auch als

sozial produktiv, da er die Elemente seiner eigenen Normierung und Regulierung, die wir dann als Kultur bezeichnen, in sich selbst entwickelt, stabilisiert und verändert, und zugleich die Grenzen gesellschaftlicher Toleranz auslotet. ${ }^{71}$

Die Grenzen der spätmittelalterlichen Gesellschaft wurden dementsprechend durch die von Martin Luther initiierten Streitigkeiten neu ausgelotet. Luther formulierte in seinen zahlreichen Schriften Positionen, die (untergründig) seit dem Mittelalter sukzessiv herangewachsen, bis zu dem Zeitpunkt aber durch die vorherrschenden Machtstrukturen unterdrückt worden waren oder aus anderen Gründen keine Durchschlagkraft besessen hatten. ${ }^{72}$ Luther präzisierte die Kritik, die schon im Mittelalter und dann besonders im Spätmittelalter Tenor sowohl gelehrter und ungelehrter Bevölkerungsgruppen (und Anlass mehrerer Reformversuche) war, und brachte sie mit Hilfe des Drucks an die Oberfläche.

Die Kirche hatte ihr eurozentrisches Imperium über Jahrhunderte aufgebaut und war mit den weltlichen Hierarchiestrukturen weitgehend eng verwoben. Sozial wie politisch war sie machtvolle Kontrollinstanz des menschlichen Lebens und bestimmte das gesamte Mittelalter hindurch sowohl ideologisch als auch praktisch den Alltag und das Zusammenleben. ${ }^{73}$ Sie gestaltete sämtliche Tages-, Wochen- und

${ }^{71}$ Baumann et al. (2008b), S. II.

${ }^{72}$ Mehr zu den verschiedenen Reformbestrebungen vor Luther bei Rapp (2006), S. $24 \mathrm{I}-304$.

73 Bernd Moeller beschreibt ausführlich die Rolle der Kirche mit ihren vielzähligen Einflussbereichen und macht damit deutlich, wie omnipräsent sich die mittelalterliche Kirche zeigte: „In gewisser Hinsicht handelte es sich hier ja um einen für das ganze Mittelalter bedeutsamen Sachverhalt: Daß die Kirche das Leben regierte, das ewige Heil vermittelte und deren irdische Wege lenkte, überwachte und beurteilte; daß sie die Wahrheit verwaltete und alle Lehre, Bildung und Weisheit zur Verfügung stellte; daß sie das Verhältnis der Menschen zur Natur regulierte, indem sie den Tages-, Jahres- und Lebenslauf mit sakralen Veranstaltungen begleitete; daß sie mit ihren Grundsätzen die gesellschaftlichen Ordnungen formte, Ehe und Familie, Stand und Beruf, Staat und Wirtschaft, das Reich und die Christenheit; daß sie beträchtliche materielle Güter besaß und selbst als Grundherr, Richter und Obrigkeit eine wirtschaftlich-politische Großorganisation bildete; daß sie zumal für die Notstände 
Jahresabläufe mit ihren zahlreichen Ritualen von der Messe bis zur Taufe $^{74}$ und beeinflusste die mentale Lebensanschauung, nicht zuletzt durch den „Besitz an heilsvermittelnden Gaben und sinngebenden Wahrheiten ".75 Mit dem religiösen Menschen- und Weltbild ging eine sich zum Spätmittelalter tendenziell steigernde Volksfrömmigkeit einher, die sich in einer aktiven Beteiligung von Laien über die geforderten Rituale hinaus äußerte. Trotz dieser Frömmigkeitstendenzen und der allgemeinen Vormachtstellung geriet die Kirche aus verschiedenen Gründen auch immer wieder in Verruf: „Es waren Gegenpositionen ausgebildet, Befreiungsversuche unternommen worden, die Kirche selbst war durch Mißstände, Unsicherheiten und Spaltungen geschwächt, der radikale Protest, die ,Ketzerei', hatte geblüht“..76 Mönche und Priester waren oftmals selbst weit entfernt davon, die Ideale, die sie predigten, zu erfüllen. Zudem begann die Kirche zunehmend, die Bevölkerung für ihre Dienste finanziell heranzuziehen. Der vermehrte Missbrauch des Ablasshandels ist ein prominentes Beispiel dafür, wie der Klerus sich durch das Heilsbedürfnis der Menschen bereicherte, um die Kassen von Rom zu füllen. Die finanzielle Ausbeutung sowie das nicht selten offensichtliche unmoralische Verhalten einiger Vertreter des Klerus hatten zu einem spätmittelalterlichen Antiklerikalismus geführt: Auf der Basis einer gesteigerten Frömmigkeit der Laien verurteilte man die lasterhaften Amtsträger der Kirche, „[d]as Vertrauen der Laien in die heilsvermittelnde Kraft der Priester nahm ab und schlug in ein aggressives Misstrauen gegenüber dem Klerus allgemein um “. ${ }^{77}$

Als Kind seiner Zeit und vor allem als Mönch kannte Luther die religiöse Weltordnung und den Missbrauch dieser Hierarchien, z. B. beim Ablass. Er hatte sowohl das gesteigerte Heilsbedürfnis als auch die gleichzeitige Unzufriedenheit der Bevölkerung mit der Ausübung der kirchlichen Ämter und Aufgaben verinnerlicht. ${ }^{7}$ Als Augustiner hatte Luther bereits das Konzept der göttlichen Gnade, die den Sünder ohne das Zutun menschlicher Werke errettet, verinnerlicht, was zu seiner

und Grenzfälle des Lebens zuständig und sachverständig war, Tröstung und Hilfe bot, aber auch zu drohen, zu ängstigen, zu entsetzen wußte - dies alles hatte schon im frühen Mittelalter gegolten." Moeller, Bernd (1999): Deutschland im Zeitalter der Reformation. Göttingen: Vandenhoeck \& Ruprecht, S. 36.

${ }^{74}$ Rapp (2006), S. I 87.

75 Moeller (1999), S. 39.

${ }^{76}$ Ebd., S. 37.

77 Goertz, Hans-Jürgen (2004): Deutschland I500-I648. Eine zertrennte Welt. Paderborn: Schöningh/UTB, S. 8I.

${ }^{78} \mathrm{Vgl}$. Goertz (2004), S. 8If. 
Ablehnung ebendieser menschlichen Werke und deren Missbrauch beigetragen haben wird. Mit der Verurteilung der Missstände seiner Zeit brachte er die kritischen Tendenzen auf den Punkt und forderte damit bewusst oder unbewusst auch die bestehenden Machtstrukturen heraus. Zunächst erweckte es den Anschein, dass er diesen unterliegen sollte: Im Jahr I 52 I wurde Luther vom Papst exkommuniziert und die Reichsacht über ihn verhängt. Der Streit, den er entfacht hatte, war jedoch nicht mehr aufzuhalten, seine Schriften hatten sich innerhalb von ein paar Jahren verbreitet und andere waren inspiriert worden, sich zu beteiligen. Der Streit erweiterte sich über die Grenzen von zwei Akteuren hinweg, indem weitere Instanzen hinzukamen, ${ }^{79}$ wie beispielsweise andere, z. T. radikale Reformationsbewegungen.

Diese weiteren Instanzen bzw. Dritten können bei Streitsituationen, wie Gunther Gebhard, Oliver Geisler und Steffen Schröter betonen, eine wichtige, manchmal auch zwischen den Kontrahenten vermittelnde, Rolle einnehmen. So können es u. a. konkrete Personen(gruppen) oder auch die Medien sein, die der gegenüberliegenden Seite das Vorhandensein eines Streits erst bewusst machen. ${ }^{\circ}{ }^{\circ}$ Durch das Eingreifen von Dritten kann ein Streit folglich auch weitere Verzweigungen und zusätzliche Akteure erhalten - z. B. einer größeren Öffentlichkeit zugänglich gemacht werden - wodurch er komplexere Formen annehmen kann als die Eins-zu-eins-Situation. Durch seine Verbreitung durch (Massen-) Medien hat Streit die Möglichkeit, zu einer kulturellen Praktik mit Breitenwirkung, mitunter sogar zum Medienereignis, zu werden. Wenn Streit kulturell dominant wird und auf wesentliche Bereiche des gesellschaftlichen und kulturellen Lebens Einfluss nimmt, ${ }^{8 \mathrm{I}} \mathrm{kann}$ schließlich von Streitkultur - im Sinne von einer Kultur, die vom Streit dominiert

79 Zum Zweck der Anschaulichkeit ist das hier evozierte Bild des Streits mit drei Akteuren bzw. Akteurgruppierungen sehr vereinfacht. Die Komplexität der Religionsstreitigkeiten ist damit nicht zu erfassen, jedoch soll das Konzept von Streit und dessen Ausweitung anhand der vereinfachten Darstellung von drei Instanzen erklärbar gemacht werden.

8० Gebhard, Gunther, Oliver Geisler \& Steffen Schröter (2008b): „Einleitung“. In: Dies. (Hg.): StreitKulturen: Polemische und antagonistische Konstellationen in Geschichte und Gegenwart. Bielefeld: transcript, S. I I-33, hier S. I 8.

${ }^{8_{1}}$ Norbert Richard Wolf versteht unter ,Streitkultur' nicht nur einen von Streit dominierten kulturellen Sektor, sondern fügt seiner Auffassung noch eine aufwertende Dimension hinzu: „Die Kontroverse wird anspruchsvoll. Sie wird `Streit-Kultur<, trotz aller Heftigkeit erreicht der Streit eine ,verfeinerte, kultivierte Form'." Wolf (I996), S. I 45 (Binnenzitat in einfachen Anführungszeichen: „So ein Interpretament von Kultur in Wörterbuch der deutschen Gegenwartssprache. Hg. von Ruth Klappenbach und Wolfgang Steinitz. Bd. 3. 2. Aufl. Berlin I973, S. 2254 “). 
wird - gesprochen werden. Dieses Verständnis von ,Streitkultur ${ }^{6}$ erfasst einen der zwei Bedeutungszweige des Begriffs. Hier ist das durch Streit beeinflusste kulturelle Leben gemeint, die zweite Bedeutung wird im Folgenden noch eingehender erläutert. ${ }^{82}$

Eine Verbreitung durch weitere Akteure und vor allem das neue Medium Buchdruck war auch bei der Entstehung des reformatorischen Glaubensstreits der Fall, denn „[s]ie [die Massenmedien] sind zugleich Bühne und Protagonist der öffentlichen Diskurse, beobachten und kommentieren die aufeinanderbezogene Rede der Akteure und veröffentlichen sie spezifisch gefiltert. " ${ }^{3}{ }_{3}$ Durch den Buchdruck war der Streit somit in kürzester Zeit auf eine öffentliche Ebene vorgedrungen. Das Geflecht der vielen kleineren Streitakte wuchs rasant zu einer enormen Dichte heran, so dass der Streit in vielen Bereichen (z. B. politisch, sozial, religiös) ein dominierender Diskurs und omnipräsent wurde. Er hatte eine große Bandbreite der Bevölkerung ergriffen und äußerst antagonistische Standpunkte herausgebildet. In Abgrenzung zu den zeitgenössischen dominanten Strukturen nahmen neue Positionen, die die alte kulturelle Ordnung in Frage stellten, Formen an.

Die starke Polarisierung der Reformation bestätigt, dass Streit im Allgemeinen mittels seiner entzweienden, separierenden Funktion identitätsstiftende und -abgrenzende Qualitäten besitzt. ${ }^{84}$ So formten sich im Glaubensstreit, vorerst noch recht einheitlich, die zwei Lager metaphorisch gesprochen - rund um Wittenberg und Rom. Dies fand offenkundigen Niederschlag in den Streitschriften, die Anhänger der gegnerischen Lager miteinander austauschten. Man griff sowohl den gegnerischen Standpunkt als auch die Personen selbst massiv an, grenzte sich durch Beleidigungen und Beschimpfungen von der jeweils anderen Gruppe oder Position klar ab; die Polemik bzw. verbale Gewalt hatte Einzug in den Streit erhalten. Im Gegensatz zu Gebhard et al., die in der "Absenz von Gewalt" ein Abgrenzungsmerkmal zu anderen Formen der Auseinandersetzungen, wie z. B. dem Kampf oder dem Krieg sehen, ${ }^{85}$ ist das Verständnis von Streit nach Magnus Eriksson und

${ }^{82}$ Siehe Kapitel 2.I.I Verständnis von ,Streit' und ,Streitkultur', Abschnitt Die begriffliche Abgrenzung von, Streit'.

$8_{3}$ Vgl. Keller (2003), S. 29I.

${ }^{84} \mathrm{Vgl}$. dazu: „Zugleich schafft Streit individuelle und kollektive Identität, indem er durch Mechanismen der In- und Exklusion Differenzen markiert, interne Bindungen stärkt und zur Solidarisierung innerhalb einer Gruppe bzw. mit einer Gruppe führt.“ Laureys \& Simons (20I0b), S. 9.

${ }_{5}$ Gebhard et al. (2008b), S. I4. 
Barbara Krug-Richter passender. Sie definieren Gewalt als „[e]ine physische oder verbale Aggression gegen die körperliche, seelische oder soziale Integrität eines oder mehrerer Mitmenschen, die darauf abzielt, etwas zu erzwingen ". ${ }^{86}$ Damit betonen sie das intentionale Moment von Gewalt, das sich grundsätzlich mit den Wirkungsabsichten von Streit deckt. Sie schließen Gewalt nicht aus dem Eigenschaftskatalog des Streits aus und setzen ihren Fokus auf die Untersuchung der Grenzen der sozialen Akzeptanz von Gewaltanwendung. Dieses Verständnis von „gerechter (potestas) und ungerechter Gewalt (violentia) " 87 ist im Kontext des Streits in der Reformationszeit sinnvoll, da verbale Gewalt, insbesondere Polemik, ${ }^{88}$ eine wichtige Rolle für die religiösen Streitigkeiten jener Zeit spielt. Wie zuvor angedeutet wurde, wird sie maßgeblich zur Bildung und Festigung der verschiedenen Lager, zur Abgrenzung von den jeweils ,Anderen' sowie zu Prozessen der Integration und Profilbildung innerhalb der ,eigenen“ Gruppe instrumentalisiert und zeigt sich in der praktischen Ausübung als ein „act[] of identity“. ${ }^{89} \mathrm{Im}$ Zusammenhang mit der Untersuchung der Polemik als einem radikalen Akt der Abgrenzung ${ }^{90}$ wird noch genauer auf die Formen von akzeptierter und nicht akzeptierter sprachlicher Gewalt eingegangen.

${ }^{86}$ Eriksson, Magnus \& Barbara Krug-Richter (2003b): „Streitkulturen - Eine Einführung “. In: Dies. (Hg.): Streitkulturen. Gewalt, Konflikt und Kommunikation in der ländlichen Gesellschaft (I6.-I9. Jahrhundert). Köln u. a.: Böhlau, S. I-I6, hier S. 7 .

${ }^{87}$ Eriksson \& Krug-Richter (2003 b), S. 7.

${ }^{88}$ Zur Polemik und ihrer Konzeptualisierung siehe das Folgekapitel 2.2 Polemik als Methode der Streitinszenierung.

89 Fludernik, Monika \& Hans-Joachim Gehrke (Hg.) (2004): Normen, Ausgrenzungen, Hybridisierungen und 'Acts of identity' (= Identitäten und Alteritäten I8). Würzburg: Ergon. Die Funktion, eine Gruppenidentität zu schaffen, weist auch Almut Suerbaum für die Polemik in Predigten nach: „,[P]olemical statements about heretics derive their significance from articulating Christian identity. Their focus i soften not an attack against specific theological posittions with a view to changing the opponent's view, [...] but rather te definition of cultural identity in opposition to an external 'Other'. “ Suerbaum, Almut (2OI 5): „Language of Violence: Language as Violence in Vernacular Sermons “. In: Suerbaum, Almut, George Southcombe \& Benjamin Thompson: Polemic: Language as Violence in Medieval and Early Modern Discourse. Aldershot: Ashgate, S. I25-I48, hier S. I34.

$9 \circ \mathrm{Vgl}$. dazu die Feststellung Hans-Joachim Gehrkes: „[J]enseits der Notwendigkeit von Abgrenzungen [ist] ein sehr breites Spektrum von Relationen von Eigenem und Anderem möglich [...]. Die radikale, binäre und exkludierende Ausgrenzung ist eine Variante, aber keine zwingende.“ Gehrke, Hans-Joachim (2004): „Einleitung“. In: Fludernik, Monika \& ders. (Hg.): Normen, Ausgrenzungen, Hybridisierungen und 'Acts of identity' (= Identitäten und Alteritäten I 8). Würzburg: Ergon, S. I I-I9, hier S. I3. 
Neben der verbalen Gewalt hatte auch physische Gewalt Einfluss auf den Streitverlauf der Reformation. Viele Reformatoren (anfangs Luther, später dann vermehrt die ,Radikalen') sowie Drucker setzten mit ihren Veröffentlichungen nicht selten ihr Leben oder ihre Existenz aufs Spiel und waren durch herrschende Obrigkeiten bedroht. Über Luther wurde die Reichsacht verhängt, Wiedertäufer wurden öffentlich hingerichtet und sämtlichen Beteiligten einer Publikation konnten Gefängnisstrafen drohen. Für Reformatoren und Drucker war dies nicht zuletzt auch ein Anlass, ihre Schriften anonym oder unter einem Pseudonym zu publizieren. Dieser Bedrohung war auch Melchior Hoffman ausgesetzt, der mehrmals vertrieben, seiner Besitztümer enteignet und schließlich I 533 ins Straßburger Gefängnis geworfen wurde. Die ihm widerfahrene physische Gewalt hatte Auswirkungen sowohl auf die Form seiner Publikationen als auch auf den Inhalt. ${ }^{9 \mathrm{I}}$ Hoffman selbst vertrat jedoch die Auffassung, dass physische Gewalt kein akzeptables Mittel zur Durchsetzung der Reform sei. Allein „dat sweert des geests“ “92 solle gegen die Gegner geführt werden. In Erwartung der baldigen Apokalypse überantwortete Hoffman es der göttlichen Gewalt, die Bösen von den Guten, die Ketzer von den Rechtgläubigen zu trennen. Hoffmans selbstauferlegte Aufgabe war die eines Propheten, der die rechte Lehre verkündete und zur Bekehrung vor dem Eintreten des Jüngsten Gerichts aufrief. Sein Selbstverständnis als göttliches, Sprachrohr' bestätigt, dass der gewählte Fokus dieser Untersuchung in seiner Betonung der ,rhetorischen Streitkultur', welche die sprachlichen Mittel des Streits ins Zentrum rückt, der historisch und methodisch adäquate ist.

Andere (z. B. visuelle) Komponenten gehören zwar ebenfalls zu den möglichen Mitteln der Streitausübung, aber „[e]rst durch die Sprache wird die Auseinandersetzung zum Streit", da die Formulierung der Positionen und Einstellungen mittels sprachlicher Äußerungen geschieht. Seien es nun Aussagen zum Gegenstand oder Selbst- und Fremdzuschreibungen, erst durch diese sprachlichen Positionierungen

91 Hoffman publizierte während seiner Haft pseudonym bzw. unter dem Namen anderer, da ihm das Schreiben Ende Juli I 533 im Gefängnis verboten und ihm Papier und Schreibwerkzeug entzogen wurde. Inhaltlich thematisiert er in seinen Schriften wiederholt die unfaire Art und Weise, wie Obrigkeiten und Lutheraner mit ihm umgehen und kreidet seinen Gegnern deren Gewalttätigkeit an.

92 „das Schwert des Geistes“. Anonymus [i. e. Melchior Hoffman] (I 533): Die eedele hoghe ende troostlike sendebrief / den die heylige Apostel Paulus to den Romeren gescreuen heeft / verclaert ende gans vlitich mit ernste van woort to woorde wtgelecht Tot eener costeliker nutticheyt ende troost allen godtvruchtigen liefhebbers der eewighen onentliken waerheyt. [o. O.: o. Dr.], Trb. Kurztitel: Römerbrief. 
gewinnt der Streit an Konturen. ${ }^{93}$ Dies wird auch anhand des Beispiels der reformatorischen illustrierten Flugblätter deutlich: In den meisten Fällen sind die Illustrationen nur im Zusammenhang mit dem erklärenden Text zu verstehen. ${ }^{94}$ Das oftmals allegorische Bild kann erst mittels der sprachlichen Erklärung dekodiert bzw. die Mehrdeutigkeit des Bildes in eine Richtung gelenkt werden. ${ }^{95}$ Ausgehend von diesem grundlegend sprachlichen Charakter des Streits lässt sich eine Streitsituation feststellen, wenn sich

[m]indestens zwei Akteure oder auch soziale Gruppen [...] hauptsächlich mit verbalen Mitteln auseinander, miteinander oder auch gegeneinander [setzen]; es wird versucht zu überzeugen, andere ,auf Linie` zu bringen, in eine bestimmte Richtung zu drängen oder aber zum Schweigen zu bringen, auszuschließen. ${ }^{96}$

Komplettierend wird die Definition von Carmen Spiegel hinzugezogen, die eher eine demonstrative anstatt der von Gebhard et al. indizierten persuasiven Haltung konstatiert:

Bezogen auf den zwischenmenschlichen Bereich ist Streit die sprachliche Manifestation einer Konfliktaustragung zwischen mindestens zwei Aktanten, die [...] verbal divergierende Standpunkte oder Problemsichtweisen demonstrieren. ${ }^{97}$

Spiegel fügt dem noch ein weiteres, vorrangig sprachliches Element hinzu: „Kennzeichen auf der Äußerungsebene ist ein wesentlich emotionaler Gesprächsstil verbunden mit Imageverletzungen. “98 Sie nimmt damit Bezug auf das, Wie?‘ und ergänzt die bisherige Erklärung der Gegebenheit ,Streit' um den Modus ,Streit', der sich als Polemik äußern kann.

93 Gebhard et al. (2008b), S. I 5.

94 Vgl. dazu Klug, Nina-Maria (2012): Das konfessionelle Flugblatt I 563-I 580 . Eine Studie zur historischen Semiotik und Textanalyse. Berlin \& Boston: De Gruyter, S. I66-I 67.

95 Adam, Wolfgang (I999): „Theorien des Flugblatts und der Flugschrift“. In: Leonard, Joachim-Felix, Hans-Werner Ludwig, Dietrich Schwarze \& Erich Straßner (Hg.): Medienwissenschaft. Ein Handbuch zur Entwicklung der Medien und Kommunikationsformen. I. Teilband. Berlin \& New York: De Gruyter, S. I32-I43, hier S. I33.

${ }^{96}$ Gebhard et al. (2008b), S. I 2 f.

${ }_{97}$ Spiegel, Carmen (1995): Streit. Eine linguistische Untersuchung verbaler Interaktionen in alltäglichen Zusammenhängen. Tübingen: Narr, S. I 8.

${ }_{98}$ Spiegel (I995), S. I9. 
Für die adäquate Untersuchung der Polemik des I6. Jahrhunderts und die Bewertung der Glaubensstreitigkeiten ist es sinnvoll, die damalige Semantik und die konzeptuellen Vorstellungen zu beleuchten auch um anachronistische Schlussfolgerungen zu umgehen.

\section{Bedeutungsgeschichtliche Aspekte von ,Streit‘ im 16. Jahrhundert}

Geht man der Bedeutung von ,Streit' aus einer diachronen Perspektive auf den Grund, wird schon bei der Wörterbuch-Recherche im Deutschen Wörterbuch von Jacob Grimm und Wilhelm Grimm (DWB) deutlich, dass die semantischen Facetten des Wortes die verschiedenen deutschen Sprachstufen hindurch bestehen geblieben sind: „bereits im althochdeutschen sind fast alle bedeutungszweige des wortes vertreten. "Dies ändert sich bis zum heutigen Deutsch nicht grundlegend, jedoch haben sich die Schwerpunkte verlagert bzw. die Dominanz einiger Bedeutungszweige hat sich in den verschiedenen Sprachstufen immer wieder verschoben. Laut DWB gibt es sieben solcher Bedeutungszweige, die ,Streit' durch die Zeit hindurch abdeckt:

A. der meinungsstreit [...], B. die um einen strittigen gegenstand geführte auseinandersetzung, vor allem von konflikten auf rechtlichem und politischem gebiet [...], C. hader und zerwürfnis im persönlichen lebenskreis des einzelnen wie auch innerhalb einer gemeinschaft [...], D. physischer kampf [...], E. der gebrauch im sinne des wettstreits [eher seltener] [...], F. die vorstellung des physischen kampfes [...] auf seelische oder dinglich-begriffliche konfliktsituationen [angewendet] [...], G. bedeutungen [...], die sich im gebrauch des adj. streitig und bei aisl. vertretungen der sippe streit wiederfinden. [z. B.] I) [...] starrsinnig-oppositionelle[s] oder hartnäckig strebende[s] verhalten [].99

Diese sieben Bedeutungszweige sind auch heute noch weitgehend gültig, aber „seit dem I9. jh. ist streit hauptsächlich in den wiedererstark-

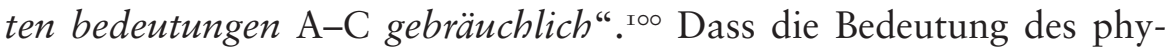
sischen Kampfes (D) seit dem Neuhochdeutschen im Wortgebrauch abgenommen hat, ist durch das vermehrte Aufkommen von ,Krieg' und besonders ,Kampf ${ }^{`}$ bedingt, die ,Streit' in dieser Bedeutung ersetzen. ${ }^{\text {Ior }}$ Das Schwinden dieses Bedeutungszweiges unterstützt die oben genannte Eingrenzung des Streitkonzepts als überwiegend von physischer

99 „STREIT“, DWB I9, Sp. I3 I 2, I3 I7, I3 I9, I32 I, I325, I326 \& I332.

100 Ebd., Sp. I3 I I.

гог Vgl. ebd., Sp. г3 г2. 
Gewalt befreit. Die ursprüngliche Übersetzung Luthers macht aber zum Großteil noch von dieser Bedeutung Gebrauch, was typisch für das Frühneuhochdeutsche war:

die wbb. [Wörterbücher] des I6. jhs. bieten streit fast ausschlieszlich in dieser anwendung, und LUTHER gebraucht es regelmäszig im sinne von bellum, pugna, proelium, certamen der vulgata. für die bedeutung ,bellum ${ }^{\circ}$ wird jedoch seit dem $\mathrm{I} 6 . j$. j. krieg bevorzugt [...]. ${ }^{\mathrm{1} 22}$

Für den Streit im Sinne der Bedeutung C finden sich in Luthers Übersetzung, ,hadder ${ }^{6}$ und ,zanck', welche wiederum in heutigen Übersetzungen mit ,Streit' wiedergeben werden. ${ }^{103}$

In Texten der Reformation wird ,Streit' jedoch vermehrt nur in übertragener Bedeutung ohne physische Gewalt und „so bereits im I6. jh. im sinne der gelehrten kontroverse (A 2 a) [gebraucht], auch in der bedeutung zank, handel, zerwürfnis (C), die aber erst seit dem I9. jh. in gröszerer häufigkeit auftritt" ${ }^{\text {I04 }}$ Beispiele lassen sich bei einer Vielzahl von Autoren finden, die die Reformation und ihre einzelnen Streitigkeiten als ,Streit' bezeichnen. Luther spricht in der Babylonischen Gefangenschaft vom „Ablaßstreit“, ${ }^{105}$ benutzt „disputieren“ ${ }^{106}$ im Austausch für ,streiten' und spricht besonders den inneren Streit der Seele an. ${ }^{107}$ Auch ,unterhaltende‘ literarische Texte des I5. und I6. Jahrhunderts wie etwa Sebastian Brants Narrenschiff (I 494) ${ }^{\text {108 }}$ und Schwänke von Hans Sachs ${ }^{\text {I09 }}$ verwenden ,Streit‘ für sowohl den physischen Kampf als auch

${ }^{102}$ Ebd., Sp. I3 I 2.

${ }^{103}$ Diese Ergebnisse sind bei Textvergleichen einzelner Bibelstellen gemacht worden, die mit Hilfe der Bibelausgabe und -konkordanz www.bibel-online.net vorgenommen wurden. Grundlage des Vergleichs sind die dort zugängliche Bibelübersetzung Luthers von 1945 und unterschiedliche zeitgenössische evangelische Bibelausgaben.

I04 „STREIT“, $D W B$ I9, Sp. I 3 I 2.

I05 Luther, Martin (I 520): Von der Babylonischen Gefangenschaft der Kirche. In: Projekt Gutenberg-DE. URL: http://gutenberg.spiegel.de/buch/von-der-babylonischengefangenschaft-der-kirche-269/I (I8.10.20I5), Kapitel 2.

${ }^{106}$ Ebd., Kapitel I.

${ }^{107}$ „Das ist der höchste Streit, den wir haben, daß wir das Wort behalten und dabei bleiben; wenn das aus dem Herzen gerissen wird, so ist der Mensch verloren. “ Luther, Martin (o. J.): „Sonntag nach Epiphanias“. In: Predigten für ein Jahr. In: Projekt Gutenberg-DE. URL: http://gutenberg.spiegel.de/buch/27I/35 (I8.IO.20I5), Kapitel 35 .

to8 „Wenn Reuter und Schreiber greifen an I Einen fetten, schlichten, bäurischen Mann, I Ist der es, so den Streit fing an." Brant, Sebastian (I494): Das Narrenschiff. URL: http://webergarn.de/narren/narrenschiff/index.html (I 8.I0.201 5), Kapitel 79.

${ }^{\circ}$ Im Schwank Das Kälberbrüten droht der Bauer dem Pfarrer, welcher lediglich zwischen den bäuerlichen Eheleuten zu schlichten versucht: „Herr, mischt euch nit in 
für die Auseinandersetzung mit Worten. Auch Melchior Hoffman bedient sich unter anderem der Bedeutung für Streitigkeiten, die die Gelehrten seiner Zeit austragen: „Waher kumpt solcher streit vnd hader vnder den lerern [...] “. ${ }^{\text {Iо }}$ Zusammen mit ,Hader' genannt, bedeutet ,Streit ${ }^{`}$ hier ebenfalls den (gelehrten) Meinungsstreit bzw. die persönliche Auseinandersetzung.

Insgesamt bestätigen der Blick auf die historische Entwicklung der Semantik von ,Streit' und die hier aufgeführte exemplarische Zusammenfassung des Wortgebrauchs in der Reformationszeit die bisherigen Eingrenzungen für diese Arbeit. Festzuhalten wäre jedoch das beinahe einheitliche Vorkommen von "Streit' im Sinne des physischen Kampfes und kriegerischer Handlungen in frühneuhochdeutschen Bibelübersetzungen (inklusive Luthers Übersetzung). Für die Reformationsschriften lässt sich eine - aus heutiger Sicht - modernere Verwendung feststellen. Dies lässt die Schlussfolgerung zu, dass gerade die Reformationsstreitigkeiten die Dominanzverhältnisse der Bedeutung des Wortes ,Streit' in die Richtung der sprachlichen (gelehrten) Auseinandersetzung, des „Wortkampfes“, ${ }^{11}$ gelenkt haben. Damit bestätigt sich die moderne Semantik und Konzeption von ,Streit" bereits auch für die Reformationszeit.

\section{Die begriffliche Abgrenzung von ,Streit}

Wie beim frühneuzeitlichen Gebrauch von ,Streit', ,Hader', ,Zank' usw. sind die Grenzen auch bei heutigen Begriffen, die Ähnlichkeiten miteinander haben, diffus. So tauchen etwa ,Auseinandersetzung', ,Konflikt ${ }^{6}$ und ,Streit' in unterschiedlichen Kontexten und Bedeutungen auf und werden vielfach synonym gebraucht. In der aktuellen Forschung werden diese Begrifflichkeiten und ihre Abgrenzungen zwar diskutiert, es herrscht aber Uneinigkeit über ihre Hierarchisierung. Beispielsweise ist es nicht einhellig definiert, in welchem Verhältnis ,Konflikt ${ }^{`}$ und ,Streit' zueinander stehen und inwiefern sie Formen des jeweils anderen Konzepts sind. ${ }^{122}$ Für das weitere Verständnis dieser Arbeit dient die Auffassung Erikssons und Krug-Richters zur Orientierung, in der

unser Spiel! I Mein Weib tut euch das übelnehmen I Und sich des Streit's mit euch nit schämen. “ Sachs, Hans ( 55 I): Das Kälberbrüten. In: Projekt Gutenberg-DE. URL: http://gutenberg.spiegel.de/buch/522I/2 (I8.I0.20I5), Kapitel 2.

זr Hoffman, Melchior (I 530): Außlegūg der heimlichē Offenbarung, A7r.

iri Stolt (I974).

I12 Gebhard et al. (2008b), S. I3f. 
Streit als eine Form des Konflikts dargelegt wird. ${ }^{\text {II3 }}$ Spiegel führt diesen Gedanken noch weiter aus und sieht Streit nicht nur als eine Form des Konflikts, sondern als eine Form der Konfliktaustragung, die den friedlichen „Konfliktaustragungsformen“ wie etwa „Beratungsgespräch, Verhandlung u. ä. “ entgegengesetzt ist. ${ }^{\mathrm{II}}{ }^{4}$,Konflikt" ist folglich als Oberbegriff von ,Streit' aufzufassen. Diese Hierarchisierung wird durch die zusätzliche Bedeutung von ,Konflikt' als Beschreibung eines Zustands unterstützt, denn „Konflikte können bestehen, ohne dass sie ausgetragen werden müssen ". ${ }^{115}$ Für den Streit hingegen steht immer die aktive Ausübung, die Prozesshaftigkeit und Performativität im Zentrum. Der Terminus der ,Auseinandersetzung' impliziert ebenfalls einen aktiven Prozess des Separierens, des Sich-Auseinandersetzens. Gebhard et al. begreifen ,Auseinandersetzung ${ }^{6} \mathrm{zwar}$ synonym zu ,Konflikt ${ }^{\dagger}{ }^{116}{ }^{16}$ die performative Bedeutung des Wortes ,Auseinandersetzung 'ässt es jedoch näher an den ausführenden Sinngehalt von,Streit' rücken.,Auseinandersetzung ‘ ist aber trotzdem in einem übergeordneten Verhältnis zu ,Streit'stehend zu verstehen, da man sich auch auf andere Weise mit jemandem auseinandersetzen kann, ohne dass es in einem Streit resultiert, der grundsätzlich eine (temporäre) Entzweiung einschließt. Weder die synonyme Verwendung von ,Auseinandersetzung' und ,Konflikt', die Gebhard et al. vorschlagen, noch von ,Auseinandersetzung' und ,Streit', die das Performative gemein haben, erweisen sich als sinnvoll. Die aufgezeigten Bedeutungsunterscheidungen verpflichten zu konsequenter Abgrenzung der Begriffe voneinander.

Übertragen auf die Reformationszeit kann man davon sprechen, dass bereits im Mittelalter einige der Konflikte bestanden, die sich später in der Reformation zu Streitigkeiten entwickelten - hier kann z. B. der bereits genannte Antiklerikalismus des Spätmittelalters eingeordnet werden. Es kam jedoch nicht zu einer übergreifenden Auseinandersetzung:

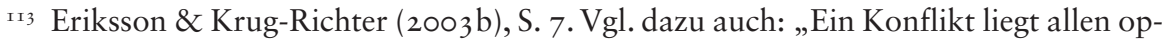
positionellen Austragungsformen zugrunde. Dies impliziert, daß Konflikte sowohl friedlich (kooperativ) wie auch kontrovers (unkooperativ) behandelt und gelöst werden können. "Spiegel (I995), S. I6.

i14 Spiegel (I995), S. I6f.

IIs Gebhard et al. (2008b), S. I4. Vgl. dazu auch Carlos Spoerhase, der in Bezug auf epistemische Kontroversen in ähnlicher Weise von einem nicht ausgetragenen „Dissens“ als einer „Nicht-Kontroverse“ im Sinne Helga Nowotnys spricht. Spoerhase, Carlos (2007): „Kontroversen: Zur Formlehre eines epistemischen Genres.“ In: Klausnitzer, Ralf \& ders. (Hg.): Kontroversen in der Literaturtheorie / Literaturtheorie in der Kontroverse. Bern: Peter Lang, S. 49-92, hier S. 65 f.

ir6 Gebhard et al. (2008b), S. I4.
} 
Entweder wuchs der Konflikt nicht zu einem gesellschaftlich wahrgenommenen Phänomen heran oder scheiterte an den allzu asymmetrischen Machtverhältnissen. Er entwickelte sich nicht zu einem öffentlich geführten und die Gesellschaft und Kultur betreffenden Streit. Dass im (Spät-)Mittelalter Streitigkeiten um dieses Thema auf individueller, nicht-öffentlicher Ebene vorkamen, ist anzunehmen und wird nicht in Frage gestellt. Im Fokus einer Kultivierung von Streit stehen aber jene kulturell bedeutenden Ereignisse, als die man vereinzelte, personal wie regional begrenzte Auseinandersetzungen erst dann begreifen kann, wenn sie sich mit anderen zu einem Geflecht verwoben haben, so dass der einzelne Streitakt einen Teil eines größeren Streits darstellt. Dies war der Fall beim Streit der Reformation: Die Positionen, Parteien und Argumentationen für die Standpunkte standen deutlich im Zentrum der Zeit, denn indem die einzelnen Streitigkeiten ein Geflecht von sich aufeinander beziehenden (Streit-)Schriften bildeten, hatten sie bedeutenden Einfluss auf die öffentliche(n) Meinung(en) und Kultur. ${ }^{117}$ Der Streit brachte klar abgegrenzte, miteinander unvereinbare Auffassungen zutage, die eine Lösung des zugrunde liegenden Konflikts zunächst unmöglich erscheinen ließen. Jede Partei sprach davon, im Besitz der Wahrheit zu sein, was weder Kompromisse noch Einigungen zuließ. Auch der kontroverse Verlauf der Reformation, die vielen Kursänderungen (z. B. die Bildung von Konfessionen anstatt der Reform einer einheitlichen Kirche), die weitere Aufspaltung der ,evangelischen' Glaubensrichtung in Lutheraner, Zwinglianer, Calvinisten, Wiedertäufer, Spiritualisten u. a. machten deutlich, dass eine Lösung des Streits zwar angestrebt war, aber nur in der Kapitulation der jeweils Anderen als möglich erachtet wurde, denn „es [gab] bei Fragen des Glaubens nur Gott oder Teufel, Gut oder Böse, Seligkeit oder ewige Verdammnis [...], nichts dazwischen. Daher erklärt sich das Nicht-Nachgeben-Können. " ${ }^{118}$

${ }_{117}$ Eine gesteigerte Form dieser Verflechtung konstatiert Ursula Paintner für die antijesuitische Polemik, deren Wirkung sie darin erfüllt sieht, dass durch die Fortführung von Argumenten und Feindbildern in anderen Texten ein „Textkontinuum“ entsteht: „Steigerungen und Wiederholungen von Klischees und Argumenten finden nicht nur innerhalb eines jeweils klar umgrenzten Textes statt, sondern die Texte beziehen sich aufeinander: Was in einer Publikation noch Vermutung oder Gerücht war, wird in der nächsten Gewißheit und in der dritten unverrückbare Grundlage für neue Vermutungen. “ Paintner (20II), S. 37.

${ }^{\text {Is } 8}$ Schwitalla, Johannes (20Iоa): „Brutalität und Schamverletzung in öffentlichen Polemiken des I6. Jahrhunderts“. In: Krämer, Sybille \& Elke Koch (Hg.): Gewalt in der Sprache. Rhetoriken verletzenden Sprechens. München: Wilhelm Fink, S. 97I23, hier S. II 7 . 
Die Fronten waren schließlich auf allen Seiten so verhärtet, dass die Situation in einer totalen Spaltung, der Konfessionalisierung, mündete, die im Folgenden zu einem der grausamsten Kriege der westlichen Geschichte führte ${ }^{\mathrm{II} 9}$ und bis heute, obgleich auf friedlicher Basis, Bestand hat. Die Lösung des Reformationsstreits war demnach eine dauerhafte Entzweiung, die erst nach Jahren des Streitens und schließlich des Kämpfens im Glaubenskrieg zu einem vorwiegend friedlichen Nebeneinander führte.

Von einer Lösung des großen Streits in der Reformationszeit kann man aus heutiger Sicht deshalb nicht sprechen, lediglich von einer Beendigung durch Transformation - über die Eskalation, die Kampf und Krieg ${ }^{\mathrm{I} 20}$ brachte, hin zur Akzeptanz der Uneinigkeit. Da es „verschiedene und recht heterogene Weisen seines [des Streits] Endes gibt und [...] sein Ausgang vergleichsweise offen ist" ${ }^{\text {다 }}{ }^{21}$ sind die Zusammenhänge von Thema, Akteur, Sprache und Streitbeendigung - hier seien z. B. die Einigung auf eine Position, der Kompromiss und das Verebben eines Streites genannt ${ }^{122}$ - relevant. Aus einer diachronen Perspektive können rückblickend weitere Hinweise auf die Streitkultur (einer bestimmten Zeit) sowie ihre (rhetorischen) Mittel und Strategien gegeben werden, denn gerade die Rolle und Haltung der Streitenden und die sprachliche Positionierung bilden die Voraussetzungen für die möglichen Formen der Beendigung. Bei einer synchronen Betrachtung der Texte kann der historische Blick auf nachfolgende Ereignisse berücksichtigt werden. Um jedoch anachronistische Fehlschlüsse zu vermeiden, sollten historische Informationen, die den Autoren zum Zeitpunkt der Textproduktion nicht bekannt waren, kritisch verwendet und diskutiert werden.

Die Ermittlung des Zusammenspiels der Faktoren, die für die Streitbeendigung relevant sind, stellt unter anderem die Akteure als wichtiges Element dar. Die Hervorhebung der Akteure deutet auf ein weiteres Merkmal von Streit hin, das auch schon im Zusammenhang mit seinem sozialen und kulturellen Potential impliziert ist: Streit ist eine „vorwiegend personalisierte Form der Auseinandersetzung“,

${ }_{119}$ Goertz (2004), S. 254.

ז20 „Krieg bezeichnet einen organisierten, mit Waffen gewaltsam ausgetragenen Konflikt zwischen Staaten bzw. zwischen sozialen Gruppen der Bevölkerung eines Staates. “ Schubert, Klaus \& Martina Klein (20I I): Das Politiklexikon. Bonn: Dietz. In: Bundeszentrale für politische Bildung. URL: http://www.bpb.de/nachschlagen/ lexika/politiklexikon/I7756/krieg (I8.I0.20I 5).

I21 Gebhard et al. (2008b), S. I9.

${ }^{122}$ Vgl. ebd., S. I9f. 
d. h. man kann „den Kontrahenten sprachlich-kommunikativ ausmachen und adressieren ". ${ }^{123}$ Die Streitschriftenwechsel der Reformation sind paradigmatisch dafür: In ihnen werden konkrete Namen genannt, oftmals nicht nur die Sache oder die gegnerische Ansicht angegriffen, sondern sich ganz gezielt gegen Personen gerichtet, die stellvertretend für ihre Gruppe und das dahinter stehende Kontingent an Auffassungen angegriffen werden. Verballhornungen von Namen (z. B. „Murnarr“ für Thomas Murner), Beschimpfungen (z. B. Hoffmans „lugenhafftiger falscher nasen geist “'24), Tiervergleiche, -metaphorik, -symbolik oder Epitheta mit Tieren ${ }^{125}$ (insbesondere auch illustrativ), das Aufgreifen von persönlichen Lebensläufen (z. B. denunziert Melchior Hoffman Marquard Schuldorp, weil Letzterer die Tochter seiner Schwester heiratete) und andere personengerichtete Diskreditierungen sind gängig eingesetzte Mittel bei Streitigkeiten, die sich zwischen einzelnen Kontrahenten abspielen. ${ }^{\mathrm{I} 26}$ Diese Strategien des persönlichen Angriffs wie auch andere Strategien des Streitens in der Reformationszeit sind Ausdruck der ihr zugrunde liegenden Streitkultur. Hier kommt der bereits angedeutete, zweite Bedeutungsstrang von ,Streitkultur' ins Spiel: Sie umfasst sowohl die Menge der Regeln und Normen, die das Streiten als Akt regulieren, als auch den konkreten Akt des Streitens selbst.

Ausgehend von dem Verständnis von Streit als kultureller Praktik kann man das Regelwerk, das dem Streiten zugrunde liegt, als einen Teil innerhalb eines größeren kulturellen Kontextes verstehen. Deshalb

${ }^{123}$ Dass die teilhabenden Parteien den Streit aktiv wahr- bzw. daran teilnehmen müssen, damit eine Streitsituation als gegeben angesehen werden kann (vgl. ebd., S. I 8), scheint prinzipiell nicht zwingend notwendig, da ein Streitpunkt auch ohne die Wahrnehmung der zweiten Instanz bestehen kann. Die Rezeption durch eine dritte Instanz - ein (öffentliches) Publikum, das in der Regel den eigentlichen Adressaten einer öffentlichen Streitsache darstellt - kann die Rezeption der zweiten Instanz ersetzen, ohne dass es das Vorhandensein des Streits widerlegt.

${ }^{124}$ Hoffman, Melchior (I 528 ): Nasen geist.

I25 Vgl. etwa Hans Sachs’ Die wittembergisch nachtigal (I 523 ): „[...] das wilde schwein deut doctor Ecken, I der vor zu Leipzig widr in facht I und vil grober seu davon bracht. I der bock bedeutet den Emser, I der ist aller nunnen tröster; I so bedeutet die katz den Murner, I des bapstes mauser, wachter, turner; I der waltesel den barfüßer I zu Leipzg, den groben lesmeister. I so deut der schneck den Cochleum. “In: Die deutsche Gedichtebibliothek. URL: http://www.gedichte.xbib.de/Sachs,+Hans_ gedicht_Die+wittembergisch+nachtigal.htm (I8.I0.20I5). Zum Teil verselbstständigen sich diese Epitheta sogar und kommen ohne ihre Träger aus. „Die Katz“ ersetzt z. B. in einigen Texten den Namen Thomas Murner gänzlich.

I26 „Im ganzen I6. Jahrhundert waren Kontroversen geprägt von stark herabsetzenden, beleidigenden, mit Tierbezeichnungen und anderen Schimpfwörtern vollzogenen Herabsetzungen des Gegners. "Schwitalla (20I0a), S. II3. 
gelten die Aussagen, die für ,Kultur' getroffen wurden, auch für den Begriff der ,Streitkultur‘. Barbara Krug-Richter konstatiert, dass „Praktiken der Konfliktaustragung, diejenigen Formen und Regeln, in und nach denen Menschen eingebunden in spezifische historische und kulturelle Kontexte ihre Streitigkeiten austrugen und -tragen" eine Untersuchung der Streitkultur möglich machen. ${ }^{\mathrm{I} 27}$ Anhand der praktischen Ausübung ist der Blick auf „bestimmte Muster des Streitverlaufs, explizite oder implizite Regeln“ - also auf die kulturellen Normen von Streit zu einer bestimmten Zeit - möglich.

$\mathrm{Zu}$ unterscheiden sind zwei Erscheinungsformen von Normen: Zeitgenössische programmatische, präskriptive Werke (wie z. B. Disputationshandbücher oder Rhetoriken) sind zu trennen von den impliziten Normen eines Streittextes, welche durch eine deskriptiv-analytische Untersuchung sichtbar gemacht werden können. Theorie und Praxis können unabhängig voneinander sein und Diskrepanzen aufweisen, d. h. die theoretische Norm muss der Praxis keine Grenzen setzen. Deshalb ist es vor allem wichtig, konkrete Streitschriften und Streitschriftenwechsel zu betrachten. Auf diese Weise kann man eine bestimmte Streitkultur untersuchen und ihre Bedingungen erfassen. In dem Zusammenhang wird Streitkultur „nicht als normatives Konzept verstanden, [...] sondern soll vielmehr als analytisches Leitkonzept genutzt werden, um Streitfälle [...] hinsichtlich ihrer kulturellen und sozialen Mechanismen zu befragen ". ${ }^{228}$ Dabei sind Fragen nach synchronen Vergleichen (z. B. mit einer anderen Streitkultur) sowie Fragen nach der diachronen Entwicklung einer Streitkultur möglich und für die folgende Untersuchung der ,rhetorischen Streitkultur' der Reformation fruchtbar.

\section{Fazit: Streitkultur als Wechselwirkung von Norm und Aufführung}

Für die kulturelle Bedeutung von Streit lässt sich festhalten, dass er in seiner entzweienden sowie verbindenden Funktion das Potential besitzt, alte Verbindungen zu lösen und neue zu schaffen und damit sozialen, kulturellen und politischen, kurzum gesellschaftlichen Strukturwandel mit sich zu bringen. ${ }^{\mathrm{I} 29}$

${ }^{127}$ Krug-Richter, Barbara (2010): „Streitkulturen. Perspektiven der Volkskunde/ Europäischen Ethnologie“. In: Laureys, Marc \& Roswitha Simons (Hg.): Die Kunst des Streitens. Inszenierung, Formen und Funktionen öffentlichen Streits in historischer Perspektive. Göttingen: V\&R unipress, S. 33 I-3 5I, hier S. 33 I.

${ }^{128}$ Gebhard et al. (2008b), S. 27.

I29 Vgl. dazu die Metapher des ,sozialen Dramas‘ von Victor Turner und „the fourpart scheme for describing the usual process of such drama: breach, crisis, redress, 
Streit ist als soziale und kulturelle Praktik zu verstehen, die gesellschaftliche Regeln widerspiegelt, verhandelt und neu definiert. Die Streitausübung ist demnach performatives Handeln, ${ }^{130}$ das ,als Nachahmung, Teilnahme und Gestaltung kultureller Praktiken begriffen “ ${ }^{{ }^{3}{ }^{\mathrm{I}}}$ wird. Insbesondere dieser performative Charakter von Streit - das Austragen bzw. Bewusstmachen eines Konfliktes - bewirkt, dass gesellschaftliche Normen und deren Grenzen herausgefordert und beeinflusst werden.

Der Begriff der ,Streitkultur' kann zwei Bedeutungsrichtungen haben. Die eine Bedeutung geht von der Gesamtkultur aus, die sämtliche kulturellen Erscheinungen in sich einschließt. In dieser Form ist ,Streitkultur ${ }^{6}$ eine Kultur, die durch Streit dominiert wird bzw. in der Streit von elementarer Bedeutung für die kulturellen Erscheinungsformen ist. Die Kultur der deutschen Reformation wäre in diesem Sinne als eine Streitkultur zu bezeichnen. ${ }^{\mathrm{I} 2}$ Jedoch soll diese Bedeutung für den Begriff ,Streitkultur ${ }^{6}$ weitestgehend ausgeblendet werden, nicht zuletzt, da die wissenschaftliche Auseinandersetzung mit Streitkultur(en) ihren Untersuchungen überwiegend die andere Bedeutung des Begriffs zugrunde legt.

In dieser zweiten Bedeutung ist ,Streitkultur' als ein Teil von Kultur zu betrachten, der die Regeln des Streitens bzw. die Konfliktaustragungsstrukturen umfasst. Dieses Regelwerk kann als ein relativ amorphes Reservoir an Regeln und Normen betrachtet werden,

and schism or continuity [...]“. Lewis, J. Lowell (2008): „Toward a Unified Theory of Cultural Performance: A Reconstructive Introduction to Victor Turner". In: St. John, Graham (Hg.): Victor Turner and Contemporary Cultural Performance. New York: Berghahn, S. 4I-58, hier S. 43f. Streit kann sowohl Initiator als auch Indiz des ,Bruches“ sein, zudem aber auch die Krise verkörpern. Er kann somit einen oder mehrere Akte innerhalb des ,sozialen Dramas‘ füllen.

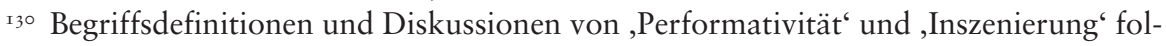
gen in Kapitel 2.I.2 Streitinszenierung und die, rhetorische Streitkultur'.

${ }^{131}$ Wulf, Christoph, Michael Göhlich \& Jörg Zirfas (200I): „Sprache, Macht und Handeln - Aspekte des Performativen“. In: Dies. (Hg.): Grundlagen des Performativen. Eine Einführung in die Zusammenhänge von Sprache, Macht und Handeln. Weinheim \& München: Juventa Verlag, S. 9-24, hier S. Io.

${ }^{132}$ Es sei darauf hingewiesen, dass der Kulturbegriff, wie bereits erwähnt, vielfältig ist und oftmals auf verschiedenen Ebenen angesetzt wird. Kriterien wie u. a. Nationalität, Regionalität, Ethnizität, Alter, sozialer Status, Gender und sexuelle Orientierung werden für die Eingrenzung von Kulturen instrumentalisiert und bedingen Definitionen von ,Kultur ${ }^{6}$ mit unterschiedlichen Implikationen. Überschneidungen, komplizierte Verästelungen und unterschiedliche hierarchische Ebenen von Kulturauffassungen und -zugehörigkeiten sind die Folge. Dieses Problem des Begriffs ,Kultur'sollte bei der Eingrenzung berücksichtigt und die realiter angewendeten Kriterien zur Begriffsdefinition konsequenterweise genannt werden. Für die Abgrenzung der Reformation als Kultur spielen dementsprechend regionale, temporale und vor allem diskursive Kriterien eine Rolle. 
da die Grenzen permanent neu verhandelt werden. Da die Streitkultur ebenso wie die Gesamtkultur der ständigen Veränderung durch seine singulären Erscheinungsformen unterliegt, gilt auch für die Streitkultur das wechselseitige Verhältnis von konkreter Ausübung und abstrakter Regelung: Einerseits sind die einzelnen Streitakte durch die Regeln bedingt und machen diese insofern sichtbar, andererseits können die Regeln bewusst in Frage gestellt und (infolgedessen) umgestaltet werden. ${ }^{133}$ Eine Streitkultur ist historisch variabel und kontextgebunden, so dass sie immer an die jeweiligen (kommunikativen) Ausformungen gekoppelt zu betrachten ist. Insofern müssen die Streitakte im Zentrum einer Untersuchung stehen, anhand derer sich die „Konfliktaustragung sstrategien " 134 beobachten lassen.

Ausgehend von der Auffassung, dass die sprachlichen Mittel zentral für Streit im Allgemeinen und im Besonderen für die Religionsstreitigkeiten der Reformation sind, steht die sprachlich-literarische Manifestierung des Streits im Zentrum. Das Augenmerk soll bewusst auf „den Ort der Aufführung von Normen [...], der es den einzelnen möglich macht, die Normen zu präsentieren [und herauszufordern (Ergänzung KL)], von denen sie zugleich unterworfen werden[,] “i35 gerichtet werden. Im Fall der Reformation sind Textmedien (Druckerzeugnisse wie Flugblätter und Flugschriften) zwar nicht der einzige, aber doch ein zentraler und wesentlicher Aufführungsort der Streitkultur, der für Untersuchungen zur Verfügung steht. ${ }^{136}$

\subsubsection{Streitinszenierung und die, rhetorische Streitkultur}

Mit der Einführung des Begriffs der ,rhetorischen Streitkultur' wird in dieser Arbeit versucht, die Breite des Begriffs ,Streitkultur

${ }_{33}$ Vgl. dazu Thomas Gloning, der die Historizität von Kontroversen und ihren (Spiel-) Regeln betont: „Finally, there is a historical aspect: language games change over time, but they do not change by themselves. The historical development of the language game of controversy is a result of individuals responding to the challenge of changing circumstances. Therefore, changes in the established practice come about as a result of innovative individual practice under specific circumstances. "Gloning, Thomas (2005): „Early modern controversies and theories of controversy: The rules of the game and the role of the persons“. In: Barrotta, Pierluigi \& Marcelo Dascal (Hg.): Controversies and Subjectivity. Amsterdam: John Benjamins, S. 26328I, hier S. 264.

${ }_{334}$ Eriksson \& Krug-Richter (2003 b), S. 8.

${ }_{135}$ Wulf et al. (200I), S. I6.

${ }^{136}$ Die Quellenlage ist selbstverständlich ein beschränkender Faktor, den es zu berücksichtigen gilt. 
einzugrenzen. Bisherige Untersuchungen von Streitkultur(en) haben sich in zweierlei Hinsicht mit dem Konzept beschäftigt. Ein Teil der Untersuchungen konzentriert sich mehr auf das soziale (nicht primär sprachliche) Handeln der Streitakteure sowie auf die sozialen, gesellschaftlichen Reglements u. a. auch durch institutionelle Einrichtungen. Insbesondere die Untersuchung des Spannungsfeldes von kirchlichen, moralischen oder gesetzlichen Regeln und ihrer Einhaltung durch die Akteure bzw. die Kontrolle der Einhaltung dieser Regeln in konkreten Streitfällen wird dabei beleuchtet. Mechanismen der Streithandhabung, Konfliktlösung oder auch der Bestrafung infolge einer Regelübertretung durch die Gesellschaft und ihre Kontrollinstanzen (wie etwa Gerichte) stehen häufig im Fokus von Analysen, die sich zeitlich, räumlich oder thematisch eingegrenzten Aspekten widmen. ${ }^{\mathrm{I} 7}$ Die Schwerpunkte jener Untersuchungen liegen auf anthropologischen, sozialwissenschaftlichen und/oder sozialpsychologischen Fragen. Insbesondere das soziale Handeln und dessen Regelungen spielen eine wichtige Rolle. Im Kontext eines solchen historischen Erkenntnisinteresses ist in erster Linie die Rekonstruktion dieser gesellschaftlichen Mechanismen das Ziel, was aber die sprachlichen Ausformungen von Streit in den Hintergrund geraten lässt.

Andere Untersuchungen von Streitkultur(en) konzentrieren sich zwar mehr auf die Streittexte und führen ihre Analyse damit prinzipiell auf rhetorischen Grundlagen aus. Die rhetorischen, argumentativen Strategien werden aber nicht explizit untersucht, was nicht zuletzt von der wissenschaftlichen Herangehensweise und der Quellenhandhabung abhängig ist. Auch hier wird in vielen Analysen hauptsächlich den sozialen Regeln und ihren ,Aufführungen ${ }^{{ }^{6} 3^{8}}$ nachgegangen, d. h. die

${ }^{137}$ Gerade in der Geschichtswissenschaft sind Untersuchungen von Konflikten und Konfliktsteuerung im Mittelalter und der frühen Neuzeit üblich. Hauptaugenmerk von Untersuchungen können z. B. bäuerliche Konflikte in ländlichen Gegenden (vgl. Eriksson \& Krug-Richter 2003b), Fehdeführung (vgl. z. B. Reinle, Christine (2003): Bauernfehden. Studien zur Fehdeführung Nichtadliger im spätmittelalterlichen römischdeutschen Reich, besonders in den bayerischen Herzogtümern (= Vierteljahrsschrift für Sozial- und Wirtschaftsgeschichte, Beiheft I70). Stuttgart: Franz Steiner) oder, Alltagsgezänk‘ (vgl. Haack 2008) sein.

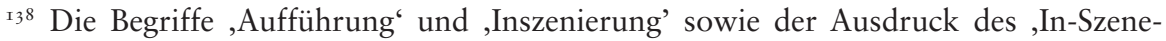
Setzens' werden weitestgehend synonym verwendet. ,Inszenieren' und ,In-SzeneSetzen' haben jedoch ihren Schwerpunkt auf der Produktionsseite (etwas wird von jemandem inszeniert bzw. in Szene gesetzt), während ,Aufführung' eher Bezug zur Rezeptionsseite (etwas wird vor jemanden aufgeführt) herstellt. Es handelt sich allerdings lediglich um geringfügige Bedeutungsnuancen, die größtenteils zu vernachlässigen sind. 
soziale Seite der Streitkultur wird ins Hauptaugenmerk genommen bzw. Streitkultur wird als ein soziales Konstrukt verstanden. Die Texte dienen hauptsächlich der Sichtbarmachung von sozialen Kontrollmechanismen und Prozessen. Vielfach wird dabei ausgeblendet, dass die sprachliche Ausformung der Streitaustragung rhetorischen Regelhaftigkeiten folgt bzw. diese aufbricht oder reflektiert. Die rhetorische Dimension von ,Streit' und ,Streitkultur' wird zumeist nicht explizit behandelt, obwohl diese ebenso an ihren Kontext gebunden ist wie die ,Streit" und ,Streitkultur' inhärente soziale Dimension.

Daneben gibt es ebenfalls Ansätze, die sich mit gerade jenen Fragen beschäftigen und eine rhetorische Dimension bei der Untersuchung hinzuziehen oder diese in den Mittelpunkt rücken. Dieser Untersuchungsschwerpunkt ist von den anderen beiden genannten Ausrichtungen nicht grundsätzlich bestimmten wissenschaftlichen Disziplinen zuzuordnen. Trotz prinzipiell unterschiedlicher Herangehensweisen von beispielsweise der Literaturwissenschaft und der Geschichtswissenschaft können sie eine ähnliche Orientierung haben, so dass die hier vorgenommenen Gruppierungen von Untersuchungen nicht unbedingt mit den Fachgrenzen konform sind. Um die letztgenannte Art von Ansätzen von den anderen beiden auch terminologisch trennen zu können, reichen daher weder die Identifizierung des fachlichen Ansatzes noch die bisherigen Begrifflichkeiten aus, die im Rahmen einer Untersuchung von ,Streitkultur' vorhanden sind. Zur Nuancierung wird deshalb der Unterbegriff der ,rhetorischen Streitkultur` eingeführt.

Die Schwerpunktsetzung auf der, rhetorischen Streitkultur' gründet auf der Auffassung, dass Streit sprachbasiertes performatives Handeln ist. Als solches ist es als Inszenierung zu verstehen, ${ }^{\mathrm{I} 39}$ bei der nicht nur soziale, sondern auch rhetorische Normen aufgeführt werden. Um dies im Detail zu klären, müssen zuerst die Bedeutungen der Begriffe ,Performativität' und ,Performanz' verdeutlicht werden.

I39 Soziales Handeln wird grundsätzlich als ein sich wechselseitig konstruierendes Geschehen verstanden, was einem einseitig auf den Handelnden und dessen Intentionen ausgerichteten Verständnis entgegengesetzt ist. Vgl. dazu: „Wenn soziales Handeln nicht auf Intentionalität reduziert wird, sondern sein performativer Charakter betont wird, bedeutet dies eine Veränderung der Perspektive. Soziales Handeln wird dann als Aufführung und Inszenierung begriffen. “ Wulf, Christoph (200I): „Mimesis und Performatives Handeln. Gunter Gebauers und Christoph Wulfs Konzeption mimetischen Handelns in der sozialen Welt“. In: Ders., Michael Göhlich \& Jörg Zirfas (Hg.): Grundlagen des Performativen. Eine Einführung in die Zusammenhänge von Sprache, Macht und Handeln. Weinheim \& München: Juventa Verlag, S. 253-272, hier S. 253. 
,Performativität' erfreut sich im Zuge des performative turn in den letzen Jahren zunehmender Beliebtheit, was zu einer "rhizomatischen“ “4 Entwicklung des Begriffs geführt hat ${ }^{\mathrm{I} 4 \mathrm{I}}$ und eine Differenzierung der zugrunde liegenden Auffassung notwendig erscheinen lässt. Grundsätzliche Auffassung des performative turn ist,

dass Kultur nicht als Gewebe distinkter, decodierbarer Einzelelemente, sondern als performance zu verstehen sei. Die ,Ausdrucksdimensionen von Handlungen und Handlungsereignissen bis hin zur sozialen Inszenierungskultur ‘ wird nun in den Fokus gerückt, aus ,Ereignissen, Praktiken, materiellen Verkörperungen und medialen Ausgestaltungen werden die Hervorbringungs- und Veränderungsmomente des Kulturellen erschlossen` (Bachmann-Medick 2007: 104-I43, die Zitate auf S. I04). ${ }^{\text {I42 }}$

Kultur wird als Produkt von performativen Handlungen gesehen, die durch ihre Wiederholung in variierenden Kontexten kulturelle (Be-) Deutungsmuster hervorbringen, verkörpern, formen und verändern. Beispielsweise wird sozial und kulturell erlerntes Wissen aufgegriffen, aufgeführt und mehr oder weniger bewusst modifiziert:

,Performativität‘ zielt also darauf, dass die Wiederholung von Zeichenausdrücken in zeit- und raumversetzten neuen Kontexten - eine Wiederholung, welche erst die Allgemeinheit im Gebrauch dieser Ausdrücke stiftet - zugleich eine Veränderung der Zeichenbedeutung bewirkt. ${ }^{\mathrm{I} 3}$

${ }^{140}$ Klaus W. Hempfer benutzt diesen Ausdruck in Rückbeziehung auf den Rhizombegriff von Gilles Deleuze und Félix Guattari. Hempfer, Klaus W. (20I I): „Performance, Performanz, Performativität. Einige Untersuchungen zur Ausdifferenzierung eines Theoriefeldes“. In: Ders. \& Jörg Volbers (Hg.): Theorien des Performativen. Sprache - Wissen - Praxis. Eine kritische Bestandsaufnahme. Bielefeld: transcript, S. I3-4I.

${ }^{14}{ }^{1}$ „Performanz kann sich ebenso auf das ernsthafte Ausführen von Sprechakten, das inszenierende Auffübren von theatralen oder rituellen Handlungen, das materiale Verkörpern von Botschaften im ,Akt des Schreibens“ oder auf die Konstitution von Imaginationen im ,Akt des Lesens“ beziehen.“ Wirth, Uwe (2002): „Der Performanzbegriff im Spannungsfeld von Illokution, Iteration und Indexikalität“. In: Ders. (Hg.): Performanz. Zwischen Sprachphilosophie und Kulturwissenschaften. Frankfurt/Main: Suhrkamp, S. 9-60, hier S. 9.

${ }^{142}$ Häsner et al. (20II), S. 69. Siehe dazu auch Fischer-Lichte, Erika (2004): Ästhetik des Performativen. Frankfurt/Main: Suhrkamp, S. 36.

${ }^{143}$ Krämer, Sybille (2004): „Was haben ,Performativität‘ und ,Medialität' miteinander zu tun? Plädoyer für eine in der ,Aisthetisierung' gründende Konzeption des Performativen. Zur Einführung in diesen Band“. In: Dies. (Hg.): Performativität und Medialität. München: Wilhelm Fink, S. I3-32, hier S. I6. 
Performative Handlungen sind demnach solche, die mittels ihrer Ausführung, ihrer Performanz, ${ }^{\mathrm{I} 44}$ etwas über den eigentlichen Sinngehalt der Handlung hinaus tun. Übertragen auf Kultur bedeutet dies, dass jene Handlungen (Be-)Deutungsmuster verändern, indem sie etwas in einer bestimmten Weise aufführen oder inszenieren.

Orte solcher kultureller Aufführung können mit einem erweiterten Performativitätsbegriff auch Texte sein. ${ }^{\mathrm{I} 45}$ Trotz fehlender Körperlichkeit und nicht vorhandener Simultanität von Produktion und Rezeption sowie „Ereignis und Effekt“, ${ }^{146}$ was gemeinhin den Performativitätsbegriff auszeichnet, können Texte performativ sein, ${ }^{147}$ da sie

selbst als >Aktanten in Vollzüge eingebunden sein bzw. ‘aufgeführt< werden [können]; sie können als Vehikel der ,Zirkulation sozialer Energie (S. Greenblatt) fungieren, und sie können eine wesentliche Rolle im kulturellen identity fashioning spielen. ${ }^{\mathrm{I} 48}$

Texte zeigen sich auf diese Weise nicht nur als Quelle und Spiegel von Kultur, die gelesen bzw. decodiert werden müssen, sondern erweisen sich als in ein komplexes Wechselspiel von Ereignis und Wahrnehmung eingebunden, bei dem es um ein „,in Szene gesetztes` Geschehen“ geht, „welches Akteur- und Betrachterrollen einschließt. " ${ }^{449}$

${ }^{\text {I44 }}$ Der Begriff ist ebenso wie ,Performativität‘ variabel. Klaus W. Hempfer unterscheidet zwischen ,Performanz ' und ,Performance' und versteht in Anlehnung an die linguistischen Kategorien „[k]nowledge of language (competence)“ und „use of language (performance)“ unter ,Performanz ‘ alle sprachlichen Äußerungen, während er unter ,Performance‘ lediglich den Begriff der theatralischen Aufführung fasst.Hempfer (20I I), S. I7. Für diese Arbeit ist diese strikte Trennung nicht notwendig, die Kernbedeutung des Aus- bzw. Aufführens ist beiden Begriffen, ,Performanz' und ,Performance', gemein. Vgl. dazu auch Barbara Beckers Unterscheidung „zwischen künstlerischer und alltagsästhetischer Inszenierung“: „Während in künstlerischen Inszenierungen die Eröffnung imaginärer Räume ein wesentliches Moment darstellt, dienen alltagsästhetische Inszenierungen vornehmlich der Darstellung von Gegenwart.“ Becker, Barbara (2004): „Selbst-Inszenierung im Netz“. In: Krämer, Sybille (Hg.): Performativität und Medialität. München: Wilhelm Fink, S. 4I3-429, hier S. 4I7.

${ }^{145}$ Häsner et al. (2OII) zeigen dies detailliert in ihrem Aufsatz.

${ }^{146}$ Ebd., S. 72.

${ }^{147}$ „Konzeptualisierungen textueller Performativität kompensieren diesen Mangel, indem sie auf textuelle Strategien der Simulation von Präsenz oder Kopräsenz fokussieren. Zugleich werden diese Konzeptualisierungen damit an den theaterwissenschaftlichen Performanzbegriff anschließbar.“ Ebd., S. 72.

${ }^{148}$ Ebd., S. 70. Vgl. dazu auch Fluderniks \& Gehrkes (2004) Bezeichnung der „acts of identity“, die als einzelne Handlungen betrachtet werden können, die in ihrer Gesamtheit das „identity fashioning“ ausmachen.

${ }^{149}$ Krämer (2004), S. I4. 
Der Glaubensstreit der Reformation stellt ein solches Geschehen dar, das in Texten inszeniert wird, entsprechend Barbara Beckers grundlegender Bestimmung von ,Inszenierung' als

ein Ensemble von Techniken und Praktiken, mit denen etwas [z. B. der Glaubensstreit] zur Erscheinung gebracht wird, wobei der Prozess des Erscheinens selbst mit eingeschlossen ist. Inszenierung ist zudem ein absichtvolles, auf Wirkung angelegtes Handeln, das eine gestalterischkreative Instanz voraussetzt und eine strategische Ausrichtung auf spezifische Gruppen von Adressaten beinhaltet. ${ }^{\mathrm{I} 0}$

Die große Menge der gedruckten Schriften während der Reformation (von Theologen und Laien), die große Anzahl der in den Streit eingebundenen Autoren(typen) und ein neues, volkssprachliches Publikum sind Ausdruck der sprachlichen Streitinszenierung. Die Reformationszeit ist eine, die sich in Hinsicht auf die literarische Produktion hauptsächlich durch das Streitschrifttum auszeichnet.

Jedoch lassen sich nicht sämtliche sprachlichen Manifestationen von Streit als Ausdruck einer ,rhetorischen Streitkultur' bezeichnen, ${ }^{\mathrm{I} 5 \mathrm{I}}$ eine Relevanz kommt einer ,rhetorischen Aufführung' erst im öffentlichen Streit zu. So lässt sich aus dem Referenzbereich der Theatermetapher ableiten, dass die Zuschauer eine notwendige Kategorie für das Vorhandensein einer Aufführung darstellen. Aufgrund seiner Ausrichtung auf ein Publikum ist dem öffentlich ausgetragenen Streit ein sozialer wie auch ein rhetorischer Inszenierungscharakter inhärent. Als ein Teil von ,Streitkultur' zeichnet sich die, rhetorische Streitkultur' entsprechend dadurch aus, dass bei ihrer Aufführung folgende Faktoren im Mittelpunkt stehen: Ein Streit

I. wird öffentlich in sprachbasierten Medien inszeniert,

2. greift dabei sprachliche und literarische Muster oder Traditionen auf (textsortenbasiert, stilistisch, rhetorisch usw.) und

\footnotetext{
${ }^{150}$ Becker (2004), S. 4I 5. Ergänzung in eckigen Klammern durch K. L.

I5I Wie bereits erwähnt wurde, gibt es historische Untersuchungen zur Streitkultur, die besonders Gesetzestexte als Quellen der programmatisch-normativen Seite und Polizeiakten, Gerichtsprotokolle etc. als Quellen der performativen Seite betrachten, um Rückschlüsse auf eine bestimmte Streitkultur ziehen zu können. Damit legen sie den Fokus besonders auf (Alltags-)Delikte und individuelle Streitakte. Sprache ist zwar grundlegend für jene Streitakte und ihre gerichtliche Aushandlung, sie steht aber nicht im Mittelpunkt für die Streitigkeiten und spielt damit eine untergeordnete Rolle.
} 
3. trägt zur Verhandlung und (Re)Produktion zugrunde liegender Regeln und Normen bei, die sich auf die Verwendung dieser Muster oder Traditionen beziehen.

Eine ,rhetorische Streitkultur ${ }^{6}$ umfasst demnach diejenigen öffentlichen kulturellen Streitpraktiken und -reglementierungen, die auf rhetorischen Kategorien und Mustern beruhen, sie (explizit oder implizit) reflektieren und gleichzeitig (re)konstituieren. Anhand dieser rhetorischen Prozesse wird die bereits erwähnte kulturelle Produktivität von Streit beobachtbar.

Jeder Streitkultur liegen, ebenso wie soziale Regeln und Muster, bestimmte rhetorische Dispositionen und Vorraussetzungen zugrunde, die in der Streitausübung sichtbar werden. Jedoch erscheint es erst dann sinnvoll, von ,rhetorischer Streitkultur ${ }^{6}$ zu sprechen, wenn ein Streit ein komplexeres Geflecht von Texten mit sich bringt, ${ }^{152}$ das die drei genannten Faktoren ins Zentrum rückt: eine öffentliche sprachliche Inszenierung eines Streits, die mit Rückgriff auf die Reglementierungen ebensolcher Inszenierungen jene Regeln rekonstruiert und erneuert. Nicht zu verwechseln mit dem Geflecht aus Streittexten ist z. B. die Kontroverse, die den Austausch von Streitschriften zwischen zwei oder mehreren Personen oder Parteien zu einem bestimmten Streitthema meint. Das Geflecht besteht aus Schriften, die nicht an bestimmte Personen oder Themen gebunden sind, insofern sie zu dem übergreifenden Streit gehören. Martin Gierl unterscheidet „[m]it Streitschrift, Streitschriftenwechsel, Streitstrang und Streitzusammenhang [...] vier wesentliche[] streitstrukturierende Kommunikationseinheiten ", ${ }^{153}$ die sich auf verschiedenen Ebenen ansiedeln lassen. Gierl erklärt die Entstehung eines Geflechts von Texten, das - ausgehend von den einzelnen Schriften - den Regeln der Streitkultur ausgesetzt ist:

${ }^{152}$ Der einzelne private Streit fällt aus diesem Kontext heraus, weil er nicht zur öffentlichen Aufführung gelangt und im privaten Streitfall die sozialen Reglementierungen eher im Fokus stehen als die rhetorischen. Ebenso soll auch der Rechtsstreit, der strengen Traditionen und Regeln unterliegt, nicht zur rhetorischen Streitkultur gezählt werden, da der strenge Rahmen die freie Verhandlung von sprachlichen und literarischen Mustern nicht zulässt bzw. eine rhetorische Dimension für diese Art des Streits geringere Enfaltungsmöglichkeiten hat. Erst die freiere Streitausübung über die (Massen-)Medien (z. B. Buchdruck im I6. Jahrhundert) gewährleistet die Voraussetzungen für den kulturellen, wechselseitigen Prozess, der die rhetorische Streitkultur ausmacht.

ז53 Gierl (1997), S. 33. 
Unabhängig jedoch vom behandelten Inhalt, gehorchen die Streitschriften den formalen Regeln theologisch-literarischen Streitens. Der einzelne, eine bestimmte Frage erörternde Text ordnet sich einem Streitschriftenwechsel zu. Die einzelnen Streitensembles gruppieren sich thematisch zu Streitsträngen. Untereinander in mehrfacher Weise verbunden, sind derartige Streitstränge schließlich zum Streitzusammenhang vernetzt. ${ }^{54}$

Was Gierl hier für das Ende des I7. Jahrhunderts herausarbeitet, kann auch partiell für die Reformationszeit geltend gemacht werden, jedoch liegt das Interesse dieser Arbeit bei den Einzelschriften, sowie in geringerem Umfang beim Schriftenwechsel, so dass Gierls Ebenen des Streitstrangs und Streitzusammenhangs keine Verwendung finden.

Aus den einzelnen reformatorischen Glaubensstreitigkeiten und dem damit verbundenen Aufschwung gedruckter Streitschriften in der Volksprache Deutsch bildete sich sukzessiv ein Geflecht aus Texten, aus der eine volkssprachliche Streitkultur hervorging: Aus einer klassisch und lateinisch geprägten (Streit-)Rhetorik sowie aus den überwiegend mündlich tradierten scholastischen Disputationsregeln ${ }^{155}$ erwuchsen neue volkssprachliche Streittechniken und rhetorische Strategien. ${ }^{156}$ Das Hinzutreten von Laien zu den Autortypen und die Volkssprache brachten Neuerungen mit sich, die in veränderten Streitaufführungen resultierten, denn Laien konnten zu dieser Zeit freier mit Texten umgehen bzw. mussten es sogar aufgrund fehlender Kenntnisse der Konventionen. Selbst gebildete Laien waren nicht auf gleiche Weise an die strengen rhetorischen Regeln der lateinischen Schule gebunden oder fühlten sich diesen möglicherweise nicht gleichermaßen verpflichtet wie studierte

${ }_{154}$ Ebd.

${ }^{155}$ „[Die Disputation] wurde als knowing how, als ein praktisches, verinnerlichtes und applizierbares Regelwissen im universitären Alltag eingeübt, aber nicht theoretisch-methodisch im Sinn einer im Detail verschriftlichten Anleitung aufbereitet.“ Traninger, Anita (2012): Disputation, Deklamation, Dialog. Medien und Gattungen europäischer Wissensverhandlungen zwischen Scholastik und Humanismus. Stuttgart: Franz Steiner, S. 68. Vgl. dazu auch Gindhart, Marion \& Ursula Kundert (2010): „Einleitung“. In: Dies. (Hg.): Disputatio I200-I800. Form, Funktion und Wirkung eines Leitmediums universitärer Wissenskultur. Berlin \& New York: De Gruyter, S. I-I 8, hier S. I6.

${ }^{156} \mathrm{Vgl}$. dazu: „Wesentliche Redestrategien in den Streitschriften liegen in der antiken und christlichen Rhetorik begründet. Für die Volkssprache gab es aber keine Rhetorik-Lehrbücher, so daß wichtige Rede-Techniken und -Strategien aus der lateinischen Rhetorik entlehnt, daneben auch volkssprachliche Elemente integriert wurden, wodurch zahlreiche neue Mischungen entstanden, die immer wieder neu das Spannungsverhältnis zwischen prodesse, delectare und movere austarierten." Bremer (2005b), S. I2. Vgl. auch Matheson (I998), S. 2. 
Theologen, weshalb von divergierenden rhetorischen Inszenierungen von Laien auf der einen Seite und Theologen auf der anderen ausgegangen werden kann. ${ }^{157}$

Laienautoren gelangten mit der Reformation erstmals in einer größeren Anzahl auf die ,Bühne“ des Streits und nahmen mittels ihrer Inszenierungen Teil an der diskursiven Produktion und Transformation von kulturellen (Be-)Deutungsmustern sowie von rhetorischen Techniken des Streitens. Sinnbildlich gesprochen schrieben sie sich in das Geflecht von sich aufeinander beziehenden Texten ein, das nicht nur die sozialen und gesellschaftlichen Verhaltensregeln im Streit, sondern auch die rhetorischen Normen der argumentativen Strukturen reproduzierte, herausforderte und neu formierte.

Nicht nur für die Reformation, sondern in einem allgemeinen Sinne können die Texte des Streits als jene sprachlichen Erzeugnisse gelten, die sich innerhalb des rhetorischen Raums, den der Streit eröffnet, platzieren und dessen Grenzen verschieben, erweitern oder verengen. ${ }^{158} \mathrm{Im}$ Zentrum eben dieses rhetorischen Raumes steht die Polemik als grundlegendes inszenatorisches Prinzip.

\subsection{Polemik als Methode der Streitinszenierung}

Das Verständnis von Polemik als zentralem inszenatorischem Prinzip der ,rhetorischen Streitkultur' wirft zwingend die Frage nach den Merkmalen und Erscheinungsformen von Polemik auf. Was ist

${ }_{157} \mathrm{Vgl} .:$ „Indeed, one of the marks of lay writing is that it lacks the grammatical control that characterizes the work of the literary elite. [...] Lay culture drew what it wanted or needed from the learned culture, particularly with the respect to religious ideas. On the whole, however, lay culture was more innovative. Learned culture, by the very definition, had to continue in the traditional paths of grammar, rhetoric, logic, and theology. [...] Lay culture could develop new forms. " Chrisman, Miriam U. (I988): „Printing and the Evolution of Lay Culture in Strasbourg I480-1 599“. In: Hsia, R. Po-Chia (Hg.): The German People and the Reformation. Ithaca \& London: Cornell University Press, S. 74-100, hier S. 99.

${ }^{158}$ Erich Straßner konstatiert für die Flugschriftenliteratur der Reformation: „Das Verdienst der Flugschriften besteht in der Re- und Neukonstituierung einer religiösen, kulturellen, sozialen und politischen Handlungspraxis und Handlungsorientierung.“ Straßner, Erich (I999): „Kommunikative Aufgaben und Leistungen des Flugblatts und der Flugschrift“. In: Leonard, Joachim-Felix, Hans-Werner Ludwig, Dietrich Schwarze \& ders. (Hg.): Medienwissenschaft. Ein Handbuch zur Entwicklung der Medien und Kommunikationsformen. I. Teilband. Berlin \& New York: De Gruyter, S. 794-802, hier S. 795. Dieses umwälzende Potential ist auch bezogen auf den rhetorischen Bereich zu verstehen, da er ein Teil der kulturellen Praktik des Schreibens ist. 
überhaupt Polemik? Wie lässt sich Polemik ein- und abgrenzen und wie zeigt sie sich in streitinszenierenden Schriften der Reformationszeit? Ziel der Beantwortung dieser Fragen ist es, in Auseinandersetzung mit der aktuellen Forschung eine Definition des Begriffs ,Polemik ${ }^{6} \mathrm{zu}$ erarbeiten, die als Grundlage für die folgenden Untersuchungen von Melchior Hoffmans Schriften fungiert. Das Vorgehen für diesen Zweck ist zunächst ex negativo, d. h. die Merkmale von ,Polemik' werden in Abgrenzung zu dem, was ,Polemik' nicht (oder nicht allein) ist, erörtert.

Als ersten Ausgangspunkt für die Bestimmung von ,Polemik' soll der bereits erläuterte Begriff des Streits dienen: Es ist bereits herausgearbeitet worden, dass er eine „Konfliktaustragungsform “159 ist, die sich in erster Linie dadurch von anderen Formen der Konfliktaustragung (z. B. Verhandlung) unterscheidet, dass „ein wesentlich emotionaler Gesprächsstil verbunden mit Imageverletzungen [Kennzeichen auf der Äußerungsebene ist]. “6 Untersuchungen zu den Streitigkeiten der Reformation bestätigen einen hohen Grad an Emotionsaufgeladenheit der Reformationspamphlete, der häufig auf höchst persönlichen Anliegen der Schreiber basierte (insbesondere gilt dies für Laien). ${ }^{{ }^{6 I} \mathrm{~T}}$ Tiefe persönliche Überzeugung und eine die Zeit beherrschende Sorge sowohl um das eigene Seelenheil als auch um das der Mitmenschen erwecken den Eindruck, dass nicht nur eine menschliche Leserschaft adressiert wurde, sondern auch Gott selbst. ${ }^{162}$ Die Tendenz zur Personalisierung von Streitfragen, die insbesondere durch Luthers Schriften initiiert worden war, trug zusätzlich zur Emotionalisierung bei. Insofern ist ein emotionaler Gesprächsstil für die streitinszenierenden Schriften der Reformationszeit ein nachweisbares Charakteristikum. Jedoch kann emotionaler Stil - je nach Art der Gefühlsäußerung - sowohl

${ }_{159}$ Spiegel (I995), S. I6.

I60 Spiegel (I995), S. I9.

${ }^{161}$ Die Feststellung eines hohen Grades an Emotionalität in einem Text lässt jedoch nicht zwingend auf die emotionale Stimmung des Autors schließen. Inwiefern die Inszenierung im Text die ,reale“ Befindlichkeit des Autors wiederspiegelt, muss im konkreten Fall untersucht werden. „Aus einer behaupteten oder sich im Stil ausdrückenden emotionalen Erregung der polemischen Figur lässt sich nicht ohne weiteres schließen, dass der Autor beim Schreiben emotional erregt war." Dieckmann (2005), S. 38 .

${ }^{162}$ „We have learnt to conceive of the pamphlet as a stylised conversation, intimately linked with sermon and classroom and social event. We need to be much more aware of its cultic bite, its confessional note, its blessings and imprecations, its exhortations and calls to discipleship, what we have called its doxological quality. As often as not it was addressed to God as much as to the hearer." Matheson (I 998), S. $54 \mathrm{f}$. 
versöhnliche als auch aggressive Rede bedeuten. Allein emotionaler Stil als Kriterium scheint demnach nicht ausreichend für ein polemisches Prinzip von Streitinszenierung: Interjektionen (exclamatio), auf Mitleidserregung gerichtete Anrufungen und Bitten (z. B. Apostrophe) können gänzlich ohne die Absicht von Kampf oder Krieg mit Worten ${ }^{163}$ verwendet werden.

Die ebenfalls erwähnten Imageverletzungen hingegen implizieren von Grund auf Formen der aggressiven Rede bzw. der verbalen Gewalt, da sie einen Angriff auf oder ein Eindringen in die Integrität einer Person oder Einrichtung darstellen. ${ }^{64}$ Verbale Gewalt - mit ihren konkreten Erscheinungsformen wie beispielsweise Beleidigungen, Beschimpfungen, pejorative Vergleiche oder Bezeichnungen, Stigmawörter ${ }^{165}$ usw. - ist im Streit und (dementsprechend) auch im Streitschrifttum allgegenwärtig.

Jedoch erscheint ,sprachliche (oder verbale) Gewalt ${ }^{{ }^{1} 66}$ nicht ausreichend und präzise zu beschreiben, was Polemik ist, denn Gewalt ist nach Sybille Krämer dem Sprechen per se inhärent: „Die Bedingungen der Möglichkeit von Sprache erweisen sich als die Bedingungen einer notwendigen Gewalt. " ${ }^{167}$ Dies begründet sie etwa damit, dass die sprechende Person das Schweigen der anderen impliziere, dass die sprechende Person sich einen Ort vereinnahme, der für andere dann nicht mehr zugänglich sei und dass Sprache „oft etwas Bedrängendes“ habe. Damit ist nicht allein die aggressive Rede, sondern jegliche Rede a priori als Gewaltanwendung zu betrachten. ${ }^{\mathrm{I} 8}$ Der Gewaltbegriff erweist sich allerdings als schwierig, weil es unterschiedliche Formen der Gewalt gibt, die zum einen positiv, zum anderen negativ konnotiert

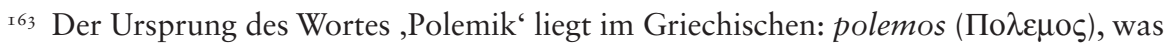
Kampf, Krieg bedeutet.

${ }^{164}$ Verbale oder sprachliche Gewalt wird hier im Sinne der negativ konnotierten Seite von Gewalt, der violentia, verstanden. Vgl. dazu die „Einleitung“ von Elke Koch sowie Sybille Krämers Aufsatz „,Humane Dimensionen“ sprachlicher Gewalt oder: Warum symbolische und körperliche Gewalt wohl zu unterscheiden sind“. In: Krämer, Sybille \& Elke Koch (Hg.) (20I0): Gewalt in der Sprache. Rhetoriken verletzenden Sprechens. München: Wilhelm Fink, S. 9-20 \& 2I-42.

165 Schwitalla (I999), S. 4I. Zu Stigmawörtern siehe Kapitel 2.2.2 Die Performativität von Polemik, Abschnitt Nicht-argumentative Streittechniken.

${ }^{166}$ Hier ist lediglich der Bereich von sprachlicher Gewalt gemeint, den Steffen Kitty Herrmann und Hannes Kuch unter dem Aspekt „Gewalt durch Sprache“ zusammenfassen. Herrmann, Steffen Kitty \& Hannes Kuch (2007): „Verletzende Worte. Eine Einleitung “. In: Dies. \& Sybille Krämer (Hg.): Verletzende Worte. Die Grammatik sprachlicher Missachtung. Bielefeld: transcript, S. 7-30, hier S. I7-22.

${ }_{167}$ Krämer (2010), S. 30 (Hervorhebungen im Original).

${ }^{168}$ Krämer (20IO), S. 3 I \& 32. 
sind. ${ }^{169}$ So können jenseits der grundlegenden Gewaltanwendung bzw. Machtausübung, die beim Sprechen stattfindet, auch negativ konnotierte Gewaltakte ausgeführt werden. Diese können beachsichtigt oder unbeabsichtigt sein: Beleidigungen können aus Versehen ausgesprochen werden (ohne beleidigende Intention) bzw. Aussagen als ebensolche interpretiert werden ${ }^{170}$ - zum Teil aufgrund unterschiedlicher kulturtypischer Deutungsmuster. Missverständnisse und unverstandene Ironie können als verbale Gewalt ausgelegt werden, wenn sie auf Unverständnis stoßen und keine Aufklärung erfahren. Auf der Ebene der Prosodie können etwa Unterbrechungen, Betonungen, Akzent, Ton usw. als Gewaltanwendung aufgefasst werden.

Den obigen Ausführungen entsprechend kann sprachliche Gewalt einerseits als ein der Sprache inhärentes Phänomen betrachtet werden (sowohl produktiv als auch destruktiv), andererseits als verletzendes Sprechen. Letzteres kann beabsichtigt und unbeabsichtigt zur Anwendung kommen. Bereits aufgrund der Vieldeutigkeit ist eine Definition von Polemik als ,sprachliche/verbale Gewalt' nicht befriedigend. Hinzu kommt noch, dass lediglich die zielgerichtete Gewaltanwendung (violentia) unter dem Begriff der Polemik gefasst werden kann, denn in Schriften, die einen Streit inszenieren, ihn entweder entfachen oder einen Beitrag zu seinem Fortbestand leisten, ist die Anwendung von verbaler Gewalt öffentlich, zielgerichtet, dient bestimmten Zwecken und wird bewusst instrumentalisiert - sie ist intendierte aggressive Rede bzw. „symbolische Gewalt“. ${ }^{175}$ Für die Definition von Polemik können somit eine Emotionalisierung im Sinne der Aggression und der Aspekt einer gewollten Anwendung von Gewalt festgehalten werden.

${ }^{169}$ Vgl. dazu: „Das deutsche Wort ,Gewalt' birgt [...] das Spannungsfeld von rechtmäßiger, ordnungsstiftender und unrechtmäßiger, zerstörerischer Gewalt. “ Ebd., S. 23. Krämer unterscheidet in Anlehnung an Friedhelm Neidhardt (I986) zwischen dem positiven „Kompetenzbegriff“ und dem negativen „Aktionsbegriff“ von Gewalt. Ebd. S. 23 f.

${ }^{170}$ Vgl. dazu ebd., S. 36-38.

${ }^{171}$ Krämer definiert die symbolische Gewalt, die durch Sprache ausgeübt werden kann, der körperlichen Gewalt grundsätzlich ähnlich: „So wie physische Körper durch Gewalt immer auch von ihrem Platz verdrängt werden und vor der Gewalt zurückweichend, fallend, fliehend ihren ,Ort verlieren', so bewirkt symbolische Gewalt, indem sie Ehre, Würde, Wertschätzung und Integrität einer Person beschädigt und verletzt, eine Verrückung bzw. Marginalisierung des Platzes, den diese Person im sozialen Raum zwischenmenschlicher Beziehungen einnimmt. “ Krämer (2010), S. 34. 
Die hier bereits angedeuteten Schwierigkeiten bei der heuristischen Herleitung einer Definition spiegeln die Situation in der Forschung wider, denn der Begriff der ,Polemik' ist umstritten und bisher nicht übereinstimmend definiert worden. In der Rhetoriktheorie zur Zeit der Reformation sucht man ,Polemik' vergeblich, obwohl ihre Anwendung in der Reformationszeit zu einem besonderen Höhepunkt gelangte: ${ }^{172}$ „Die Polemik ist ein Musterbeispiel für die meist vernachlässigte Tatsache, daß in der Geschichte der Rhetorik die Lehre und die zugehörige Praxis oft sehr weit auseinanderklaffen. " "${ }^{173}$ Es bestätigt sich somit, dass Regelwerk und Ausübung nicht in einem direkten Verhältnis zueinander stehen müssen. Die bereits in Kapitel 2.I angesprochene Kluft zwischen theoretischer Norm und Praxis zeigt sich im Falle der Polemik insofern besonders deutlich. Auch in der weiteren historischen Entwicklung des Begriffs ist die Diskrepanz zwischen beiden nicht gänzlich aufgehoben worden, so dass es bisher nicht zu konzeptioneller Übereinstimmung gekommen ist.

Im Folgenden werden daher verschiedene Ansätze der Bestimmung des Polemikbegriffs diskutiert und schließlich eine für diese Arbeit geltende Definition formuliert. Anschließend wird, in einem zweiten Schritt, Polemik als Mittel der „strukturellen Performativität“ “ ${ }^{774}$ erläutert und anhand einiger Textbeispiele veranschaulicht. Die Funktionen von Polemik für die Inszenierung des Streits stehen dabei im Vordergrund der Betrachtung.

\subsubsection{Theoretische Grundlagen des Polemikbegriffs}

Das Historische Wörterbuch der Rhetorik nennt drei Anwendungsbereiche bzw. Bedeutungen des Begriffs Polemik:

Zum einen bezeichnet P[olemik], im weiteren Sinne, eine bestimmte Verfahrensweise, eine Methode der Auseinandersetzung; zum anderen, im engeren Sinne, einen literarischen Typus öffentlichen Streitens

\footnotetext{
${ }^{172}$ Mit Hinblick auf den theoretischen Hintergrund der Polemik im I6. und I7. Jahrhundert findet sich ein Überblick über die frühneuzeitlichen RhetorikLehrbücher bei Richardsen-Friedrich, Ingvild (2000): Antichrist-Polemik in der Zeit der Reformation und der Glaubenskämpfe bis Anfang des 17. Jahrhunderts. Argumentation, Form und Funktion. Frankfurt/ Main: Peter Lang, S. 39-53.

${ }^{173}$ Braungart, Georg (I992): „Zur Rhetorik der Polemik in der frühen Neuzeit“. In: Bosbach, Franz (Hg.): Feindbilder. Die Darstellung des Gegners in der politischen Publizistik des Mittelalters und der frühen Neuzeit. Köln u. a.: Böhlau, S. I-2 I, hier S. 5 .

${ }^{174}$ Häsner et al. (20II), S. 82-84.
} 
insbesondere seit der Frühneuzeit; und, zum dritten, wird P[olemik], zumal in der Forschungsliteratur, zum undifferenzierten Sammelbegriff für heterogene, inhaltliche Kontroversen gewählt. ${ }^{175}$

Es wird deutlich, dass ,Polemik' hier auf verschiedenen Ebenen verortet wird, so dass sich nicht nur leichte Unterschiede bei Bedeutungsnuancen ergeben, sondern sich gleichsam mehrere Bedeutungen parallel entwickelt haben. Mitunter erscheint die Verwendung von ,Polemik‘ infolgedessen polysem.

Um sich den verschiedenen definitorischen Ansätzen in der Forschung zu nähern, wird zunächst genauer untersucht, inwiefern sich die Definitionen voneinander unterscheiden, wo ihre Schwerpunkte liegen und welche Kriterien sie bedienen. Bei diesem Vorgehen lassen sich vier wichtige Bereiche identifizieren, in denen sich die Begriffsbestimmungen voneinander abheben:

- Die Konkretisierung des generischen Charakters in auf Text bezogene Ordnungsschemata: Ist Polemik Gattung, Form, Methode oder Stil?

- Die Bestimmung des Modus: Ist Polemik sachliche oder unsachliche Argumentation?

- Die Identifizierung des Adressaten: Ist die gegnerische Partei oder das Publikum der eigentliche Adressat der Polemik?

- Die Explikation der Funktionen: Soll Polemik überzeugen (und vor allem wen: Gegner oder Publikum)? Dient Polemik doch eher zur Ein- oder Ausgrenzung, d. h. zur Gruppen- und Identitätsbildung?

In einigen dieser Punkte stehen sich die theoretischen Ansätze bzw. die Definitionsversuche zum Teil diametral gegenüber. Inwiefern die bestehenden Definitionen dies tun, soll folgend anhand der genannten vier Bereiche einzeln diskutiert werden, um einen geordneten Überblick über die theoretischen Ausführungen zur Polemik zu erhalten.

Bei der Konkretisierung des generischen Charakters von Polemik auf den sich auch die drei bereits genannten üblichen Verwendungen des Begriffs im Historischen Wörterbuch der Rhetorik beziehen klaffen die taxonomischen Einordnungen radikal auseinander: In seiner

175 Stauffer, Hermann (2003): „Polemik“. In: Ueding, Gert (Hg.): Historisches Wörterbuch der Rhetorik (=HWRh). Bd. 6. Must-Pop. Tübingen: Niemeyer, Sp. I4O3-I4I 5, hier Sp. I403. 
„Vorstufe einer Theorie“ fasst Jürgen Stenzel Polemik als „pragmatische Gattung “ ${ }^{176}$ auf, während z. B. Ludwig Rohner in seinem Versuch einer Streitschriftentypologie Polemik - wie das Komische oder Tragische als einen jegliche Gattungsgrenzen überschreitenden Stil definiert. ${ }^{177}$ Entgegen den Vorstellungen Stenzels, dass Polemik als größere Textform zu betrachten und die darin kleinste enthaltene Einheit der „polemische (Stil-)Zug “ sei, ${ }^{178}$ spricht Rohner vom „flüssigen Aggregatzustand“ von Polemik und konstatiert, dass sie sämtliche Formen zu transzendieren vermag. ${ }^{179}$ Eine dazwischen liegende Definition bietet Marcelo Dascal: Für ihn ist „Polemik [...] zuvörderst ein diskursives Phänomen, das der Kategorie des (im breiten Sinne verstandenen) Dialogs angehört. " ${ }^{180}$ Es ist also nicht die Rede von Polemik als einer Gattung, sondern als einer Redeform - des Dialogischen. An anderer Stelle jedoch nimmt er eine Typologie vor, in der er drei Idealtypen von Polemik (discussion, dispute und controversy ${ }^{18 \mathrm{I}}$ ) isoliert, die dann in einem zweiten Schritt

${ }^{176}$ Stenzel (I986), S. 3 (Hervorhebung K. L.). Auch Peter von Matt bezeichnet Polemik als eine Gattung, begründet oder erklärt dies aber nicht weiter. Matt, Peter von (I994): „Grandeur und Elend literarischer Gewalt. Die Regeln der Polemik“. In: Ders. (Hg.): Das Schicksal der Phantasie. Studien zur deutschen Literatur. München: Hanser, S. 35-42, hier S. 39 \& 4I.

177 Rohner, Ludwig (I987): Die literarische Streitschrift. Themen, Motive, Formen. Wiesbaden: Harrassowitz, S. 2 I 2 f.

${ }_{178}$ Stenzel (I986), S. 4.

${ }^{179}$ Rohner (1987), S. 2 I3.

I80 Dascal, Marcelo (20II): „Kontroversen und Polemiken in der frühneuzeitlichen Wissenschaft“. In: Bremer, Kai \& Carlos Spoerhase (Hg.): Gelehrte Polemik. Intellektuelle Konfliktverschärfungen um I700 (= Zeitsprünge, Forschungen zur Frühen Neuzeit, Bd. I5: 2/3). Frankfurt/Main: Klostermann, S. I46-I57, hier S. I49.

${ }^{181}$ Der Begriff ,controversy“ ist generell nicht mit Polemik gleichzusetzen, da die Forschung zu Kontroversen oftmals Prinzipien von Kontroversen behandelt, die Polemik geradewegs ausschließen, vgl. dazu z. B.: „The functional background for such a principle [Principles governing the repertoire of moves] is that most personrelated moves do not contribute in a fruitful way to the goal of the controversy, the pursuit of knowledge. [...] Expressions of disrespect not only do not aid the attainment of the goal of the controversy but on the contrary, they obstruct the achievement of goals like the improvement of knowledge. "Gloning (2005), S. 273. Gloning nennt die Kontroversen des I6. Jahrhunderts zwar als Ausnahme in dieser Hinsicht, aber der Zweck der Kontroverse scheint generell anders definiert als derjenige von Polemik: „In the Early Modern period [...] communication principles are generally described as guiding rules for an orderly, efficient and socially acceptable conduct of controversies.“ Fritz, Gerd (2008): „Communication principles for controversies: A historical perspective“. In: Eemeren, Frans H. van \& Bart Garssen (Hg.): Controversy and Confrontation: Relating Controversy Analysis with Argumentation Theory. Amsterdam: John Benjamins, S. I09-I 24, hier S. I2I. 
auf drei Arten der religiösen Polemik (intra-faith, inter-faith und extrafaith) angewendet werden. ${ }^{182}$ Hier fällt auf, dass zwei unterschiedliche Polemik-Auffassungen gemeint sind, für die jeweils andere Kriterien gelten: Bei dem einen handelt es sich um Kriterien, die an Konfliktbeginn, -verlauf und -lösung gebunden sind, ${ }^{183}$ bei dem anderen lediglich um die Glaubenszugehörigkeit der Beteiligten. Zudem impliziert dieses Vorgehen schließlich ein Verständnis von Polemik als Textgattung, da von Polemiken als Gesamttexten gesprochen wird.

Diese Beispiele zeigen nur einen Bruchteil der Möglichkeiten, wie Polemik in textbezogene Ordnungsschemata eingeordnet werden kann. Dieser Ausschnitt repräsentiert dennoch bereits die Vielfalt der Auffassungen und die Unklarheiten, die vorherrschen: Selbst dort, wo scheinbar eine Definition gefunden wird, bleibt der Begriff vage: Als Gattung kann Polemik nicht ausreichend eingegrenzt werden, da sie offensichtlich in unterschiedlicher Erscheinung aufzutauchen vermag und, wie Stenzel selbst widersprüchlich konstatiert, „[w]esentlich [...] eine spontane Redeform [ist], für die es keine Regelkompetenz gibt. " ${ }^{184}$ Doch nicht nur bei Stenzels Polemikdefinition als Gattung tauchen Widersprüche auf, sondern auch Rohners Definition von Polemik als ein Gattungen durchdringendes Phänomen ist nicht eindeutig, da der genaue Ort der Polemik nicht lokalisiert wird. Rohners Versuch zu präzisieren, was er mit seiner Definition meint, mündet in einer Aufzählung von Beschreibungen, die aufgrund ihrer divergenten Bedeutungen einer Präzision eher im Wege stehen, anstatt sie zu fördern: „Das Polemische

${ }^{182}$ Dascal, Marcelo (2004): „On the Uses of Argumentative Reason in Religious Polemics“. In: Hettema, Theo Leonardus \& Arie Van der Kooij (Hg.): Religious Polemics in Context $=$ Papers Presented to the Second International Conference of the Leiden Institute for the Study of Religions (Lisor) Held at Leiden, 27-28 April 2000). Assen: Royal Van Gorcum, S. 3-20, hier S. 3-6 \& 9. (Hervorhebungen K. L.)

${ }^{183}$ „The main criteria for the typology here proposed are: the scope of the disagreement, the kind of content involved in it, the presumed means for solving the disagreement, and the ends pursued by the contenders." Dascal (2004), S. 4 .

${ }^{184}$ Stenzel nennt die Nachbarbegriffe der Polemik: „Beschimpfung, Beleidigung, Calumnie, Diabole [...], Infamie, Injurie, Invektive, Libell, Pamphlet, Pasquill, Psogos [...], Schmährede, Streitschrift, Vituperatio “ und entkräftet damit prinzipiell schon seine Bezeichnung der Polemik als Gattung, da deutlich wird, dass die aufgezählten Begriffe wiederum auf unterschiedlichen Ebenen anzusiedeln sind, beispielsweise können die Beschimpfung als sprachliche Realisierung und das Pamphlet als Gattungsbezeichnung in keiner Weise als synonym betrachtet werden. Stenzel (I986), S. 4, Anmerkung 5. 
ist eine besondere Substanz, ein Fluidum, Medium, Ingrediens, eine Methode, ein Stil." "185

Als Ergebnis der obigen Ausführungen kann festgehalten werden, dass Polemik prinzipiell formlos ist und sich auf vielerlei verschiedene Arten äußern lässt. Sie ist Anwendung von Sprache zu einem Kommunikationszweck, so dass Oda Wischmeyer und Lorenzo Scornaienchi sie als „eine Rede- und Schreibstrategie“" ${ }^{186}$ bezeichnen. Sie konstatieren darüber hinaus, dass Polemik weder Gattung noch Form ist, aber Formen hervorgebracht hat,

vor allem die Streitschrift und das Streitgespräch. Die vielfältige Szene der literarischen Aggression - Scheltrede, Invektive, Tadel, Verleumdung, Schmähung, Kritik, Spottschrift, Pamphlet, Ironie, Satire, Persiflage - in ihren kulturellen und historischen Erscheinungsformen und Transformationen kann hier nur ins Gedächtnis gerufen werden. ${ }^{187}$

Sie bestätigen die bereits konstatierte Vielfalt der Formen, die polemisches Sprechen oder Schreiben hervorbringen kann. Somit liegt die Definition von Polemik als einer transgenerischen und transmedialen (sprachlichen) Methode am nächsten. Dies bestätigen auch Ursula Paintner, die Polemik als „Bezeichnung für eine Schreibweise bzw. einen Schreibgestus zu verwenden " sieht, ${ }^{188}$ und Andreas Stuhlmann, der sie als „Schreibweise, als operative Kategorie, in verschiedenen Gattungen aufscheinen[d]“ beschreibt. ${ }^{189}$ Die Bezeichnung der Polemik als „Redeund Schreibstrategie“ (s. o.) wird jedoch an dieser Stelle bewusst nicht gewählt: Die Entscheidung gegen die Bezeichnung ,Strategie‘ ergibt sich aus der Differenzierung zwischen Polemik als einem generellen

\footnotetext{
${ }^{185}$ Rohner (I987), S. 214.

${ }^{186}$ Wischmeyer, Oda \& Lorenzo Scornaienchi (2OII): „Einführung“. In: Dies. (Hg.): Polemik in der frühchristlichen Literatur. Texte und Kontexte. Berlin \& New York: De Gruyter, S. I-I 4, hier S. 4.

187 Wischmeyer \& Scornaienchi (20II), S. 5.

${ }^{188}$ Paintner (20II), S. 43. Auch Georg Braungart bestätigt mit seinen Überlegungen zur Verortung von Polemik innerhalb der Rhetoriktheorie, dass Polemik gattungsübergreifend ist: „Die Rhetorik der Polemik stellt die verschiedensten Mittel zu beliebigem Einsatz bereit: Mittel der Affekterregung, sophistische Syllogismen (wie es bei Melanchthon ja heißt), Techniken der Widerlegung, Möglichkeiten der Insinuation und Deprivation. Sie öffnet dem personalisierenden Angriff alle Schleusen, kann jedoch keine auch nur irgendwie verbindliche Gattungsnorm garantieren. Die licentia polemica führt weit über jede rhetorische Grenze. "Braungart (I992), S. 20.

189 Stuhlmann, Andreas (2010): „Die Literatur - das sind wir und unsere Feinde“. Literarische Polemik bei Heinrich Heine und Karl Kraus. Würzburg: Königshausen \& Neumann, S. 2I.
} 
Vorgehen und ihren jeweils einzelnen Verwendungen, den polemischen Zügen. ${ }^{190}$ Polemik ist eine Methode, ${ }^{191}$ die sich in ihren einzelnen Erscheinungsformen - den polemischen Zügen - bestimmter Strategien bedient. Da die Strategien, die der Polemik dienen, aber nicht grundsätzlich und ausschließlich polemisch sind, muss zwischen diesen Strategien und Polemik als Methode unterschieden werden.

Ausgehend von der bereits erörterten wechselseitigen Beziehung von Streitkultur und einzelnem Streitakt im (schriftlich verfassten) Text kann Polemik als Schlüsselelement der Streitinszenierung gesehen werden: Polemik ist die Methode, einen Streit öffentlich in Szene zu setzen, und zwar auf eine Weise, die die Diskrepanzen in Bezug auf die Streitsache herausstellt und zugunsten der eigenen Position bewertet. Dem Streitgegner wird gleichzeitig jegliche Grundlage für ein Rechthaben aberkannt. Innerhalb dieser Inszenierung kommt der „Kreativität des Zitats“' ${ }_{192}$ eine wichtige Rolle zu: z. B. durch direkte Antworten auf bestimmte Einzeltexte mittels Zitat, Paraphrasierung, Frage-Antwort-Struktur oder durch intertextuelle Bezüge, die durch vermehrtes Wiederaufgreifen als solche nicht mehr erkennbar sind, wie etwa Schlagwörter, eingebürgerte Namensverballhornungen usw. Mittels solcher Wiederholungen kann eine bereits bestehende Beschreibung des Sachverhalts und der interpersonalen Beziehungen des Streits neu sortiert und interpretiert werden. ${ }^{\mathrm{I} 93}$ Polemik ist dabei die Methode, einen „Antagonismus in bezug [sic!] auf eine Sache vor Publikum " herzustellen, ${ }^{\mathrm{1} 94}$ und kann insofern als zentrales strategisches kommunikatives Vorgehen bei der Streitinszenierung gesehen werden. ${ }^{195}$ In welche Form Polemik gekleidet bzw. welche Form gewählt wird, um zu polemisieren, unterliegt dem Zusammenspiel von

\footnotetext{
190 Stenzel (I984), S. 4 .

19г Vgl. dazu auch Feigenwinter-Schimmel, Gunild (I972): Karl Kraus: Methode der Polemik. Kleve: Ritscher + Noy.

${ }_{192}$ Krämer (2004), S. I6.

$193 \mathrm{Vgl}$. Krämer (2004), S. I6.

${ }^{194}$ Paintner (20II), S. 44.

195 Vgl. dazu: „Irenik und Polemik sind rhetorische Begriffe und beziehen sich auf konfliktmildernde bzw. konfliktverschärfende Kommunikationsstrategien. " Spoerhase (2007), S. 65. Vgl. dazu auch Rohner (I987), S. 2 I 4: Er zitiert Peter Sloterdijk (I983: Kritik der zynischen Vernunft, 2 Bde. Frankfurt/Main), der den inszenatorischen Charakter von Polemik hervorhebt: „Der Autor [Sloterdijk] spielt das Sprichwort ,Wenn zwei sich streiten, freut sich der Dritte' logisch nach und kommt zum Befund, das Polemische übersteige das Dialogische und selbst das Dialektische bei weitem. ,Im Streit wird ein Widerspruch nicht nur gedacht, sondern in Wirklichkeit inszeniert'." (Binnenzitat aus Bd. 2, S. 676).
} 
Gattungskonventionen, kommunikativen und kulturellen Praktiken und den Funktionen, die im konkreten Fall angestrebt sind.

Ein weiterer Punkt, bei dem definitorische Uneinigkeit herrscht, ist die Bestimmung des Modus, denn die Frage nach der Sachlichkeit bzw. Unsachlichkeit der Argumentation von Polemik ist bisher auch nicht übereinstimmend beantwortet worden. Stenzel sieht Unsachlichkeit als ein Kriterium, das Polemik zu erfüllen habe, um sich von anderen Arten der aggressiven Rede zu unterscheiden. Die mögliche Assoziation einer wütenden Beschimpfungskaskade (er gibt das Beispiel eines schimpfenden Betrunkenen) grenzt er jedoch wiederum ein: „Beschimpfung kann sich immerhin auf die bloße Reihung von Schimpfwörtern reduzieren; Polemik nicht, denn sie argumentiert. “ ${ }^{196}$ Stenzel versucht auf diese Weise, den unsachlichen Charakter von Polemik mit dem besonders in der Neuzeit betonten Kunstcharakter, dem der gelehrten literarischen Fehde oder Kontroverse, ${ }^{197} \mathrm{zu}$ vereinen. Paintner hingegen argumentiert gegen Stenzels Forderung nach Unsachlichkeit, indem sie von der Funktion ausgehend konstatiert: „[E]s gibt ebenfalls Texte, die eine Diskreditierung des Gegners allein durch sachliche Argumente erreichen, und Texte, bei denen eine vorrangige argumentatio ad hominem offensichtlich in erster Linie der Sache dient. " ${ }^{198}$ Indem sie das betont, was der Text bezweckt bzw. welche Wirkung dem Text zugeschrieben wird, stellt sie eher eine dem Text inhärente polemische Funktion als Kriterium heraus statt eines Stils oder einer Methode und eröffnet damit eine weitere Perspektive auf den Begriff der Polemik. Es wirkt, als widerspreche sie partiell ihrer eigenen grundsätzlichen Auffassung, „daß ,Polemik‘ nicht als Gattungsbegriff, sondern als Bezeichnung für eine Schreibweise bzw. einen Schreibgestus zu verwenden “I99 sei, da sie in ihrem Argument gegen Stenzel gerade nicht die Schreibweise, sondern die Funktion als polemisch identifiziert. Hier scheint sie mit Polemik nicht das Mittel an sich, sondern das Ziel zu meinen. Einen versöhnlichen Blickwinkel bietet Walter Benjamin, für den der Zweck des Polemisierens sämtliche Mittel heiligt. In der Hand des Polemikers kann seine Waffe, das Wort, aus sämtlichem Material geschmiedet sein:

\footnotetext{
I96 Stenzel (I986), S. 4 .

197 Stauffer (2003), HWRh 6, Sp. I404.

${ }_{198}$ Paintner (2OII), S. 42.

199 Paintner (20II), S. 42.
} 
„Für ihn, den wirklichen Polemiker, gibt es zwischen Polemischem und Sachlichem gar keine Grenze. “200

Für die Inszenierung eines Streits mittels Polemik stehen insofern vielfältige sprachliche Techniken zur Auswahl. Polemik muss nicht zwingend durchgängig argumentativ sein, da Beschimpfungen und Beleidigungen ebenfalls zu den polemischen Mitteln zählen, sie sollte im Kern aber auf argumentativen Strukturen aufbauen. Peter von Matt bestätigt, dass insbesondere spontane Umschläge von Ironie zu Ernst, von Witz zu Pathos, von Sentimentalität zu grobianischem Spott Polemik im Wesentlichen ausmachen. Dabei sind sämtliche sprachlichen Einsatzmöglichkeiten mit eingeschlossen: „Noble Rhetorik und plebejisches Reden sind die zwei gegensätzlichen Ausdrucksformen, die miteinander zum polemischen Kalkül gehören.“201

Ob Polemik sachlich oder unsachlich argumentiert, ist auch davon abhängig, was unter Sachlichkeit zu verstehen ist. Ist Sachlichkeit darauf bezogen, dass ad rem und nicht ad hominem oder ad personam ${ }^{202}$ argumentiert wird, kann Polemik sowohl sachliche, als auch unsachliche Züge annehmen, denn argumentiert werden kann sowohl gegen die Sache als auch gegen die Person. Allerdings macht Walther Dieckmann darauf aufmerksam, dass die Übergänge fließend sein können, da ebenso eine Person als res, Streitsache, gelten kann. Insofern wäre dann die argumentatio ad rem, obwohl es um eine Person geht. In so einem Fall kann erst dann von argumentum ad personam gesprochen werden,

${ }^{200}$ Braungart (I992), S. 4: „Zitat nach Walter Benjamin: Jemand meint. Zu Emanuel Bin Gorion, ,Ceterum Recenseo', in: Gesammelte Schriften, Tiedemann/ Schweppenhäuser (HG.), Bd. 8, I980, S. 360f“.

${ }^{201}$ Matt (I994), S. 39.

${ }^{202}$ Die Trennung des argumentum ad hominem vom argumentum ad personam beruht auf Arthur Schopenhauer, der unter dem argumentum ad hominem (oder „ex concessis") ein solches Argument versteht, das sich auf bereits gemachte Aussagen des Gegners bezieht. Zum Beispiel kann man eine Aussage des Gegners widerlegen, indem man behauptet, seine Aussage stimme nicht mit seinen bereits gemachten „Behauptungen oder Einräumungen“ überein oder stehe im Widerspruch zu ihnen, man widerlegt ihn also „mit der relativen subjektiven Wahrheit“. Schopenhauer, Arthur (I923): „Eristische Dialektik“.In: Deussen, Paul (Hg.): Arthur Schopenhauers sämtliche Werke. Bd. 6. Hg. von Franz Mockrauer. München: Piper, S. 393-428, hier S. 405f. Das argumentum ad personam hingegen „geht vom rein objektiven Gegenstand ab, um sich an das zu halten, was der Gegner darüber gesagt oder zugegeben hat. Beim Persönlichwerden aber verläßt man den Gegenstand ganz, und richtet seinen Angriff auf die Person des Gegners: man wird also kränkend, hämisch, beleidigend, grob. Es ist eine Appellation von den Kräften des Geistes an die des Leibes, oder an die Thierheit.“ Ebd., S. 426f. 
wenn die Person in einer Rolle oder in einem Bereich (z. B. privat) angegriffen wird, der nichts mit der verhandelten Sache zu tun hat. ${ }^{203}$

Eine sachliche, also auf die Streitsache bezogene, Argumentation impliziert jedoch nicht, dass man die Auffindung der objektiven Wahrheit anstrebt. ${ }^{204}$ Dies formuliert Arthur Schopenhauer in seiner posthum veröffentlichten Abhandlung über die Eristische Dialektik, die er auch die „Kunst Recht zu behalten“205 nennt: „[Sie] ist die Kunst zu disputiren, und zwar so zu disputiren, daß man Recht behält, also per fas et nefas. " ${ }^{206}$ Dabei spielt die Logik, die objektive Wahrheit, für Schopenhauer keine Rolle, sondern lediglich das, was in einem konkreten Streit- bzw. Disputationskontext als solche geltend gemacht werden soll.

Fasst man die Überlegungen zusammen, so umfasst Polemik sowohl sachliche als auch unsachliche, rationale sowie emotionale Elemente. Die konkreten Strategien der Polemik können sich auf unterschiedlichen Ebenen befinden. Es ist demnach Dieckmann zuzustimmen, der die Synthese aus allen Modi konstitutiv für die Polemik postuliert:

Obwohl die Anteile an Disputation einerseits, Pamphlet oder Pasquill andererseits, im Einzelfall unterschiedlich gewichtet sind, [...] haben polemische Texte bei allen relativen Unterschieden in der Wechselwirkung der beiden Ebenen eine grundlegende Gemeinsamkeit, die sie qualitativ sowohl von der sachlichen Diskussion als auch von dem nur verunglimpfenden Pasquill bzw. von der Satire unterscheidet. ${ }^{207}$

Polemik ist demnach im Spannungsfeld von Sachlichkeit und Unsachlichkeit sowie Rationalität und Emotionalität zu verortern, sie ist weder nur das eine noch ausschließlich das andere und kann rasch vom einen zum anderen umschlagen. ${ }^{208}$ Im Zuge dieser Synthese kann zudem konstatiert werden, dass in der Regel eine Personalisierung der Streitsache vorliegt, d. h. selbst wenn es um Sachverhalte - wie im Falle der Reformation um Glaubensfragen - geht, wird die Polemik perso-

${ }^{203}$ Dieckmann, Walther (2005): Streiten über das Streiten. Normative Grundlagen polemischer Metakommunikation. Tübingen: Niemeyer, S. 69.

${ }^{204}$ Es kann dabei nicht von einer finalen, von Natur aus existierenden Wahrheit, sondern von gesellschaftlichen, kulturellen Konventionen ausgegangen werden, die als objektive Wahrheit gelten.

205 Schopenhauer (I923), S. 403. Arthur Hübscher datiert die Schrift auf die Jahre I 830/I 83 I in Der handschriftliche Nachlaß: in fünf Bänden von I 985 .

206 Schopenhauer (1923), S. 395.

207 Dieckmann (2005), S. 47.

$208 \mathrm{Vgl}$. Stuhlmann (2010), S. 30. 
nalisiert. ${ }^{209}$ Dies sieht man bei Hoffman z. B. daran, dass er häufig den "lutherischen und zwinglischen haufen “ 2 го nennt, anstatt auf konkrete Lehrgebäude zu referieren.

Die Identifizierung des Adressaten von Polemik wird ebenso uneinheitlich vorgenommen wie die anderen bisher genannten Kriterien zur Eingrenzung. Paintner sieht für die antijesuitische Polemik klar das Publikum als Adressaten. Sie identifiziert als Hauptziel der Polemik, ein negatives Feindbild zu zeichnen, fortzuführen und zu festigen, das durch antagonistische Gegenüberstellung gleichzeitig ein positives protestantisches Selbstbild entwirft. Das Publikum hat dabei die Richterrolle einzunehmen. „Diese Konstellation ist es, die das Wesen von Polemik ausmacht, nicht etwa ein mehr oder weniger aggressiver Stil oder gar unsachliche Argumentation. "2II Paintners Ergebnisse decken sich u. a. mit Georg Braungarts Überlegungen zur Tadelrede und deren Ziele:

Die vituperatio ist also von ihrer Zugehörigkeit zum genus demonstrativum her nicht direkt handlungsorientiert. Es geht ihr vielmehr primär darum, im Zuhörer ein bestimmtes Bild der behandelten Person oder Sache zu vermitteln und ihn zu einer bestimmten Meinung von ihr zu bringen. ${ }^{212}$

Insofern ist anzunehmen, dass Paintner Polemik ebenfalls zum genus demonstrativum, der Redegattung der Darstellung, die im Gegensatz zum genus iudicale oder genus deliberativum nicht zum Handeln aufruft, zählt. Dass die Tadelrede für die frühneuzeitliche Polemik instrumentalisiert wurde, formuliert ebenfalls das Historische Wörterbuch der Rhetorik. ${ }^{213}$

${ }^{209} \mathrm{Vgl}$. dazu: „Polemic, however, to be successful, had to be directed not only at corrupt institutions and threadbare belief systems but at those who personified them, or even profited from them. Polemic soon became personal; groups and individuals were held up to ridicule and abuse. "Matheson (I998), S. 3.

${ }^{210}$ Hoffman, Melchior (I532), Das freudenreiche zeucknus, S. 429. Vollständige Angabe bei Anmerkung 667. Siehe auch Hoffman (I 532), Magestadt gottes, A2r. Vollständige Angabe bei Anmerkung 669.

${ }_{211}$ Paintner (20II), S. 456.

${ }_{212}$ Braungart (I992), S. I $5 \mathrm{f}$. Auch im Historischen Wörterbuch der Rhetorik werden zwei Adressaten identifiziert: „de[r] Getadelte[] selbst sowie das weitere Publikum. [...] Zumeist aber zielt die T[adelrede] primär auf Zustimmung und Akzeptanz beim weiteren Publikum, wobei gerade die Polarisierung zwischen dem Publikum und dem Getadelten die Absicht der T[adelrede] sein kann. “ Bremer, Kai (2009b): „Tadelrede“. In: HWRh 9. St-Z, Sp. 4I9-424, hier Sp. 420.

${ }^{213}$ „Die T[adelrede] wird [in der frühen Neuzeit] zur Redegattung der Unterweisung, die Zurschaustellung des Getadelten wird in andere, polemische Redegattungen 
Betrachtet man Hoffmans streitinszenierende Schriften oder auch polemische Texte der Reformationszeit überhaupt, fällt jedoch auf, dass in vielen Schriften auf der Textebene oftmals die direkte Rede vorherrscht (der Gegner wird in der 2. Person angesprochen). Die direkte Anrede und ihre Beantwortung in gleicher Manier machen einen Großteil des diskursiven, dialogischen Charakters der Polemik aus. Das Dialogische steht für einige Untersuchungen aus der Tradition der historischen Dialoganalyse im Vordergrund. Marcelo Dascal spricht mitunter von „polemical exchanges“, ${ }^{214}$ was den interaktiven Charakter von Polemik unterstreichen soll. Die Forderung von Untersuchungen gesamter Streitschriftenwechsel oder Kontroversen ${ }^{215}$ ist die logische Konsequenz daraus. Die Betonung des Dialogischen (zwischen den Streitparteien) schließt zudem mit ein, dass der jeweilige Gegner auch der Adressat ist und es gilt, diesen zu überzeugen. Auf diese Weise tritt das Publikum zunächst in den Hintergrund, die Persuasion in den Vordergrund. Ausgehend von dem Modell, das Jeremy Hawthorn für Persuasion entwirft, erscheint diese rein dialogisch-persuasive Situation zwischen den Streitparteien nicht sinnvoll, denn ein Unterschied zwischen Gegner und Publikum wird nicht gemacht. Aufgezählt werden allein „the persuader", „the persuasive text or discourse“, „the persuadee“ und „the determining and interlocking context“ (sozial, politisch, historisch), ${ }^{216}$ so dass als „persuadee“ nur der Gegner oder das Publikum in Frage kommt und die jeweils andere Instanz aus dem Modell entfällt.

Generell stellt die Frage nach der Adressierung eine Schwierigkeit für die Untersuchung von Texten dar, besonders für Texte des I6. Jahrhunderts: Die Adressierungsabsicht des Verfassers ist vielfach nicht mehr nachvollziehbar. Doch auch in Fällen, in denen Aussagen des Verfassers über seine Intentionen belegt sind, können diese nicht stellvertretend für die Wirkung sein, die der Text real entfaltet. ${ }^{217}$ Eine

verlagert. Das zeigt sich insbesondere in den frühneuzeitlichen Religionsstreitigkeiten: die Streitschriften greifen vielfach auf Elemente der T[adelrede] zurück und funktionalisieren sie.“ Bremer (2009b), HWRh 9, Sp. 422.

${ }^{214}$ Dascal (2004), S. 3.

215 Siehe dazu u. a. Gierl (I997).

${ }^{216}$ Hawthorn, Jeremy (I 987): „Preface“. In: Ders. (Hg.): Propaganda, Persuasion and Polemics. London: Edward Arnold, S. vii-xiv, hier S. xii.

${ }^{217}$ Mit Hinblick auf das performative Text- und Kulturverständnis, das dieser Arbeit zugrunde liegt, lässt sich die Funktion eines Textes nicht auf die intendierte reduzieren. Vielmehr entsteht die Wirkung des Textes interaktiv bzw. unter Beteiligung des Verfassers, des Lesers und deren Kontexten. Vgl. dazu auch Knape, Joachim (2000): Was ist Rhetorik? Stuttgart: Reclam, S. I04. 
Textanalyse muss deshalb sämtliche Faktoren berücksichtigen: sowohl den generellen Kontext (historisch, kulturell und literarisch-rhetorisch) als auch den unmittelbaren, persönlichen Hintergrund des Autors. Unweigerlich muss zudem der Inszenierungscharakter eines Textes mit einkalkuliert werden. ${ }^{218}$ Demnach ist es kritisch zu sehen, den diskursiven, dialogischen Charakter, der auf der Textebene gestaltet ist, auch auf die Kontextebene zu übertragen. Eine Prüfung kontextueller Umstände ist insofern obligat.

Da Polemik als methodisches Vorgehen der Streitinszenierung bestimmt werden kann, ist ebenfalls die Adressierung der Polemik auf der Textebene als Teil der Inszenierung zu verstehen. Es ist also Paintner zuzustimmen, wenn sie die „dialogische Grundhaltung eines großen Teils der Polemik nicht als tatsächliches Gesprächsangebot an den Gegner, sondern als inszenatorisches Mittel interpretier[t] “..219 Was Paintner an dieser Stelle für die antijesuitische Polemik konstatiert, gilt auch für die Polemik Melchior Hoffmans, der das Dialogische auf unterschiedliche Art inszeniert: Zum Beispiel fingiert er in Eyn sendbrief an den achtbaren Michel wachter den Verfasser (mittels des Pseudonyms Caspar Beck) sowie den Adressaten und inszeniert einen freundschaftlichen Briefwechsel, was ihm erlaubt, seinen eigenen Namen in der 3. Person zu nennen. ${ }^{20}$ Solche Fälle verdeutlichen die Rolle des Publikums als (impliziten) Hauptadressat jeder Polemik. Nicht zuletzt die Tatsache der Inszenierung in öffentlichen Medien unterstreicht die Bedeutung des Publikums als richterliche Instanz. Für die Untersuchung solcher Inszenierungen eignet sich besonders Stenzels Konzept der „polemischen Situation“, die sich aus dem "polemischen Subjekt" (dem Polemiker bzw. der Person oder Gruppe, die die Polemik äußert), dem „polemischen Objekt“ (der Person, Gruppe oder dem Organ, die/das Ziel des polemischen Angriffs ist), der „polemischen Instanz“ („dem als entscheidungsmächtig vorgestellten Publikum“) und dem „polemischen Thema" (der Streitsache bzw. dem status controversiae)

${ }^{218}$ Vgl. dazu z. B. Bremer, Kai (20II): „Reformatorische Resonanzstrategien und Inszenierungspraktiken. Luthers ,Brief an den Vater" I52I“. In: Jürgensen, Christoph \& Gerhard Kaiser (Hg.): Schriftstellerische Inszenierungspraktiken Typologie und Geschichte. Heidelberg: Universitätsverlag Winter, S. 55-67.

${ }^{219}$ Paintner (20II), S. 5I. Paintner weist jedoch darauf hin, dass die dialogische Grundhaltung durch diese Feststellung „allerdings ihre definitorische Wirksamkeit einbüßt." Ebd.

220 Siehe dazu Kapitel 4.3.2 Der fingierte Privatbrief als offener Brief in Eyn sendbrieff an $[. .$.$] Michel wachter.$ 
zusammensetzt. ${ }^{221}$ Stenzels Konzept basiert darauf, dass die polemische Instanz der „indirekte oder direkte Adressat polemischer Rede“ ${ }^{{ }_{222}}$ ist, bei der es sich um

einen Machtkampf zwischen Vertretern von Positionen oder Gruppen [handelt], und die Macht liegt dabei in der von starken Wertgefühlen begleiteten Zustimmung der polemischen Instanz zu Position und Person des Angreifers - Ohnmacht in entsprechender Ablehnung des Angegriffenen. ${ }^{223}$

Damit formuliert Stenzel eine der Hauptfunktionen oder Wirkungsabsichten von Polemik: die Beeinflussung des Publikums in Hinsicht auf dessen Urteil bzw. Personeneinschätzungen. Da sie - eng an das Konzept der rhetorischen Streitkultur gebunden - eine Methode des öffentlichen Diffamierens ist, ${ }^{224}$ muss sie, um ihre Wirkung zu entfalten, eine polemische Instanz ansprechen. Dahingehend ist sie der Gerichtsrede ähnlich, die sich ebenfalls an das Publikum bzw. die Richter wendet. ${ }^{225}$ Das ,Ansprechen' der polemischen Instanz ist demzufolge immer implizit und muss sich nicht mit der Adressierung auf der Textebene kongruent verhalten. Folglich finden viele Funktionen von Polemik, wie z. B. Persuasion, in der Regel nicht auf der Verhältnisebene des polemischen Subjekts zum polemischen Objekt statt, sondern zwischen polemischem Subjekt und polemischer Instanz.

Wie bereits angedeutet, hängt die Explikation der Funktionen von Polemik - wie auch Stenzels Beispiel zeigt - eng mit der Feststellung der dominanten Adressierung von Polemik zusammen und kann dem

${ }_{221}$ Stenzel (I986), S. 5f. (Hervorhebungen im Original). Im Folgenden wird Stenzels Terminologie auch in dieser Arbeit herangezogen. Dabei wird noch detaillierter geklärt werden, was unter den einzelnen Elementen der polemischen Situation in Bezug auf die Text- und die Kontextebene zu verstehen ist. Siehe Kapitel 2.3 Kommunikative Situationen des Polemisierens.

${ }^{222}$ Ebd., S. 5 .

223 Ebd., S. 6.

${ }^{224}$ Seit der Aufklärung wird auf den „Öffentlichkeitscharakter der P[olemik], ihre Aktualitätsgebundenheit, ihre Intentionalität und apodiktische Natur" hingewiesen. Stauffer (2003), HWRh 6, Sp. I409.

225 Die einzelnen Elemente des Stenzelschen Modells sind in gleicher Konstellation in der Gerichtsrede wiederzufinden: „Die theoretische Anleitung ging dabei seit dem ,Auctor ad Herennium“ und Ciceros ,De inventione“ systematisch von den vier Fakten aus, die die prozessuale Situation konstituieren: I. der Person des Redners, 2. der Gegenpartei, 3. den Zuhörern bzw. den Richtern und 4. vom Gegenstand der Verhandlung. " Haug, Walter (I985): Literaturtheorie im deutschen Mittelalter. Von den Anfängen bis zum Ende des I3. Jahrhunderts. Darmstadt: Wissenschaftliche Buchgesellschaft, S. 8 . 
identifizierten Hauptadressaten entsprechend unterschiedlich ausfallen. Es ist Stenzel generell zuzustimmen, wenn er Polemik immer an ein Publikum gerichtet sieht. Obgleich auf der Textebene das polemische Objekt adressiert wird, bleibt die polemische Instanz der Hauptadressat. ${ }^{226}$ In vielen polemischen Schriften der Reformationszeit, auch in denen Melchior Hoffmans, zeigt sich diese implizite Adressierung in z. B. dem Haupttext vorangestellten Vorreden oder Widmungen, die auf der Textebene einen anderen Adressaten haben als der Haupttext. Besonders in diesen Fällen drängt sich der Eindruck eines inszenierten Dialogs unmittelbar auf. Die Funktion des Dialogs ist es zuvörderst nicht, ein Kommunikationsangebot an das polemische Objekt zu machen, sondern einen Sachverhalt auf eine bestimmte Weise darzustellen und Images zu konstituieren.

Generell ist dem Dialog ein mit dem polemischen Objekt argumentativ kommunizierendes und auf Persuasion oder auch Provokation des polemischen Objekts gerichtetes Moment nicht vollkommen abzusprechen. Dieses Moment kann jedoch nicht ausschließlich auftreten, ohne dass eine polemische Instanz angesprochen würde, denn so wie der Auffassung einer ,rhetorischen Streitkultur' eine Inszenierung in öffentlichen sprachbasierten Medien zugrunde liegt, muss auch Polemik in einem öffentlichen Raum geäußert werden - sie ist die praktische rhetorische Ausformung, welche die Basis der Entstehung einer ,rhetorischen Streitkultur' darstellt.

Betrachtet man die Funktionen, die auf das Publikum bezogen sind, kann Polemik indessen verschiedene Grundfunktionen erfüllen: Zum einen kann sie dafür verwendet werden, die polemische Instanz zu überzeugen - in dem Falle würde man von einem bisher unentschlossenen Publikum bzw. einem sich in seinen Überzeugungen unsicheren Publikum ausgehen. ${ }^{27}$ Im Falle eines zugeneigten Publikums, beispielsweise aus den eigenen Reihen, kann Polemik darauf abzielen, die Gruppenzugehörigkeit zu stärken und (Gruppen-)Identität zu stiften, wodurch sie eine nach innen inkludierende und nach außen

${ }_{226}$ Diese Feststellung wird in Kapitel 2.3 Kommunikative Situationen des Polemisierens und in den Analysekapiteln (Kap. $3 \& 4$ ) eingehender begründet und an Melchior Hoffmans Schriften erörtert.

227 Bremer spricht beim Streitschriftenwechsel davon, dass sich „zwei Autoren zu einem Thema unter ähnlichen Voraussetzungen auseinandersetzen und - idealsierterweise [sic!] - versuchen, die Gunst eines Publikums zu erobern und eine Leserschaft (und Zuhörerschaft) zu überzeugen." Bremer (2005b), S. 29. 
exkludierende Funktion übernimmt. ${ }^{228}$ In beiden Fällen geht es darum, polarisierende Eigen- und Fremdimages zu entwerfen, die eine klare Grenzziehung ermöglichen:

Der Polemiker soll samt seiner Position in den Augen der polemischen Instanz als wertvoll erscheinen, der Angegriffene und seine Position als minderwertig. Polemik folgt dem Schema eines säkularisierten Manichäismus, das die Beteiligten in die Extremregionen von Licht und Finsternis auseinandertreibt. ${ }^{229}$

Ob das durch die inszenierte antagonistische Gegenüberstellung von gut und schlecht, glaubwürdig und unglaubwürdig, richtig und falsch usw. gezeichnete Fremdimage zu einem öffentlich wirksamen Feindbild avanciert, ist indessen vom Grad der intertextuellen Wiederholung, d. h. der Einbindung in den größeren Kontext kultureller Praktiken, abhängig. Hier zeigt sich besonders deutlich die „[f]unktionale Performativität“, also die „kulturelle Wirkmächtigkeit“"von Texten.230 Die funktionale Performativität ist auf der textexternen Ebene zu verorten und betrifft u. a.

die gesellschaftliche Zirkulation von Texten, durch die Produkte der schriftlichen Kultur in performative Kulturpraktiken eingebunden werden. Dies beinhaltet beispielsweise Prozesse des Aufführens und Ausstellens, Zueignens, Austauschens oder Übertragens. [...] Zugleich wird in der Betonung der intertextuellen Iterationen und transmedialen Übergänge Textbedeutung dynamisiert und als Ergebnis auch außerliterarischer kultureller Verhandlungsprozesse erkennbar. ${ }^{231}$

Somit besteht eine performative Wirkung von Texten darin, andere kulturelle Praktiken zu beeinflussen, mit ihnen zu verschmelzen und in ihnen verarbeitet und fortgeführt zu werden. Aus dem Geflecht von kulturellen Praktiken, in dem Texte, deren Themen und Diskurse eingeflochten werden, entstehen dann ebenfalls neue Texte, die in ihrer

${ }^{228}$ Vgl. die Ergebnisse von Bremer: „Religionspolemische Schriften sind damit Texte, die sich zunächst an die Angehörigen der eigenen Konfession richten, ihren Verfassern geht es um die ,kollektivierende Wirkung des Streites' und weniger um die Überzeugung des Gegners. [...] Während sich Feindschaft innerhalb der Religionspartei, nach Simmel der Gruppe, vereinheitlichend auswirkt, zwingt sie die Zweifler und Zauderer aus der Gruppe. Für sie bleibt kein Platz im religionspolemischen Antagonismus. “ Bremer (2005b), S. 22 I.

229 Stenzel (I986), S. 7.

${ }_{230}$ Häsner et al. (20II), S. 84 .

${ }^{231}$ Häsner et al. (20II), S. 85 . 
Eigenschaft des „Vollzug[s] performativer Akte als ritualisierte öffentliche Aufführung “"232 betrachtet werden können. Kultur und Einzeltext stehen auf diese Weise in dauerhafter, wechselseitig produktiver Beziehung - Polemik ist als ein den Texten inhärentes Moment in diesem Prozess inkludiert.

Zusammenfassend wird ,Polemik' in der vorliegenden Arbeit als Methode definiert, als ein sprachliches Verfahren, das in verschiedenen Formen und (rhetorischen) Gattungen auftreten kann, sich unterschiedlicher Modi der Argumentation (sachlich und unsachlich, rational und emotional) bedient und darüber hinaus die Fülle der rhetorischen Figuren, Tropen und Redestile instrumentalisiert, ${ }^{233}$ um einen Streit in Szene zu setzen. Diese Inszenierung - die Theatermetaphorik birgt dies in sich - ist immer (auch) an ein Publikum gerichtet, das eine urteilende Funktion übernehmen soll und partiell auch im Text als eine urteilende Instanz konstruiert wird. ${ }^{234}$ Die übergreifende Aufgabe von Polemik ist das Polarisieren auf öffentlichem Terrain mit dem Ziel, individuelle Meinungsfestigung oder -änderung zu bewirken, und somit performativ kulturelle Denkmuster, z. B. Stereotype, und deren Wandel zu lenken, d. h. eine grundlegende Funktion von Polemik ist die Ausformung des Streitakts, der wiederum in Wechselwirkung mit der Streitkultur steht. Welche Funktionen Polemik im Einzelnen und auf einer konkreteren Ebene erfüllen kann, wird nachfolgend erläutert.

\subsubsection{Die Performativität von Polemik}

Die Funktionen jeder einzelnen Verwendung von Polemik sind so vielfältig wie die Mittel, die ihr zur Verfügung stehen. Polemik ist, metaphorisch gesprochen, ein (rhetorisches) Chamäleon, das sich seiner Umgebung anpassen kann, um seinen konkreten Zweck zu erfüllen.

\footnotetext{
${ }^{232}$ Fischer-Lichte (2004), S. 4I.

${ }_{233}$ Die Mittel der Polemik sind vielfältig und unterliegen scheinbar keinen Grenzen des Erlaubten. Vgl. Rohner (I987), S. 236.

${ }_{234}$ Bremer konstatiert einen Widerspruch für die Polemiken zwischen Altgläubigen und Protestanten: Die richterliche Instanz könne nicht das im Text konstruierte Publikum sein, da die theologisch gebildeten Autoren diesem Publikum - hier identifiziert er die Laien oder auch den ,gemeinen Mann' - gleichzeitig absprechen, diese Funktion realiter übernehmen zu können. Bremer (2005b), S. 59. Dieser Widerspruch ergibt sich jedoch nicht, wenn man die Konkretisierung eines Publikums auf Textebene (als bspw. Laien) als Teil der Inszenierung betrachtet. Die Doppeldeutigkeit (der Elemente) der polemischen Situation wird in Kapitel 2.3.I Offenes und verdecktes Polemisieren genauer beleuchtet.
} 
Diese Umgebung ist dabei einerseits textextern, andererseits textintern zu verstehen. Nachdem einige der übergreifenden Funktionen, die Polemik auf der textexternen Ebene übernehmen kann (z. B. Beeinflussung der Streitkultur), bereits erörtert wurden, soll nun ein Blick auf die textinternen Funktionen von Polemik geworfen werden. Aus der Forschungsdiskussion wurde zudem bereits der Schluss gezogen, dass Polemik eine Methode ist, einen Streit mittels textueller Aufführung auf eine bestimmte Art und Weise in Szene zu setzen. Der Frage, wie Polemik es im konkreten Fall sprachlich auf der Textebene bewerkstelligt, einen Streit zu inszenieren (den „polemischen Antagonismus“ ${ }^{235}$ zu entwerfen), geht die Beschäftigung mit der „strukturellen Performativität“, der „Machart des Textes“ nach. ${ }^{236}$

Dass es möglich und sinnvoll ist, vom performativen Charakter von Gesamttexten oder Textabschnitten zu sprechen, lässt sich zum einen durch Jürgen Habermas' Ausführungen zur performativpropositionalen „Doppelstruktur der Rede“ ${ }^{237}$ attestieren und zum anderen mit einem weit gefassten Aufführungsbegriff erklären, der eine körperliche Präsenz nicht in den Katalog der notwendigen Kriterien für ,Aufführung' mit einschließt. ${ }^{23^{8}}$ Stattdessen ist davon auszugehen, dass die Anwesenheit des Körpers kompensiert wird durch „textuelle[] Strategien und Strukturen, die der Inszenierung von Körperlichkeit,

${ }_{235}$ Paintner (20II), S. 47 \& 6I.

${ }^{236}$ Beide Zitate aus Häsner et al. (20II), S. $82 \& 83$.

237 Habermas konstatiert, dass jede Äußerung - auch diejenigen, die nicht explizit performativ im Sinne John L. Austins seien - eine propositionale und performative Seite haben. Das Handeln mit Sprache se dementsprechend nicht nur Vermittlung von Inhalten, sondern ginge darüber hinaus. Habermas, Jürgen (I984): Vorstudien und Ergänzungen zur Theorie des kommunikativen Handelns. Frankfurt/Main: Suhrkamp, S. 404-409.

${ }^{238}$ Dieser Aufführungsbegriff ist einigen anderen Definitionen entgegengesetzt, die eine körperliche Präsenz als erforderliches Merkmal der Aufführung verstehen. Vgl. z. B. Erving Goffman (Wir alle spielen Theater), der seine Theatermetaphorik auf die face-to-face-Interaktion beschränkt und damit sämtliche Kommunikation via Medien von der sozialen Aufführung ausschließt. Vgl. dazu: Bausch, Constanze (200I): „Die Inszenierung des Sozialen. Erving Goffman und das Performative“. In: Wulf, Christoph, Michael Göhlich \& Jörg Zirfas (Hg.): Grundlagen des Performativen. Eine Einführung in die Zusammenhänge von Sprache, Macht und Handeln. Weinheim \& München: Juventa Verlag, S. 203-225, hier S. 204. Auch Erika Fischer-Lichte nennt eine körperliche Komponente für den Aufführungsbegriff konstitutiv: „Es ist die leibliche Kopräsenz von Akteuren und Zuschauern, welche eine Aufführung allererst ermöglicht, welche die Aufführung konstituiert. “ FischerLichte (2004), S. 47. 
sinnlicher Präsenz oder ereignishaftem Vollzug dienen.“239 Mittels dieser Strategien kann die zeitliche und räumliche Distanz von Autor und Leser aufgelöst werden und eine Gleichzeitigkeit von Produktion und Rezeption, eine Begegnung von Produzent und Rezipient simuliert werden. ${ }^{20}$ Polemik zeigt sich vor allem in dieser Hinsicht als performativ, denn sie ist zum einen, von ihrem Wirkungsanliegen herrührend, grundsätzlich aktualitätsgebunden, so dass kontextuelle Bezüge notwendigerweise hergestellt werden müssen. Zum anderen ist sie, wie bereits gezeigt wurde, genuin rezipientenorientiert und diskursiv, in den meisten Fällen zudem auch auf der Textebene dialogisch angelegt, so dass entweder das polemische Objekt oder die polemische Instanz direkt angesprochen werden. Welche diskursiven und rhetorischen Strategien im Einzelnen zur strukturellen Performativität der polemischen Inszenierung beitragen, wird im Folgenden anhand einer Auswahl der für die Schriften Melchior Hoffmans wichtigsten und am häufigsten vorkommenden Strategien erörtert.

\section{Redewiedergabe und intertextuelle Bezüge}

Ein beliebtes Mittel der Polemik, den Gegner auf die Bühne des Geschehens zu holen, ist es, ihn selbst sprechen zu lassen. ${ }^{24 I}$ Deshalb sind die konkreten Formen der Redewiedergabe und das Herstellen umfangreicherer oder geringer fassbarer intertextueller Bezüge ${ }^{242}$ auf die Schrift des Gegners gängige Verfahren polemischer Texte, ${ }^{243}$ das

${ }_{239}$ Häsner et al. (20II), S. 83. Das Autorkollektiv führt dazu weiter aus: „Hierzu zählen etwa Indexikalisierungsstrategien [...], das Fingieren von Mündlichkeit, Verfahren der Blicklenkung und Visualisierung, showing statt telling [...], das VorAugen-Stellen von Geschehenszusammenhängen sowie Apostrophierungen des Lesers als anwesenden Kommunikationspartner und generell Modellierungen des Rezipienten." Ebd.

${ }^{24}$ Vgl. dazu auch Knape: „Es gibt einerseits Strategien, Performanz im Text herzustellen und damit die mündliche Performanz zu kompensieren (oder imitieren), aber auch das Gegenteil ist der Fall: Man nutzt die Möglichkeit, die das Buch gibt (langes Nachdenken) und reduziert z. B. den Text bis zur Unverständlichkeit.“ Knape, Joachim (2008): „Performanz in rhetoriktheoretischer Sicht“. In: Kämper, Heidrun \& Ludwig M. Eichinger (Hg.): Sprache - Kognition - Kultur. Sprache zwischen mentaler Struktur und kultureller Prägung. Berlin \& New York: De Gruyter, S. I35-I 50, hier S. I 50.

${ }^{24 \mathrm{I}}$ Matt (I994), S. 40.

${ }^{242}$ Auch die Redewiedergabe ist zu Formen der Intertextualität zu rechnen, wird hier aber wegen ihrer speziellen, eingegrenzten Form einzeln behandelt.

243 Vgl. Schwitalla, Johannes (I986): „Martin Luthers argumentative Polemik: mündlich und schriftlich“. In: Worstbrock, Franz Josef \& Helmut Koopmann (Hg.): 
polemische Objekt als eine (im Text) agierende oder zumindest anwesende Person zu inszenieren. Das polemische Subjekt kann seinen Text z. B. als eine Ad-hoc-Replik oder unmittelbare Reaktion auf bereits gemachte Aussagen und Handlungen (evtl. vorausgehende Schriften) des polemischen Objekts inszenieren. Die Wiedergabe des bereits Vergangenen kann infolgedessen als ein probates sprachliches Mittel der textuellen Streitinszenierung identifiziert werden, um das Vor-Augen-Stellen bzw. die performative Konstruktion des Streits zu fördern. Strategisch kann dies auf unterschiedliche Weise umgesetzt werden: durch ein direktes Zitat, durch Paraphrasieren bestimmter Aussagen, durch die summierende oder nacherzählende Wiedergabe von Themen(-strängen) oder durch Referenz auf einen Gesamttext oder im Text enthaltenen Diskurs. ${ }^{244}$

Durch das direkte Zitat ebenso wie durch die Redewiedergabe in indirekter Rede eröffnen sich Möglichkeiten zur Verdrehung, Widerlegung, Ironisierung oder Verspottung der gegnerischen Äußerung. Beim wörtlichen Zitat ${ }^{245}$ kann dies durch die Einbettung des Originalwortlauts sowohl in eine neue sprachliche Umgebung als auch in einen anderen Blickwinkel geschehen, so dass,

von der Perspektive der beiden Sprecher der Wiedergabeäußerung und der Originaläußerung aus betrachtet, [...] sich eine Redewiedergabe in der Form der direkten Rede als eine ,Nebeneinanderstellung zweier Perspektiven im

Formen und Formgeschichte des Streitens. Bd. 2. Der Literaturstreit. Tübingen: Niemeyer, S. 4I-54, hier S. 52.

${ }^{244}$ Vgl. dazu: „Der intertextuell organisierte, seine punktuelle Identität aufgebende Text stellt sich durch ein Verfahren der Referenz (dekonstruierend, summierend, rekonstruierend) auf andere Texte her.“ Lachmann, Renate (I984): „Ebenen des Intertextualitätsbegriffs“. In: Stierle, Karl-Heinz \& Rainer Warning (Hg.): Das Gespräch. München: Fink, S. I33-I38, hier S. I34. Die Definition von Intertextualität an dieser Stelle rekurriert demnach auf „ein eingeschränktes (intensives) Verständnis von I[ntertextualität] [...], ,im Sinne einer reinen Beschreibungskategorie für Texte, deren Struktur durch die Interferenz von Texten oder Textelementen organisiert ist.““ Pekar, Thomas ( I998): „Intertextualität“. In: HWRh 4. Hu-K, Sp. 526-533, hier Sp. 527. Binnenzitat aus Lachmann (I984), S. I33 (s. o.).

245 Ein wörtliches Zitat ist in Texten des I 6. Jahrhunderts noch nicht durch Satzzeichen als ein solches gekennzeichnet, deswegen ist es schwer als Zitat zu identifizieren. Es kommen wiederholt Markierungen durch Fettdruck vor, aber häufiger gibt es keine typographischen Unterschiede. Selbst wenn die Satzstruktur eine direkte Rede ankündigt, muss es sich nicht um ein wörtliches Zitat handeln. Zudem muss immer auch bedacht werden, dass im Frühneuhochdeutschen noch nicht durchgehend die Verbendstellung im Nebensatz zur Anwendung kam, was eine Unterscheidung zwischen direkter und indirekter Rede zusätzlich erschwert. 
Wechsel von der Perspektive des Redemitteilenden zu der des Redenden bezeichnen [lässt]. ${ }^{246}$

Beim wörtlichen Zitat entsteht demnach ein Nebeneinander von zwei Ebenen. Durch Veränderung des Kontextes, in den die wörtliche Äußerung eingebettet wird, kann jedoch die Äußerung verzerrt und ihre Gesamtbedeutung abgewandelt werden. Zum Beispiel kann ein ursprüngliches Moment der Ironie durch die Entfernung des Zitats aus seiner sprachlichen Umgebung oder Entkopplung der kontextuellen Anknüpfung entfallen und die Interpretation gegensätzlich sein. Ebenso ist der umgekehrte Fall möglich: Die zitierte Äußerung kann ironisiert und der Gegner so verspottet werden. Aber nicht nur Ironie, sondern auch Mehrdeutigkeit von Worten, Satzelementen oder Gesamtäußerungen kann durch den Austausch der sprachlichen Umgebung für die Verdrehung der Originaläußerung instrumentalisiert werden. So birgt selbst die Redewiedergabe in der direkten Rede mehrere Möglichkeiten für den Polemiker, die gegnerischen Aussagen zugunsten der eigenen Positionen einzusetzen. Insbesondere die Erhaltung des Originalwortlauts kann dabei als ein den Spott unterstreichendes Element fungieren, indem suggeriert wird, dass der Gegner sich mit seiner Äußerung selbst widerlegt oder verspottet.

Die Redewiedergabe in indirekter Rede hingegen bietet unmittelbarer die Möglichkeit einer Manipulation, denn „bei der indirekten Rede kommt der Originalsprecher erst über den Wiedergabesprecher zu Worte.“ Die Ebene der Originalaussage wird insofern nur „suggeriert oder evoziert“..24 So kann der Polemiker die gegnerische Äußerung als andere Ebene angeben, sie aber nach eigenen Vorstellungen modifizieren, so dass sie der Polemik dient. Zum einen kann die Originaläußerung ebenso wie beim wörtlichen Zitat in ein völlig anderes sprachliches Umfeld gesetzt und der kontextuellen Bezüge entbunden bzw. mit neuen verknüpft werden, zum anderen kann aber auch der Wortlaut an sich - und damit implizite Bedeutungen - verändert werden, indem die Perspektive des Polemikers einfließt. So kann z. B. das Austauschen, Weglassen oder Hinzufügen einzelner Worte die Bedeutung gravierend beeinflussen.

${ }^{246}$ Landén, Barbro (I985): Form und Funktion der Redewiedergabe in einigen ausgewählten historischen Darstellungen. Stockholm: Almqvist \& Wiksell International, S. 25 (Binnenzitat: Kändler I975: „Rededarstellung“. In: Fleischer, W. \& G. Michel (Hg.): Stilistik der deutschen Gegenwartssprache. Leipzig, S. 210).

247 Beide Zitate: Landén (I985), S. 26 \& 28. 
Neben den beiden Grundformen der Redewiedergabe stellen auch allgemeinere intertextuelle Bezüge zur Schrift des Gegners eine wichtige Strategie dar, den Gegner sich selbst ,zur Schau stellen zu lassen'. Im Gegensatz zur Redewiedergabe, die eine spezielle Form der Intertextualität ist, sollen unter ,intertextuellen Bezügen' all solche Verfahren verstanden werden, „in denen in pointiertem und markiertem Bezug ein Einzeltext auf einen anderen verweist, indem er diesen zitiert oder auf ihn anspielt, ihn paraphrasiert oder übersetzt, fortschreibt oder adaptiert, parodiert oder travestiert. “ ${ }^{248}$ Ein Bezug mag beispielsweise strukturell sein, indem die Struktur der gegnerischen Schrift angepasst wird. Alternativ kann auch nur angedeutet werden, dass etwas gesagt wurde, ohne den Wortlaut (exakt oder leicht verändert) wiederzugeben. Auch die weniger konkreten intertextuellen Bezüge tragen dazu bei, dass der Gegner in der Schrift als ,anwesend' inszeniert wird. Zudem ermöglicht die intertextuelle Bezugnahme auf unterschiedlichen Ebenen eine direkte Auseinandersetzung mit dem gegnerischen Text: zum Beispiel mit einem Gegenargument, mit einem Vorwurf oder auch mit einer generalisierten Gesamtaussage eines Textes. Viele Streittechniken wie etwa Verdrehung, Ironisierung, Parodisierung, Verspottung etc. basieren auf dem Prinzip der Intertextualität und ihre Verwendung ist insofern eine wesentliche Strategie der Polemik.

Dass Redewiedergaben und intertextuelle Bezüge einen wichtigen Stellenwert in polemischen Schriften der Reformationszeit haben, zeigt sich nicht zuletzt durch die Vielzahl der Metakommentare, in denen ihre fehlerhafte oder missbräuchliche Verwendung beim Streit angekreidet wird. Solche Vorwürfe fungieren nicht allein als Ermahnung, die Regeln einzuhalten, sondern sind ebenfalls Strategien der Streitinszenierung, die den Gegner wiederum als frevelhaft erscheinen lassen. So eignet sich die Redewiedergabe sowohl auf Seiten des Wiedergebenden als auch auf Seiten des bereits Wiedergegebenen für polemische Angriffs- und Verteidigungsmanöver. Beide Varianten bringen zudem den jeweiligen Gegner mit auf die Bühne, so dass der Effekt eines im Text stattfindenden Dialogs entsteht. Eine explizite Adressierung des Gegners oder des Publikums (jeweils in der 2. Person) kann diesen Effekt der „strukturelle[n] Performativität““ ${ }^{249}$ zusätzlich verstärken.

${ }^{248}$ Pfister, Manfred (I994): „Intertextualität“. In: Žmegač, Viktor (Hg.): Moderne Literatur in Grundbegriffen. Tübingen: Niemeyer, S. 2I 5-2 I 8, hier S. 2 I 7.

${ }_{249}$ Häsner et al. (20II), S. 82. 


\section{Die polemische Bibelauslegung}

Von den bereits erörterten intertextuellen Bezügen qualitativ zu unterscheiden ist die polemische Bibelauslegung. Sie stellt zwar ebenfalls eine Form der Intertextualität dar, ihr Prätext ist aber kein Produkt des polemischen Gegners, sondern - und das ist für das I6. Jahrhundert hervorzuheben - wird als das ,Wort Gottes' anerkannt.. ${ }^{25}$ Durch eine kontextualisierende Exegese von Bibelstellen, d. h. durch die Herstellung von Bezügen der biblischen Vorlage auf die aktuelle Gegenwart, vermag eine polemische Bibelauslegung jedoch harte Angriffe auf einen Gegner zu evozieren. Bei einer solchen Polemik ist insbesondere die Autorität der Heiligen Schrift dienlich, denn im Gegensatz zu anderen Schriften ist die Bibel aus der religiösen Perspektive des I6. Jahrhunderts Trägerin absoluter und unangefochtener Wahrheit. Diese Glaubwürdigkeit macht sich der Polemiker bei der polemischen Bibelauslegung zunutze, so dass Vergleiche mit biblischen Geschichten, Gleichnissen oder Figuren von der biblischen Autorität leben. Zum Beispiel können negative biblische Figuren mit dem polemischen Objekt und anderen feindlichen Personen gleichgesetzt werden. Das prominenteste Beispiel einer solchen polemischen Exegese ist Luthers Antichrist-Polemik gegen den Papst auf der Basis der Offenbarung des Johannes. ${ }^{25 \mathrm{I}}$ Aber nicht nur Personenvergleiche, sondern auch gesamte biblische Zusammenhänge können umgedeutet werden, indem sie allegorisch auf die eigene Wirklichkeit ausgelegt werden. ${ }^{252}$ Durch den

${ }^{250}$ Vgl. dazu Matheson, der die Bibelzitate als „God's graffiti“ bezeichnet: „We think of the Bible in terms of a text to be exegeted. The sixteenth-century Reformers saw it as the exegetical tool which illumined the whole of reality. Their cultural landscape, accordingly, was studded with these graffiti, the Biblical quotations from prophets, evangelists and apostles, the divine wisdom which seemed to settle every argument." Matheson (I998), S. 24I.

${ }^{251}$ Hofmann, Hans-Ulrich (I982): Luther und die Johannes-Apokalypse (= Beiträge zur Geschichte der biblischen Exegese). Tübingen: Mohr, S. I64. Hofmann spricht in dem Zusammenhang ebenfalls von Luthers „polemische[r] Verwendung der Apk“. Ebd. Zur Antichrist-Polemik siehe auch Richardsen-Friedrich (2000).

${ }^{252}$ Dieses Verfahren der Bibelauslegung war in der Reformationszeit nicht nur für polemische Zwecke üblich: „It has become a cliché that the Biblical message leapt fresh from vernacular pages, and was interwoven into everything from personal piety to domestic arrangements, to the reimagining of society. Equally importantly, however, contemporary issues were read back into Biblical space. Lay people, women, and the marginalised, as well as scholars and preachers made new connections between Old Testament and New, past, present and future, God and the human condition. They learned to ,read' their societies, as well as their Bibles, differently." Matheson (1998), S. I60. 
Bezug auf den Kontext, in den die polemische Schrift eingebettet ist, unterstützt aber auch die polemische Bibelauslegung das Performative, indem sie den klaren Verweis auf das ,Hier und Jetzt' schafft und quasi nicht nur eine Reinterpretation, sondern auch eine ,Reinszenierung' der Bibel vornimmt.

\section{Nicht-argumentative Streittechniken}

Das Erwecken einer bildlichen, körperlich anmutenden Streitsituation ist nicht nur auf einer argumentativen Ebene, durch z. B. intertextuelle Bezüge, gegeben, sondern auch durch nicht-argumentative Streittechniken bzw. "affektische Mittel“.253 Sie decken den Teil der Polemik ab, der sich nicht an einer auf rationaler Ebene geführten sachlichen (ad rem) Diskussion oder Argumentation orientiert, d. h. es handelt sich um die unsachliche Seite der Polemik, die auf das Inszenieren und Wecken starker (negativer) Emotionen in Bezug auf die persona des polemischen Objekts zielt. Bei Verwendung nichtargumentativer Streittechniken bezieht sich die Polemik nicht mehr argumentativ auf die gegnerischen Aussagen oder Auffassungen, sondern greift dort an, wo die Streitsache (res) streng genommen aufhört: beim „Persönlichwerden".254

Die für das Persönlichwerden verwendeten sprachlichen Strategien lassen sich mit denen der Invektive vergleichen. Da sie „eher eine bestimmte Redeabsicht als eine formal umrissene rhetorische Gattung “255 darstellt, liegt der Vergleich nahe: Die unsachliche Polemik verfolgt die gleichen Wirkungsabsichten wie die Invektive: „[Letztere] will bloßlegen

${ }_{553}$ Dieckmann, Walther (1975): Sprache in der Politik. Einführung in die Pragmatik und Semantik der politischen Sprache. Heidelberg: Carl Winter, S. 99. Dieckmann stellt sie den intellektuellen Mitteln gegenüber. Ebd.

254 Es soll hier zwischen argumentum ad personam (Schopenhauer) und Persönlichwerden im Sinne Dieckmanns unterschieden werden. Letzterer argumentiert, dass das argumentum ad personam nicht mit dem von ihm eingesetzten Begriff des Persönlichwerdens übereinstimmt: Zum einen impliziere ersteres, dass argumentiert werde, so dass sämtliche nicht-argumentative Streittechniken aus dem Bedeutungsbereich herausfallen. Zum anderen könne die res z. B. auch eine Person selbst sein, so dass in solch einem Fall ein argumentum ad personam eigentlich ein argumentum ad rem sei. Insofern setzt Dieckmann das Persönlichwerden erst dort an, wo die Grenzen der Sache überschritten werden, beispielsweise wenn man in einer Diskussion der beruflichen Funktion einer Person nicht mehr die berufliche, sondern die Privatperson angreift. Dann sei die Grenze der Sache überschritten. Dieckmann (2005), S. 63-76 (Hervorhebungen im Original).

255 Neumann, Uwe (I998): „Invektive“. In: HWRh 4, Sp. 549-56r, hier Sp. 549. 
und entlarven, was sich hinter einer Person verbirgt: sie destruiert die angemaßte Rolle und legt das vermeintliche wirkliche Wesen offen. “256 Um dieses Ziel zu erreichen, werden verschiedene rhetorische Mittel eingesetzt, zu denen z. B.

entehrende Vergleiche, Metaphorik [...], Schwarz-Weiß-Malerei durch Gegenüberstellung mit einer untadeligen Person [...], Verallgemeinerungen, Unterstellungen, Wortspiele (insbesondere Namensspott), die ,Entwertung positver [sic!] Begriffe' durch Ironie und neologistische Wendungen, die ein negatives Merkmal des Angegriffenen herausstellen[,] ${ }^{257}$

zählen. Dieser Aufzählung ist zu entnehmen, dass die rhetorischen Mittel sehr vielseitig und in unterschiedlichen Bereichen der elocutio zu verorten sind, wie z. B. rhetorische Figuren und Tropen. Zur Präzisierung könnten weiterhin Sprichwörter, Redewendungen, Allegorien und Fabeln (nebst anderen Gattungen) genannt werden, die zur Schmähung des Gegners beitragen können, indem sie Negativbeispiele liefern, die auf das polemische Objekt übertragen oder zu Vergleichszwecken herangezogen werden.

Da die reformationspolemischen Schriften über die individuelle Polemik eines Einzelnen hinausgehen, ist neben den bereits genannten rhetorischen Mitteln das Schlagwort von besonderer Bedeutung. Der Gebrauch eines Wortes als Schlagwort ${ }^{25}$ ist ein gesellschaftliches Phänomen von Sprache, weil Schlagwörter in ihrer Bedeutung abhängig von dem „speziellen [...] Wortschatz“ sind, ${ }^{259}$ der innerhalb eines bestimmten öffentlichen ${ }^{260}$ Diskurs- oder Sachbereichs (hier die Reformation) aktuell ist. ${ }^{261}$ Der Begriff des Schlagwortes ist

${ }_{256}$ Ebd., Sp. 549 f.

257 Ebd., Sp. 555.

${ }^{258}$ „Ein Wort ist nie als solches ein Schlagwort, sondern wird dazu immer erst in bestimmten Situationen. [...] Ein Wort ist nicht Schlagwort, sondern wird als Schlagwort gebraucht. “ Dieckmann (I975), S. IO2.

259 Für die Reformation lässt sich ebenfalls ein spezieller Wortschatz feststellen, wie Dieckmann ihn für die „Sprache der Politik“ konstatiert. Ebd., S. 47.

${ }^{260}$ „Das Schlagwort dient der Beeinflussung der öffentlichen Meinung [...]. “ Ebd., S. I02. Vgl. auch: „Daß Wortprägungen erst dann zu S[chlagwörtern] werden, wenn sie in einem bestimmten Zeitraum einen gewissen Grad an Aktualität gewonnen haben, macht ihren Zusammenhang mit einer (wie auch immer gearteten) Öffentlichkeit deutlich.“ Niehr, Thomas (2007): „Schlagwort“. In: HWRh 8, Sp. 496-502, hier Sp. 497.

${ }^{261}$ „Im Laufe der Zeit verlieren viele Wörter ihren Schlagwortcharakter, indem die kommunikative Situation, in der sie entstanden sind, sich überlebt hat. [...] Vielleicht kann man deshalb behaupten, daß einem Schlagwort ein wenig vom 
grundsätzlich wertneutral, obgleich er fälschlicherweise oftmals als negativ interpretiert wird. ${ }^{262}$ Es gibt sowohl affirmative bzw. meliorative als auch pejorative Schlagwörter, die unter dem zunächst neutralen Begriff des Schlagwortes zusammengefasst werden. Die linguistische Forschung unterscheidet daher u. a. zwischen ,Stigmawörtern' (auch ,Unwertwörtern'), die einen negativen „emotiven Wortinhalt“ ${ }^{“ 263}$ besitzen, und ,Fahnenwörtern' (auch ,Hochwertwörtern'), die das positive Gegenstück dazu darstellen. ${ }^{264} \mathrm{Da}$ Schlagwörter aber von ihrem funktionalen Gebrauch bestimmt sind, muss berücksichtigt werden, dass ein Wort nicht entweder Stigmawort oder Fahnenwort ist, sondern in jeweils anderen Verwendungskontexten (u. a. abhängig von der Parteizugehörigkeit des Sprechers) sowohl Stigmawort als auch Fahnenwort sein kann. ${ }^{265}$ Gerade das Charakteristikum einer semantischen Flüchtigkeit bzw. Fluidität macht das Schlagwort so attraktiv

,Zeitgeist" innewohnt. “ Diekmannshenke, Hans-Joachim (1990): Die Schlagwörter der Radikalen der Reformationszeit (I 520-I 536): Spuren utopischen Bewusstseins. Frankfurt/Main: Lang, S. I4.

${ }_{262}$ Vgl. Diekmannshenke (I994), S. I3 und Dieckmann (I975), S. I02.

${ }^{263}$ Liedtke, Frank, Karin Böke \& Martin Wengeler (I996): Politische Leitvokabeln in der Adenauer-Ära. Berlin \& New York: De Gruyter, S. 39.

264 „Unter dem neu eingeführten Oberbegriff ,Brisante Wörter‘ liefert Hermanns I 982 eine erste präzisierende Definition von Fahnenwort und dem von ihm kreierten Neologismus Stigmawort, die verschiedentlich aufgegriffen wurde.“ Liedtke et al. ( I996), S. 39. Liedtke et al. weisen jedoch darauf hin, dass „sich im Falle des Terminus Stigmawort im linguistischen Fachjargon ein etwas anderer Gebrauch durchgesetzt“ hat, der nicht exakt der Definition Fritz Hermanns’ entspricht: „Hierunter werden allgemein negative Schlagwörter gefaßt, und die ursprüngliche Komponente des Kenntlichmachens eines Parteistandpunktes trat in den Hintergrund." Ebd. Von dieser Bedeutung ausgehend leiten Liedtke et al. ebenfalls das ,Fahnenwort als Pendant zum ,Stigmawort' ab. Die linguistische Forschung geht über diese vereinfachte Zweiteilung von Schlagwörtern hinaus und unterscheidet eine Vielzahl weiterer Wortkategorien (z. B. Leitwörter, Schlüsselwörter etc.). Siehe dazu Niehr (2007), HWRh 8, Sp. 497. Zu den Bezeichnungen ,Hochwertwörter ${ }^{`}$ und ,Unwertwörter' sowie zur Abgrenzung von Schlagwörtern und Schlüsselwörtern siehe Brylla, Charlotta (2003): Die schwedische Rezeption zentraler Begriffe der deutschen Frühromantik. Schlüsselwortanalysen zu den Zeitschriften Athenäum und Phosphoros. Stockholm: Almqvist \& Wiksell International, S. 34-47.

265 Vgl. Niehr (2007), HWRh 8, Sp. 497. Diekmannshenke sieht zwar von einer solchen Unterteilung des Schlagwortes ab - im Hinblick auf die Flüchtigkeit einer solchen Bezeichnung (ein Stigmawort kann auch zum Fahnenwort werden und umgekehrt) wäre ihm auch zuzustimmen, aber da gerade die Transformation der Bedeutungen von Interesse sein kann, sind die Kategorien keinesfalls als hinfällig zu betrachten. Eine Kategorisierung kann daher nie generalisierend für ein Schlagwort geschehen, sondern muss die jeweilige Funktion eines Schlagwortes in seinem Kontext im Blick haben. 
für die agitatorische Rede: „Aufgrund der ideologischen Polysemie des Schlagwortes entsteht der sogenannte semantische Kampf ", ${ }^{266}$ der bei jeder Verwendung neu ausgefochten wird. Infolgedessen vermag ein Schlagwort, das aus seinem ursprünglichen Kontext gelöst und in eine andere Umgebung umgesiedelt wird, einen vollkommen veränderten Bedeutungsinhalt zu transportieren.

In der Polemik werden Schlagwörter (vor allem Stigmawörter) strategisch eingesetzt, da in ihnen

die Programme kondensiert [werden]; sie erheben Relatives zu Absolutem, reduzieren das Komplizierte auf das Typische, Überschaubare, EinfachGegensätzliche und bilden dadurch bipolare Wortschatzstrukturen aus; sie bringen das Abstrakt-Ferne sprachlich nahe und geben der Meinungssprache ihre emotionellen Obertöne. ${ }^{267}$

In Schlagwörtern verdichten sich dementsprechend komplexe Sinnzusammenhänge, Werturteile und Einstellungen in einem kurzen und prägnanten sprachlichen Ausdruck, was sie zu einem besonders effizienten Mittel der persuasiven Sprache werden lässt. Darüber hinaus ist ihnen „ein affektives Moment [inhärent], das sich besonders für Rede, Flugblätter, Manifeste und dergleichen unmittelbar auf Propaganda und Agitation hin orientierte Äußerungen schriftlicher und verbaler Art eignet. “268 Insofern können Schlagwörter auch für das Erzeugen eines polemischen Antagonismus eingesetzt werden, denn „[s]ie dienen der Unterscheidung, der Auf- oder Abwertung, der Polarisierung oder Vereinnahmung, der Solidarisierung oder Ausgrenzung “. ${ }^{269}$ Schlagwörter besitzen dementsprechend ein großes performatives Potential.

Nicht zu verwechseln ist das pejorative Schlagwort, das Stigmawort, mit dem Schimpfwort, denn letzteres gehört „zum festen gesellschaftlichen Beleidungsrepertoire“, 270 ist vom Bedeutungsinhalt festgelegt (immer negativ) und besitzt nicht die komprimierten programmatischen Implikationen ${ }^{27}$ und die dementsprechend komplexe Wirkmächtigkeit, die dem Stigmawort inhärent sind. ${ }^{272}$ Die Funktion des Schimpfwortes

\footnotetext{
${ }^{266}$ Brylla (2003), S. 44.

267 Dieckmann (I975), S. I03.

${ }^{268}$ Diekmannshenke (I994), S. I6.

269 Niehr (2007), HWRh 8, Sp. 498.

${ }^{270}$ Baur, Alexander (2OII): „Beleidigung “. In: HWRh Io, Ergänzungen A-Z, Register, Sp. I I6-I28, hier Sp. I 9 .

${ }_{271}$ Diekmannshenke (I994), S. 22.

${ }^{272}$ „Der programmatische Charakter ist so ausgeprägt, daß es zu seinem Verständnis in aller Regel keines sprachlichen Kontextes mehr bedarf.“ Ebd., S. I 5.
} 
erschöpft sich allein in der Ehrverletzung und Aberkennung des „soziale[n] Geltungsanspruch[s]“ des Gegenübers. ${ }^{273}$ Für dieses Ziel bedienen sich Schimpfwörter verschiedener topischer Bereiche wie beispielsweise Aussehen, sozialer Status, Abstammung, Sexualität usw., die sich u. a. durch die Technik der „metaphorische[n] Gleichsetzung von Mensch und Sache [...] bzw. Mensch und Tier" umsetzen lassen. ${ }^{274}$ In der Reformationspolemik kommen sowohl Schimpfwörter als auch Stigmawörter vermehrt zum Einsatz. Mitunter sind die Grenzen zwischen beiden fließend, so dass der Gebrauch jeweils in seinem Kontext untersucht werden muss. ${ }^{275}$

Die Funktion nicht-argumentativer Streittechniken wie Metaphern, Vergleichen, Stigmawörtern, Schimpfwörtern, Allegorien, Fabeln etc. in polemischen Schriften liegt darin, die zwei Pole des polemischen Antagonismus zu bestätigen, zu festigen und weiter auseinanderzutreiben. Nicht-argumentative Streittechniken haben in der Regel hohen Pathosgehalt und schaffen dadurch eine besondere Stimmung, die die rationalen Argumente auf einer emotionalen, affektiven Ebene komplettiert. Durch ihre Anschaulichkeit - eventuell auch durch ihren Witz sind viele dieser Streittechniken leicht zu rezipieren und memorieren, ${ }^{276}$ was wiederum die funktionale Performativität der polemischen Schrift durch z. B. Referenzen und Wiederholungen in anderen Schriften, Mundpropaganda etc. fördert.

\section{Das Wirkungspotential struktureller Performativität}

In dem Bereich von einzelnen Wörtern bis hin zu zusammenhängenden Texten erstrecken sich die unterschiedlichen rhetorischen Vorgehensweisen, die strukturelle Performativität erzeugen. Durch die Redewiedergabe, intertextelle Bezüge auf die Schrift des Gegners oder auf die Bibel, und eine Fülle von nicht-argumentativen Streittechniken lassen die Autoren der Reformationspolemik ihre Gegner szenisch auftreten (bspw. in Gestalt eines Tieres) und schreiben das

${ }_{273} \operatorname{Baur}(20 \mathrm{II})$, HWR $\mathrm{IO}$, Sp. I I6.

274 Ebd., Sp. I I 8 f.

275 Zum Beispiel befindet sich das Wort, Pharisäer' an der Grenze zwischen Schimpfwort und Stigmawort, da es mal nur als Beleidigung benutzt wird, mal aber eine darüber hinausgehende programmatische Bedeutung hat. Vgl. auch Diekmannshenke (I994), S. 22.

${ }^{276}$ Es sei an die unterschiedlichen Namensverballhornungen oder Ersatznamen erinnert, die durch ihre Iteration zum Teil den eigentlichen Namen vollkommen ersetzen: z. B ,der Bock' für Hieronymus Emser. 
polemische Objekt so auf ihre Weise in den Text ein. Eine Funktion dieser performativen Streitinszenierung ist die Imageschädigung des Kontrahenten, die sowohl die Ehre als auch die Glaubwürdigkeit des Gegenübers miteinbezieht. ${ }^{277}$ Die Schädigung des Gegnerimages ist zumeist mit der Imagepflege des polemischen Subjekts gekoppelt, die hingegen die Glaubwürdigkeit und Überzeugungskraft erhöhen und der „Identitätssicherung “ ${ }_{278}$ dienen soll. Eine andere damit im Zusammenhang stehende Funktion ist das Schaffen und Aufrechthalten von Gruppenidentitäten. Indem Individuen z. B. strategisch exkludiert oder inkludiert werden, ${ }^{279} \mathrm{kann}$ das Wir-Gefühl innerhalb der eigenen Partei, deren Mitglieder oftmals die Hauptempfänger von polemischen Schriften sind, gestärkt werden. ${ }^{280}$

\subsection{Kommunikative Situationen des Polemisierens}

Als Methode der performativen Streitinszenierung kann Polemik sich vieler unterschiedlicher Mittel der Textkonstruktion bedienen, um ihre Funktionen zu erfüllen. Nicht nur die bereits erörterten sprachlichen Streittechniken - das Wie und das Was der Aussagen - prägen maßgeblich das Erscheinungsbild und die performative Wirkungskraft von Polemik, sondern auch die gröberen Rahmenbedingungen des Äußerns bzw. die Verpackung von Polemik.

277 Diesen Mechanismus der „Ehrverletzung“ durch sprachliche „Zu-schreibung[en] und Prädikation[en]“ erklärt Anja Lobenstein-Reichmann. Mit solchen Prädikationen, wie z. B ,Ketzer', „[...] werden sprachlich und textlich geschaffenen Kollektividentitäten inskribiert, in die einzelne Menschen [...] eingeschrieben werden können, unabhängig davon, ob sie den Zuschreibungensmerkmalen entsprechen oder nicht." Die Folge davon bzw. auch die intendierte Funktion bei Polemik ist, dass „[die] aktuale Identität [...] gegenüber der ihr zugeschriebene virtualen so stark in den Hintergrund [tritt], dass nur noch die letztere das Bild prägt, und über den Einzelnen im Sinne von ,Individuum' nichts mehr ausgesagt wird. Der Einzelne geht in der ihm zugeschriebenen virtualen Gruppenexistenz auf.“ LobensteinReichmann, Anja (20I3): Sprachliche Ausgrenzung im späten Mittelalter und in der frühen Neuzeit. Berlin \& Boston: De Gruyter, S. 8f.

${ }_{278}$ Wischmeyer \& Scornaienchi (20II), S. 9

279 Vgl. Gehrke (2004), S. I9f.

${ }^{280}$ Vgl. dazu: „We may conclude that a polemic often has an internal function. [...] Thus, while a polemic is intended against an opponent, the main effect may be a strengthening or reordering of one's own group. "Hettema, Theo Leonardus \& Arie Van der Kooij (2004): „Introduction“. In: Dies. (Hg.): Religious Polemics in Context. (= Papers Presented to the Second International Conference of the Leiden Institute for the Study of Religions (Lisor) Held at Leiden, 27-28 April 2000). Assen: Royal Van Gorcum, S. xi-xv, hier S. xv. 
Bleibt man in der Metaphorik der Aufführung oder Inszenierung auf einer Bühne, kann die Form eines Textes mit der Theaterbühne bzw. dem Zusammenwirken von Bühnenbild, Kostümierung, Musik und Effekten etc. verglichen werden. Das Theaterstück bzw. die Aufführung des dramatischen Textes ist in hohem Maße von diesen ,äußeren“ Faktoren beeinflusst. Unterschiede in der Inszenierung eines Stoffes können veränderte Rezeptionshaltungen oder Deutungen bedingen. Gleiches gilt für die Form eines polemischen Textes. Ausgehend von der These, dass die Art der Vermittlung von Polemik eine wichtige Rolle für die Inszenierung von Streit spielt, liegt es nahe, die Untersuchungen der polemischen Texte im Einzelnen anhand der formalen Charakteristika zu ordnen bzw. der detaillierten sprachlichen Analyse einzelner polemischer Strategien einen Blick auf die Besonderheiten der Texte voranzustellen.

Aufgrund der wörtlichen Übereinstimmung liegt die Annahme nahe, dass man streitinszenierende Texte unter dem Sammelbegriff der Textsorte ${ }^{28 I}$,Streitschrift ${ }^{\star}$ zusammenfassen könnte. Auf einen ersten Blick erscheint es wie eine logische Konsequenz, denn es handelt sich um eine Schrift, mit der gestritten wird oder die den Streit in den Mittelpunkt stellt. ${ }^{282}$ Der performative Aspekt dieser Textsorte steht im Zentrum, die Inszenierung des Streits ergibt sich durch die

${ }^{28 \mathrm{I}}$ Die Bezeichnung der ,Streitschrift' als eine Textsorte geht auf die Klassifizierung von Johannes Schwitalla zurück, der zwischen literarischer Form und Textsorte unterscheidet: „Mit literarischen Formen meine ich bestimmte Konventionen beim Verfassen von schriftlichen Texten.“ Schwitalla (I983), S. 88. „Unter Textsorte verstehe ich Typen von Texten, die zu bestimmten Zielen geschrieben wurden.“ Ebd., S. 3. Etwas problematisch ist Schwitallas Ansatz allerdings, weil er bei der ,Textsorte von der Teleologie des Autors ausgeht: „Die zentrale Frage dieser Art von Textforschung lautet: Was wollte ein Autor mit seinem Text bei seinen Lesern/ Zuhörern erreichen und welche sprachlichen Mittel verwendete er dazu? “Ebd., S. I 2. Schwitallas Annahme einer formulierbaren Intention liegt bei der Gebrauchsliteratur zweifelsohne wesentlich näher als bei schönliterarischen Texten. Dennoch bleibt die Intention eine abstrakte Größe, die nicht mit Sicherheit erschließbar ist. Es erscheint stattdessen sinnvoller, von Funktionen oder Funktionspotentialen, die im Text selbst angelegt und nicht beim Autor zu suchen sind, zu sprechen. Diesen Einwand mitgedacht, erscheint Schwitallas Unterscheidung zwischen Textsorten und literarischen Formen zunächst als fruchtbar. Dass die allzu strikte Trennung von Funktion und Form jedoch Schwierigkeiten bereitet bzw. sich als unmöglich erweist, zeigt die weitere Diskussion.

${ }^{282}$ Bremer bestätigt, dass die „S[treitschrift] zu den literarischen Zweckformen zu zählen“ ist und sich „je nach Anlaß und Streitpunkt als sehr flexibel [erweist], was der starken Wirkungsorientiertheit der S[treitschrift] geschuldet ist." Bremer, Kai (2009a): „Streitschrift“. In: HWRh 9. St-Z. Sp. I 89-I9I, hier Sp. I 89. 
Gleichzeitigkeit von sprachlicher Aussage und Handlung: Die Schrift „streitet“ in dem Moment ihrer sprachlichen Vermittlung. Dies allein macht es jedoch schwierig, einzugrenzen, was eine ,Streitschrift ${ }^{`}$ formal betrachtet ist.

Dass die von Johannes Schwitalla vorgeschlagene Unterscheidung zwischen Textsorte und literarischer Form nicht exakt aufgehen kann, stellt die Bezeichnung ,Streitschrift" geradezu unter Beweis. Die Streitschrift lässt sich nach Schwitalla durch ihre Funktion bestimmt als Textsorte identifizieren und nicht als literarische Form. Ein Mangel der Klassifizierung liegt aber in der Schwierigkeit - womöglich gar der Unmöglichkeit -, einen Text in seine (Haupt-)Funktion und Form einzuteilen und diese voneinander getrennt $\mathrm{zu}$ betrachten, während die Konzentration auf ein Merkmal oder wenige wichtige Merkmale zusätzlich eine Reduktion mit sich bringt. Die Problematik der praktischen Umsetzung der Trennung zwischen Textsorte und literarischer Form zeigt beispielsweise die Typologie, die Alejandro Zorzin für die Flugschriften Karlstadts vornimmt. ${ }^{283}$ Bei der Untersuchung der Publizistik Karlstadts identifiziert Zorzin sechs Schrifttypen: Kommentar und Auslegung, Thesenreihe, Streitschrift, (Send-)Brief, Traktat und Predigt. ${ }^{284}$ Durch das Platzieren der Streitschrift auf gleicher Ebene mit den anderen Formen begrenzt Zorzin die Funktion des Streitens auf die Streitschrift: Es entsteht schnell der Eindruck, dass beispielsweise der (Send-)Brief oder der Traktat nicht zum Zweck des Streitens eingesetzt werden. Infolgedessen scheint Zorzins Texttypologie verschiedene Ebenen miteinander gleichzustellen, so dass die definitorische Trennschärfe verloren geht.

Diese Schwierigkeiten beim Definieren der ,Streitschrift' werden auch im Historischen Wörterbuch der Rhetorik thematisiert. Einer zu erwartenden Begriffsbestimmung wird schon vorab die Unmöglichkeit einer

\footnotetext{
${ }^{283}$ Zorzin (I990), S. I64-I80.

${ }^{284}$ Ebd., S. I64. Bei der Feststellung der verschiedenen Typen „geht es [ihm] in erster Linie darum, ein methodisches Hilfsmittel bereitzustellen, das die Untersuchung im Rahmen [seiner] Fallstudie erleichtert. Die Flugschriften-,Typen'sollten sowohl die verschiedenen literarischen Formen als auch die unterschiedliche Funktion der Publikationen miteinbeziehen. Dabei ist zu berücksichtigen, daß es den ,Idealfall einer Koinzidenz von Stoff, Form, Stil, Aussage, Tradition, Gebrauch und Wirkung zu einem Тyp' wahrscheinlich überhaupt nicht gibt. [Binnenzitat nach H. Kuhn: Literaturtypologie, S. 263] Die Festlegung eines bestimmten ,Typs' erfolgt sowohl aufgrund bestimmter Formmerkmale als auch im Blick auf den möglichen ,Sitz im Leben', den geschichtlichen und literarischen Kontext einer Schrift.“ Ebd., S. I64f. (Hervorhebungen im Original).
} 
solchen entgegengesetzt: „Eine präzise Definition von S[treitschrift] kann nicht befriedigend geliefert werden." Fortlaufend heißt es: „Grundsätzlich kann aus beinahe jedem wertenden oder widersprechenden Text eine S[treitschrift] werden; maßgeblich dafür sind neben der (Teil-)Öffentlichkeit ein Streitgegenstand und ein Adressat. “" ${ }^{285}$ Von diesen Grundvoraussetzungen ausgehend liegt es nahe, die Streitschrift mit polemischen Texten gleichzusetzen, denn es lassen sich eindeutig die polemische Instanz in der „(Teil-)Öffentlichkeit“, das polemische Thema im „Streitgegenstand“ und das polemische Objekt im „Adressat[en]“ wiedererkennen. In einem anderen Ansatz, die Streitschrift genauer zu definieren, konstatiert Bremer, dass Streitschriften

grundsätzlich dialogisch konzipiert [sind], in dem Sinne daß sie Kontrahenten zur Reaktion in derselben Gattung herausfordern. Sie zeigen üblicherweise den Verfasser, den Gegner und den theologischen Streitpunkt an, der in Anlehnung an das Disputationswesen ,Hauptpunct' oder status controversiae genannt wird. ${ }^{286}$

Indem Bremer den Verfasser anführt, fügt er eine wichtige Instanz zu den bereits genannten hinzu, allerdings schließt seine Formulierung Schriften weitgehend aus, die den Autor namentlich nicht nennen. ${ }^{287}$ Ferner sieht Bremer den Streit erst mit der zweiten Schrift, einer Antwort, als begonnen an. ${ }^{28}$ Unbeantwortete Schriften fallen deshalb unter die Kategorien "Satiren und Pasquillen" ${ }^{289}$ und werden nicht als Streitschriften bezeichnet. Insofern würde die Bezeichnung der Streitschrift für Initiationsschriften immer retroaktiv gesetzt. Auf diese Weise erhielten die Rahmenbedingungen der Produktion (Verfassername? Replik?) und Rezeption (Herausforderung des Gegners gelungen?) ein zu großes Gewicht. Da es jedoch zu einengend erscheint, dass Einzelschriften (ohne gegnerische Antwort) und Schriften ohne die Angabe des ,realen Autors aus diesem Definitionsrahmen fallen, ${ }^{290}$ bleibt vorerst eine definitorische Ungenauigkeit bestehen.

\footnotetext{
${ }^{285}$ Beide vorangestellten Zitate in Bremer (2009a), HWRh 9, Sp. I 89.

${ }^{286}$ Bremer (2005b), S. 6.

287 Auch ist die Rolle des polemischen Subjekts nicht eins zu eins gleichzusetzen mit dem Verfasser, was nachfolgend noch ausführlich diskutiert wird.

${ }^{288}$ Bremer (2005b), S. 6f.

289 Ebd., S. 6.

290 Auch Paintner merkt dazu an: „Im Einzelfall ist es schwer zu klären, ob eine Schrift, die Erwiderungen erfährt, diese auch wirklich ,provoziert' hat, und ob eine Schrift, die nicht erwidert wird, deswegen nicht dialogisch konzipiert war.“ Paintner (20II), S. 5 I.
} 
Sämtliches polemisches Schrifttum unter dem Dach der ,Streitschrift ${ }^{\star}$ $\mathrm{zu}$ fassen, würde indessen den Formen und Funktionen der Streitinszenierung nicht gerecht; der Formenreichtum streitinszenierender Texte würde in der Breite der Bezeichnung verschwinden. Im Zusammenhang mit einer Untersuchung der Polemik erscheint eine tiefergehende Differenzierung einzelner streitinszenierender Schriften sinnvoll, denn Streit kann auch in Schriften inszeniert werden, die vordergründig eine andere Funktion erfüllen, z. B. kann ein Bibelkommentar polemische Elemente enthalten und einen Streit damit in Szene setzen, ohne dass die exegetische Hauptfunktion verloren geht. Eine eindeutige und ausschließliche Bezeichnung mit dem Label ,Streitschrift' wäre insofern nicht vertretbar.

Dass die Bezeichnung, Streitschrift` nicht grundsätzlich für alle Schriften gelten kann, die einen "polemischen Antagonismus“291 entwerfen, beruht u. a. darauf, dass man für Klassifizierungen unweigerlich den gesamten Text als eine Einheit betrachtet. Die mit dem taxonomischen Verfahren einhergehende Abstraktion, die nur die wichtigen oder dominanten Eigenschaften eines Textes herausstellt, öffnet einerseits Möglichkeiten zur Gesamtbetrachtung eines Textes, bedingt andererseits aber gleichzeitig eine Reduktion desselben auf diese identifizierten Merkmale und konstatiert eine prinzipiell nicht existierende Geschlossenheit und Homogenität eines Textes. Für die Bezeichnung eines Textes als ,Streitschrift' bedeutet dies, dass das Kriterium des Streitens betont wird und andere Kriterien exkludiert werden. Dies hat den Vorteil, dass Gemeinsamkeiten auf der funktionalen Ebene hervorgehoben werden können, weist aber den Mangel auf, dass weder die literarische Form noch die kommunikativen Rahmenbedingungen des betroffenen Textes größere Beachtung finden. Oftmals werden derartige Informationen nur am Rande gegeben und nicht intensiver untersucht. ${ }^{292}$

Aufgrund der Problematik der Textklassifizierungen soll in der vorliegenden Arbeit der Fokus weniger auf die Gattungsbezeichnung und die Gesamteinheit ,Text', sondern vielmehr auf die konkrete Form der im Text vorhandenen Streitinszenierung gelegt werden - so können

${ }^{291}$ Paintner (20II), S. 47 \& 6I.

${ }^{292}$ Beispielsweise wird im Historischen Wörterbuch der Rhetorik lediglich erwähnt, dass die Streittechniken vielfältig sind: „Sie reichen von der persönlichen Verunglimpfung mittels Invektiven und pamphletischem und grobianischem Sprechen bis hin zum sachlichen, ausschließlich argumentierenden Traktatstil. Die S[treitschrift] bedient sich daher zahlreicher Gattungsmuster." Bremer (2009a), HWRh 9, Sp. I 89f. 
auch polemische Textabschnitte in Schriften, die nicht als ,Streitschrift ${ }^{\star}$ gelten, Beachtung finden. Mit der Form der Streitinszenierung ist vor allem die kommunikative Vermittlung von Polemik gemeint, denn um Polemik in allen Schriften gleichermaßen untersuchen zu können und verschiedene Formen der Streitinszenierung erkennbar zu machen, erscheint es sinnvoll, einen Schritt für die analytische Textarbeit zu entwickeln, der zwischen der Betrachtung des Aufbaus des gesamten Textes und der Rhetorikanalyse einzelner Textpassagen liegt und insbesondere die polemische Situation als Kommunikationsrahmen ins Zentrum rückt.

Noch vor einer detaillierten Analyse einzelner rhetorischer Strategien können so bereits Erkenntnisse aus der Kommunikationssituation von Polemik gezogen werden, da die Art der Streitinszenierung bzw. die Gestaltung der polemischen Situation unterschiedliche polemische Strategien mit sich bringt. Die unterschiedlichen Ausformungen des Kommunikationsrahmens werden hier als Formen des Polemisierens bezeichnet. Der substantivierte Infinitiv des Verbs ,polemisieren' ist für die Benennung der einzelnen Kategorien bewusst gewählt worden, um ihren prozessualen, transportierenden Charakter zu betonen, denn unter ihnen sollen Wege der Kommunikation von Polemik und nicht die Polemik selbst verstanden werden.

Um die Funktionen der Polemik in Texten des Streits im Allgemeinen und in Melchior Hoffmans Schriften im Besonderen besser ergründen zu können, werden zunächst die verschiedenen Arten der PolemikVermittlung auf zwei Ebenen identifiziert. Die erste Ebene betrifft die Beziehung zwischen Text und Kontext, die zweite Ebene allein den Text. Der Trennung der beiden Ebenen entsprechend werden zum einen Formen offenen oder verdeckten Polemisierens sowie zum anderen Formen direkten oder indirekten Polemisierens klassifiziert. ${ }^{293}$ Im fol-

293 Es sei an dieser Stelle darauf hingewiesen, dass die Kategorien dieser Arbeit in keiner Relation zu den Kategorien „Explicit and Implicit polemics“ (alternativ auch als „direct“ und „indirect“ bezeichnet), „Hidden polemics“ und „Seemingly hidden polemics“ bei Yairah Amit stehen. Amit konzentriert sich bei ihrer Klassifizierung auf das polemische Thema (sie nennt es „polemical subject“): Unter „Explicit polemics“ versteht sie Fälle, in denen sowohl ein polemisches Thema als auch eine Stellungnahme zu dem Thema explizit sind (S. 56). „Implicit polemics“ hingegen bedeutet, dass zwar ein polemisches Thema explizit vorhanden ist, es aber keine klare Stellungnahme oder Haltung im Text dazu gibt (S. 57). „Hidden polemics“ bildet den Gegensatz zu den beiden bereits genannten Formen, denn in diesem Fall ist das polemische Thema versteckt bzw. wird nicht explizit oder gewöhnlichen Verfahren gemäß genannt (S. 93). Die Kategorie der „seemingly hidden polemics“ ist bei Amit 
genden Kapitel werden die Begriffe der unterschiedlichen Formen des Polemisierens eingeführt und anhand der polemischen Situation erklärt. Die angewandten Kriterien werden präzisiert und mögliche Funktionen angesprochen. Für die vorgeschlagene Klassifizierung ist die literarische Form zunächst zwar nicht ausschlaggebend, sie steht aber durchaus im Zusammenhang mit den einzelnen Arten des Polemisierens und wird deshalb bei den Textanalysen als komplettierendes Moment herangezogen werden. Die hier nachfolgende Klassifizierung bietet insofern einen ersten Ansatzpunkt für die Analyse polemischer Texte, an den sich weitere analytische Verfahren anknüpfen.

\subsubsection{Offenes und verdecktes Polemisieren}

Der Ansatzpunkt zur Unterscheidung einzelner Formen des Polemisierens ist die Ausformung der polemischen Situation eines Textes im Verhältnis zu seinem Kontext. Wie bereits erläutert, setzt sich die polemische Situation aus den vier einzelnen Bestandteilen Subjekt, Objekt, Thema und Instanz zusammen. ${ }^{294}$ Jürgen Stenzel erwähnt zwar beiläufig, dass die polemische Situation, die auf der Textebene konstruiert wird, nicht mit der ,realen' Schreibsituation des Autors, also der polemischen Situation auf der Kontextebene, übereinstimmen muss. ${ }^{295}$ Er entwickelt den Gedanken aber nicht weiter, ob und inwiefern eine Übereinstimmung oder Nichtübereinstimmung des polemischen Subjekts mit der „Realexistenz“ ${ }^{296}$ des Verfassers Auswirkungen auf die Polemik und ihr Wirkungspotential hat. Stenzel blendet den Punkt für seine weiteren Überlegungen zu einer Typologie der Polemik gänzlich aus. Paintner formuliert zwar deutlich, dass bei der polemischen Situation im Text „nicht die Rede von Verfasser und Publikum

schließlich eine versteckte Polemik, die allerdings so klare Zeichen gibt, dass das polemische Thema der „,silent" controversy“ keiner expliziten Formulierung bedarf (S. 22 I). Amit, Yairah (2000): Hidden Polemics in Biblical Narrative. Leiden: Brill. Amits Klassifizierung für die biblischen Erzählungen wird für diese Arbeit nicht verwendet, da sie auf die Polemik der Reformation nicht übertragbar ist. Die in dieser Arbeit entwickelten Bezeichnungen sind unabhängig von ihrer Arbeit entstanden.

294 Siehe dazu Kapitel 2.2.I Theoretische Grundlagen des Polemikbegriffs.

295 Stenzel erwähnt die Möglichkeit der Nicht-Übereinstimmung von polemischem Subjekt und dem Autor der Polemik lediglich in einer Fußnote: „Gemeint ist damit [mit dem polemischen Subjekt] zunächst der Autor. Ob und wieweit sich die Rolle des Polemikers, in die der Autor sich hineinschreibt, von seiner Realexistenz entfernt, müßte die Untersuchung des jeweiligen Einzelfalls ergeben." Stenzel (I984), S. 5, Anmerkung I I (Hervorhebungen im Original).

${ }^{296}$ Ebd., S. 5, Anmerkung I I. 
als ,tatsächlichen“ Personen ist“ und es sich vielmehr „bei allen an Polemik beteiligten Instanzen um in den jeweiligen Text eingeschriebene Rollen [handelt]“, ${ }^{297}$ verfolgt die hinter diesem Gedanken stehenden Implikationen aber ebenso wenig wie Stenzel. ${ }^{298}$ Auch Dieckmann denkt den angefangenen Gedanken Stenzels weiter, indem er konstatiert,

dass die in einem polemischen Text oder auch in einer ausgedehnten polemischen Kontroverse sich darstellende Figur immer mehr oder weniger gemäß den Erfordernissen der polemischen Zielrealisation modelliert wird und deshalb keine sicheren Rückschlüsse auf die empirische Person des Schreibers zuläßt, wie umgekehrt nicht angenommen werden darf, dass dieser sich unverstellt und ungebrochen im polemischen Text ausdrückte. ${ }^{299}$

Dieckmann empfiehlt in dem Zusammenhang, die „Diskrepanz zwischen Autor und Textfigur als den Normalfall anzusehen und lieber umgekehrt zu fragen, ob und wieweit man beide im Einzelfall miteinander identifizieren kann. "300 Er stimmt insofern mit Paintner überein, indem er es als sinnvoll erachtet,

den Stenzelschen Begriff der polemischen Situation auch terminologisch aufzuspalten in die (mit Einschränkungen) objektive, von außen betrachtbare Realsituation und die inszenierte polemische Konstellation, die der Polemiker in und mit seinem Text schafft $[\ldots] .{ }^{30 r}$

Dieckmann bestätigt hiermit die bereits erörterte Unterscheidung zwischen Textebene und Kontextebene.

Was jedoch trotz des Hinweises auf die „Diskrepanz zwischen Autor und Textfigur" nicht berücksichtigt wird, ist die Art der Diskrepanz. Der Beschaffenheit des Verhältnisses zwischen Inszenierung und

297 Paintner (201 I), S. 43.

${ }^{298}$ Zum Beispiel verpasst Paintner es, die Kategorien „Urheber und Drucker“ in ihren gleichnamigen Unterkapiteln unter dem Gesichtspunkt der Inszenierung zu problematisieren. Anonyme Veröffentlichungen erklärt sie mit dem Umgang mit der Zensur und argumentiert, es sei ,angebracht, [...] soweit möglich, die Urheber sozial zu verorten. “ Ebd., S. 234-237.

299 Dieckmann (2005), S. 37 f.

300 Ebd., S. 38.

${ }^{301}$ Ebd., S. 38 . Siehe auch die Herleitung: „Die von Stenzel in Hinblick auf das polemische Subjekt getroffene Unterscheidung zwischen ,Autor in seiner Realexistenz und ,Rolle des Polemikers im Text ' lässt sich analog auf alle anderen Elemente der polemischen Situation übertragen. In gleicher Weise bekommen nämlich auch das polemische Objekt, das polemische Thema, die polemische Instanz und die soziale Welt, in der die Auseinandersetzung stattfindet, eine doppelte Ausprägung. “ Ebd. (Hervorhebungen im Original). 
,Tatsächlichem‘ wurde insofern bisher geringe Beachtung geschenkt. Jedoch rechtfertigt sich die Beschäftigung mit ihr auf der Basis der Grundannahme, dass es Auswirkungen auf die Verwendung und das Funktionieren der Polemik hat, wenn die polemische Inszenierung, die ein Text darbietet, und die textexterne, ,reale ${ }^{6}$ polemische Kommunikationssituation übereinstimmen. Mögliche Fragen wären dementsprechend, ob und inwieweit die einzelnen Bestandteile der polemischen Situation (Subjekt, Objekt, Thema und Instanz) der Textebene jeweils auch Bestandteile der ,realexistenten' polemischen Situation sind, in die der Text eingebunden ist bzw. aus der heraus er entstanden ist. Die Konstruktion der textinternen polemischen Situation in Übereinstimmung mit oder in Diskrepanz zu der, Realsituation muss als strategisches Vorgehen des Autors betrachtet und von daher bei einer Polemikanalyse berücksichtigt werden. Vor allen Dingen spielt es eine Rolle für die Polemik, welche persona vom Autor als polemisches Subjekt inszeniert wird. ${ }^{302}$ Inwiefern sich diese These begründen lässt, wird im Folgenden anhand der unterschiedlichen Formen der Autorinszenierung, die in einem Ordnungssystem als ,offenes' und ,verdecktes Polemisieren'verortet werden, erörtert.

\section{Die Rolle der (In-)Kongruenz von Autor und polemischem Subjekt}

Das entscheidende Kriterium für die Differenzierung zwischen offenem und verdecktem Polemisieren ist die qualitative Kongruenz ${ }^{303}$ von Autor und polemischem Subjekt. Dieser Fokus ergibt sich daraus, dass das Verdecken der anderen drei Bestandteile entweder nicht ohne Funktionsverlust vorgenommen werden könnte - und damit zur paradoxen Auflösung von Polemik beitragen würde - oder keine Relevanz für die Funktion von Polemik besäße.

${ }^{302}$ Dabei ist zwar davon auszugehen, dass der Autor eine reale Person ist, deren Identität muss aber nicht zwingend bekannt sein. Anonymes und pseudonymes Publizieren sind dementsprechend auch als Inszenierungen zu verstehen.

303 Eine qualitative Kongruenz könnte man graphisch so darstellen: $\mathrm{X}^{\text {Kontext }}=\mathrm{X}^{\mathrm{Text}}$. Im Gegensatz dazu wäre eine qualitative Inkongruenz z. B.: $\mathrm{X}^{\text {Kontext }}=\mathrm{Y}^{\mathrm{Text}}$. Auch bei der qualitativen Kongruenz bleibt die bereits erwähnte Diskrepanz (Dieckmann) zwischen Autor und inszeniertem polemischen Subjekt vorhanden, da der Text immer eigenständiges Produkt und vom Kontext zu unterscheiden ist. Deshalb wird nachfolgend darauf verzichtet, durchgehend auf diese Form der (In-)Kongruenz hinzuweisen. Was folglich genau unter ,Kongruenz ${ }^{`}$ zu verstehen ist, wird im weiteren Verlauf des Kapitels ausführlich erklärt. 
Zunächst einmal muss Polemik prinzipiell ein polemisches Objekt im Auge haben, das identifiziert werden kann, d. h. das Objekt der Textebene kann zwar maskiert oder versteckt sein, notwendige Bedingung für das Funktionieren von Polemik ist doch eine mögliche Demaskierung oder Dekodierung durch die Leserschaft, also eine klare Verbindung zwischen Text- und Kontextebene, zwischen polemischem Objekt und der ,realexistenten' polemischen Zielscheibe (eine Person, Gruppe oder Institution, gegen die sich die Polemik richtet). Ohne die Möglichkeit der Identifikation des polemischen Objekts kann es zu keiner Meinungsbildung kommen, so dass die Polemik ihre Funktion verliert, einen polarisierenden Antagonismus bzw. „säkularisierten Manichäismus"304 vor einem Publikum zu entwerfen.

Für das polemische Thema gelten die gleichen Bedingungen, denn nur, wenn die ,Übersetzung' des Themas, über das gestritten wird, gelingt, kann die Polemik ihrer Funktion entsprechend erfolgreich sein. Würde der Transfer des polemischen Objekts oder des polemischen Themas zwischen Text und Kontext gestört, höbe sich die Polemik selbst als zweckgesteuerte Methode auf und würde so zu einer Paradoxie.

Der Transfer des Streitgegenstands ist hingegen etwas schwierigerer zu identifizieren, denn die Kongruenz eines polemischen Themas auf Text- und Kontextebene ist nicht eindeutig zu belegen. Es gibt zwei Wege, wie man ihr logisch auf den Grund gehen kann: mittels der Annahmen, dass entweder eine eventuelle Übereinstimmung der polemischen Akteure auf beiden Ebenen ebenfalls eine thematische Kongruenz mit sich bringt, oder dass das Thema der Textebene automatisch in die Kontextebene übertragen wird - in dem Fall muss es gleichwohl Schlüsselinformationen im Text geben, die eine Einbettung in den Kontext möglich machen. Unterstützend lässt sich in dem Zusammenhang das Verständnis von Kultur (welche hier unter ,Kontext' einzuordnen ist) als Produkt performativer Handlungen und Kulturpraktiken und insofern auch von Texten heranziehen. Ausgehend von der kulturkonstruierenden und -reproduzierenden Funktion von Texten lässt sich begründen, dass das im Text eingeschriebene Thema sich in einem wechselseitigen Austausch auf den Kontext überträgt.

Stenzels Begriff des polemischen Themas bleibt aber dennoch eine schwierige und unkonkrete Kategorie der polemischen Situation, da es sich generell nur schwer ermitteln lässt, welches das polemische Thema

304 Stenzel I984, S. 7 
ist, um das eigentlich gestritten wird. ${ }^{305}$ Insbesondere bei Schriftwechseln kann das Thema variieren oder sich schließlich völlig auf eine Metaebene verlagern, ${ }^{306}$ so dass das polemische Thema eines Schriftenwechsels im Prinzip dann nicht mehr eindeutig zu erkennen ist. Dies kann z. B. anhand des Streitschriftenwechsels, den Hoffman mit Amsdorf I 528 führte, deutlich gemacht werden. Grundsätzlich wird in den Schriften das polemische Thema der Datierung der Apokalypse verhandelt, was in einer Debatte mündet, ob die Datierung überhaupt rechtmäßig sei. Im weiteren Verlauf geht es unter anderem darum, ob Hoffman die Datierung mit Bibelstellen untermauern könne, ob Amsdorf die richtigen Bibelstellen auslege usw. Die daraus resultierende Frage nach dem polemischen Thema kann entsprechend vielfältig ausfallen: Ist die Apokalypse das polemische Thema? Ist es die Datierung der Apokalypse oder die Rechtmäßigkeit der Datierung? Beim Fortschreiten des Schriftwechsels geht es den beiden schließlich nur noch darum, wer von beiden die Wahrheit sagt. Hoffman und Amsdorf gelangen so im Verlauf des Streits immer mehr auf eine Metaebene, auf der die Regeln des Streitens offen diskutiert werden.

Ob die Metaebene und die einzelnen Etappen Varianten eines Themas sind oder sie jeweils unterschiedliche polemische Themen darstellen, ist fraglich. Wo die Grenze eines polemischen Themas liegt, ist unklar; zumindest gibt Stenzel bei der Einführung seines Denkmodells der „polemischen Situation“ “ 07 darüber keinen Aufschluss. Es wäre dem Modell insofern anzukreiden, dass es das polemische Thema im Verlauf eines Streits nicht in seinen Nuancen erfassen kann. Eine anschauliche Verlaufsbeschreibung der Streitsache bietet sich mithilfe

305 Vgl. dazu Paintner, die zu Recht anmerkt, dass Stenzel den in der polemischen Situation zentralen Begriff des ,polemischen Themas' ad absurdum führt, „zumal Stenzel Polemik als Rede definiert, in der ,unsachlicher Stil dominiert' [Stenzel I 984 , S. 4], die also, so muß man wohl verstehen, vorrangig nicht auf das polemische Thema als ,Sache' bezogen ist. " Paintner (20II), S. 44.

306 Vgl. dazu: „Wenn die Kontrahenten in der zu erörternden Streitsache nicht weiter kommen, sich nicht einigen oder wenigstens aufeinander zu bewegen können, beschuldigen sie sich gegenseitig rhetorischer Schein- oder Betrugsmanöver. Häufige Beschuldigungen sind, daß der Gegner sophistische Strategien verwende und mit fucus verborum seine Absichten verschleiere. " Mahlmann-Bauer, Barbara (20I0): „,Luther gegen Eck, Luther gegen Erasmus und Castellio gegen Calvin“. Die Normalform reformatorischer Streitgespräche und die Entgleisung eines innerprotestantischen Streits“. In: Laureys, Marc \& Roswitha Simons (Hg.): Die Kunst des Streitens. Inszenierung, Formen und Funktionen öffentlichen Streits in historischer Perspektive. Göttingen: V\&R unipress, S. I67-2 I 8, hier S. I75.

307 Stenzel (1984), S. 5-7. 
von Stenzels polemischer Situation dementsprechend nicht an. Überaus wertvoll zeigt das Denkmodell sich indessen, um in einer synchronen Betrachtung den jeweiligen Streitstatus näher zu beleuchten. So ermöglicht es jeweils synchrone Schnittstellen eines Streitverlaufs (z. B. Untersuchungen von Einzelschriften oder Textabschnitten) zu erstellen, die wiederum zu einer vergleichenden diachronen Betrachtung mit anderen Schnittstellenanalysen beitragen können. Das Problem der Abgrenzung eines polemischen Themas kann durch dieses Vorgehen hingegen nicht gelöst werden, da es bei einer Streitanalyse retrospektiv identifiziert werden muss. Einer fundierten Untersuchung obliegt es, das polemische Thema für eine bestimmte Schnittstelle zu ermitteln, es mit Themen anderer untersuchter Schnittstellen zu vergleichen und eventuelle Abweichungen zu bewerten: Handelt es sich noch um dasselbe oder ein neues Thema?

Das polemische Thema bleibt insofern eine abstrakte, schwer fassbare Größe, die im analytischen Verfahren punktuell identifiziert werden muss. Dafür, von einem Themenwechsel zu sprechen, würde jedoch plädieren, dass ein Schriftwechsel im Grunde eine Änderung des polemischen Themas impliziert, denn jede Seite versucht jeweils das Thema in eine andere, der eigenen Person dienlichen Richtung zu steuern. Auch verhindern neue thematische Impulse das Abebben eines Schriftwechsels bzw. das Abklingen des Streits.

Bei der polemischen Instanz ist eine Übereinstimmung der Textund der Kontextebene generell nicht von Relevanz. Eine Rezeption ist zwar Voraussetzung für eine Wirkung der Polemik, die schließlich ,reale' Leserschaft ist aber nicht in der textinternen polemischen Situation angelegt. Wichtig für die Polemik ist allein die Konstruktion der polemischen Instanz im Text: Ob die polemische Instanz des Textes eine mögliche Übereinstimmung mit einem potenziellen Publikum der Kontextebene suggeriert oder ob die Instanz nicht oder fiktiv definiert ist, verändert die Kommunikationssituation und somit die Streitinszenierung. ${ }^{308}$ Möglich wäre zum Beispiel, dass die polemische Instanz weder angesprochen noch auf irgendeine Weise erwähnt wird oder dass sie eine vom Autor entworfene Fiktion ist. Selbst bei einem möglichen Kontextbezug bleibt das auf Textebene vom Publikum entworfene Bild (die Inszenierung der polemischen Instanz) von den ,realexistenten` Rezipienten zu unterscheiden.

${ }_{308}$ Dies kann z. B. durch Widmungen an Obrigkeiten oder Anreden an die Bewohner einer bestimmten Stadt sein. 
Anders verhält es sich dagegen mit dem Transfer des polemischen Subjekts zwischen Text- und Kontextebene. Zeigt der Autor einer polemischen Schrift sich auch gleichzeitig als polemisches Subjekt, bleibt für die Textebene nur die Inszenierung der eigenen Person, denn mit der Entscheidung, sich selbst als polemisches Subjekt auf der Textebene einzusetzen, trifft er gleichzeitig eine Entscheidung für eine Reihe daran geknüpfter Inszenierungsbedingungen sowie -potentiale. ${ }^{309}$ Gleiches gilt für die andere Alternative, die Autorschaft durch Einsatz eines nicht mit sich übereinstimmenden polemischen Subjekts auf der Textebene zu verdecken, denn auch solch eine Inszenierung unterliegt bestimmten Bedingungen. Folglich rechtfertigt sich eine genaue Unterscheidung dieser unterschiedlichen Verhältnisse zwischen Autor und polemischem Subjekt. ${ }^{\text {10 }}$

\section{Offenes Polemisieren}

Die Kommunikationsssituation der Polemik, bei der der ,reale' Autor zum polemischen Subjekt des Textes analog ist bzw. bei der eine qualitative Kongruenz der beiden vorliegt, wird aufgrund der Offenlegung der ,Identität' des Autors, der als polemisches Subjekt im Text ,auftritt', unter dem Begriff des offenen Polemisierens gefasst. ${ }^{31 \mathrm{II}}$ Das für die Beschreibung des Verhältnisses verwendete Adjektiv , analog' (alternativ in den folgenden Ausführungen auch ,deckungsgleich', ,konform‘, ,kon-

${ }^{\circ 09}$ Vgl. dazu: „Dabei zeigt sich, daß in vielen Fällen die Verfasserrolle bewußt inszeniert und die Lesererwartung in eine bestimmte Richtung gelenkt wird; bereits im Nennen oder Verschweigen eines Namens, Titels oder offensichtlichen Pseudonyms auf dem Titelblatt äußert sich ein Versuch der Rezeptionssteuerung, der dem argumentativen Gesamtziel des Textes dient.“ Paintner (20II), S. 40.

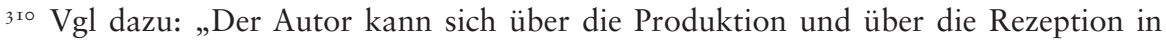
seinem Werk konstituieren. Es ist folglich zu untersuchen, wie der Autor seine Autorvorstellung im Text sprachlich realisiert und inwiefern diese Autorvorstellung mit dem Erzähler-Ich verbunden ist." Unzeitig, Monika (2010): Autorname und Autorschaft. Bezeichnung und Konstruktion in der deutschen und französischen Erzählliteratur des I 2. und I3. Jahrhunderts. Berlin \& New York: De Gruyter, S. 205. Obwohl der Untersuchungsgegenstand Unzeitigs ein anderer ist und der Erzähler durch die Rolle des polemischen Subjekts zu ersetzen wäre, ist ihre Forderung auch für das Text-Kontext-Verhältnis von Autor und textinterner Autorkonstruktion in polemischen Texten sinnvoll, denn die Art der Autorinszenierung zieht weitere Konsequenzen für die Polemikvermittlung nach sich.

${ }^{311}$ Die Wahl der Bezeichnungen der Kategorien ,offenes` und ,verdecktes` Polemisieren ist in Anlehnung an die Namensgebung der Kategorien der offenen (overt) und verdeckten (covert) Intermedialität bei Wolf, Werner (I999): The Musicalization of Fiction. A Study in the Theory and History of Intermediality. Amsterdam: Rodopi, S. 37-44 getroffen worden. 
gruent', ,übereinstimmend' usw.) kann von seiner Bedeutung ausgehend nur ungenau beschreiben, in welchem Nexus sie zueinander stehen. Die hier aufgezählten Adjektive vermögen die komplizierte, ambivalente Verbindung dieser auf zwei verschiedenen Ebenen angesiedelten Subjekte, nicht widerzuspiegeln. ${ }^{312}$ Es ist dem verzwickten Verhältnis von Selbstinszenierung und Selbst, ${ }^{313}$ also dem komplexen Prozess der Identitätskonstruktion im Spannungsfeld von Eigenkonstruktion und sozialer Wirklichkeit zuzuschreiben, dass die Grenzen zwischen Verbinden und Trennen, zwischen Kongruenz und Differenz, unscharf sind. Trotz dieser formulierten Vorbehalte gegenüber einer simplifizierenden Gleichung, soll hier dennoch das Gemeinsame, also die (qualitative) Übereinstimmung zwischen der Inszenierung auf Textebene und dem ,real' existenten Autor auf Kontextebene, betont und die angesprochene Diskrepanz zwischen beiden zunächst in den Hintergrund gerückt werden. Die Inszenierung, die auf der Textebene stattfindet, ist demnach immer mit ihren kontextuellen Umständen zu betrachten, was Paintner wie folgt erklärt:

Innerhalb der einzelnen Texte handelt es sich [...] um einen inszenierten Dialog. Polemisches Subjekt und Objekt sind nicht reale Personen in einem tatsächlichen Gespräch, sondern Rollen, die vom jeweiligen Verfasser in den Text eingeschrieben werden. Aus den einzelnen Texten entstehen jedoch publizistische Debatten; der ,Gegner', der auf der Ebene des Einzeltexts eine Rolleninszenierung ist, hat in der Realität durchaus die Möglichkeit, die Publikation durch eine Gegenschrift zu erwidern..$^{314}$

Paintner macht deutlich, dass sich der Gegner auf den zwei bereits genannten Ebenen (Text- und Kontextebene) manifestiert. Ohne es

${ }^{\text {I2 }}$ „Der Autor ,im Text ${ }^{6}$ ist demzufolge nicht als biographischer Verweis auf den ,realen'Autor zu interpretieren, sondern als Repräsentation des Autors und seiner Autorschaft. Gemeint ist damit die Vorstellung, die der ,reale' Autor von sich und seiner Autorschaft im Text etabliert, also ein sprachlich realisiertes Autorbild, das sich mit dem Autornamen verbindet.“ Unzeitig (2010), S. 203.

${ }_{313}$ Vgl.: „Inszenierung ist [...] nicht konträr zur Authentizität oder Wesenhaftigkeit einer Person zu setzen, vielmehr enthüllt sich eine Person immer auch bzw. überhaupt erst in der Inszenierung. Dabei ist der/die Einzelne immer auf Medien angewiesen [...].“ Becker (2004), S. 4I6.

${ }^{114}$ Paintner, Ursula (20I0): „Aus der Universität auf den Markt. Die disputatio als formprägende Gattung konfessioneller Polemik im I6. Jahrhundert am Beispiel antijesuitischer Publizistik“. In: Gindhart, Marion \& Ursula Kundert (Hg.): Disputatio I 200-I800. Form, Funktion und Wirkung eines Leitmediums universitärer Wissenskultur. Berlin: De Gruyter, S. I29-I 54, hier S. I44 (Hervorhebungen im Original). 
direkt anzusprechen, thematisiert ihre Aussage jedoch jene Art der polemischen Publizistik, die hier unter dem Sammelbegriff des offenen Polemisierens gefasst wird, da sie implizit von einer (qualitativen) Kongruenz der beiden Ebenen ausgeht. Nur im Falle des offenen Polemisierens ist die Voraussetzung gegeben, dass der auf Textebene angesprochene Gegner dem ,realen' Urheber der Polemik antworten kann, denn die Bedingung, dass der Verfasser der ersten Schrift sich offen zeigt und identifizierbar ist, muss erfüllt sein. Bei der Untersuchung der Schriften Melchior Hoffmans zeigt sich diese Art des Polemisierens insbesondere bei dem polemischen Schriftwechsel mit Nikolaus von Amsdorf, in dem sich beide Kontrahenten offen zeigen, d. h. die beiden Verfasser inszenieren sich auch jeweils in ihren Schriften als die polemischen Subjekte Melchior Hoffman und Nikolaus von Amsdorf. Der gesamte polemische Austausch der beiden Kontrahenten ist infolge der offen polemisierenden Initiationsschrift Amsdorfs in dieser Art der Vermittlung verblieben, da Hoffman ebenfalls offen polemisierend antwortet.

Zwar kann eine polemische Schrift auch beantwortet werden, wenn verdeckt polemisiert wird und der Verfasser ein von sich selbst (qualitativ) differierendes polemisches Subjekt im Text konstruiert. Jedoch sind die Möglichkeiten der Bezugnahme auf den Gegner dann auf die textinterne Inszenierung begrenzt, d. h. die Gegenschrift kann lediglich auf die Informationen reagieren, welche die polemische Schrift preisgibt. ${ }^{35}$ Beim offenen Polemisieren hingegen hat der Verfasser einer Gegenschrift mehrere Möglichkeiten: Er kann zum einen auf die textinterne Inszenierung und zum anderen auf sämtliche textexterne Informationen zur Person und deren Handlungen Bezug nehmen. Darüber hinaus bietet sich zudem noch die Option, die Selbstinszenierung als polemisches Subjekt (Textebene) mit dem, was als ,Realexistenz' des Autors aufgefasst wird (Kontextebene), abzugleichen. Eventuelle Diskrepanzen zwischen dem konstruierten Selbstbild und dem Bild des Verfassers, das aus dem Kontextwissen generiert wird, können infolgedessen aufgedeckt werden.

Die Situation einer (qualitativen) Kongruenz von Text- und Kontextebene, von Autor und polemischem Subjekt, erscheint naheliegend für die Polemikvermittlung, wenn man von einer gewöhnlichen Kommunikationssituation im Streit ausgeht, in der sich mindestens zwei Akteure, die sich hinsichtlich eines Sachverhalts uneinig

${ }_{315}$ Ausführungen dazu folgen im Abschnitt Verdecktes Polemisieren in diesem Kapitel. 
sind, offen miteinander auseinandersetzen. Die Kongruenz der beiden Kommunikationsebenen beim offenen Polemisieren lässt wenig Raum für Ambiguitäten oder Fehlinterpretationen in Bezug auf den Streitgegenstand oder die beteiligten Akteure, so dass die Streitinszenierung geringer Erklärung bedarf. Weitaus komplexer gestaltet sich der Fall, wenn die Kommunikationssituation der Text- und der Kontextebene nicht analog sind und das polemische Subjekt somit nicht mehr (qualitativ) kongruent mit dem Autor ist, sondern von der Textebene in die Kontextebene ,übersetzt ${ }^{\star}$ werden muss.

\section{Verdecktes Polemisieren}

Während beim offenen Polemisieren ein Autorbild im Text konstruiert wird, das eine Analogie zum ,realen' Autor anstrebt, zeigt sich beim verdeckten Polemisieren hingegen das Potential, jegliche Kongruenz von beiden zu vermeiden und den Urheber des Textes durch ein anderes Autorbild im Text zu verbergen. ${ }^{316}$ Der Autor schreibt sich demnach nicht als polemisches Subjekt in den Text ein, sondern es wird suggeriert, dass letzteres ein vom ,realexistenten' Autor unabhängiges Subjekt ist. Es entsteht der Eindruck, dass der Urheber der Schrift ein anderer sei, als derjenige, der eigentlich der ,reale' Autor ist. Erneut ist zu beachten, dass der ,realexistente“ Autor und das „sprachlich realisierte[] Autorbild “ 317 im Text im Allgemeinen nicht gleichzusetzen sind. Erneut ist jedoch auch zu betonen, dass die Inkongruenz, die entsteht, wenn eine mögliche Verbindung (durch z. B. den gleichen Namen) wegfällt, eine andere Wertigkeit besitzt als die Diskrepanz zwischen ,realem ‘ Autor und Autorkonstruktion im Text, die selbst bei Namensgleichheit verbleibt. Fällt ein analogiebildendes Indiz (wie z. B. der Name) weg, bleibt der Verfasser hinter einer Art Maske verdeckt, so dass das TextKontext-Verhältnis sich durch eine vollständige qualitative Inkongruenz auszeichnet: Das polemische Subjekt der Textebene ist nicht auf den ,realen'Autor zurückzubeziehen.

Bei genauer Betrachtung lassen sich drei Möglichkeiten finden, wie ein Autor seine Identität als „Texterzeugungsinstanz““ ${ }_{318}$ auf Textebene verdecken kann: Indem er erstens anonym bleibt, zweitens unter einem Pseudonym (fiktive persona) auftritt oder sich drittens als eine andere Person ausgibt bzw. unter anderem Namen (,realexistente' persona)

\footnotetext{
${ }^{16}$ Vgl. dazu Umzeitig (2010), S. 202-205.

317 Ebd., S. 203.

318 Ebd., S. 204.
} 
veröffentlicht. Bei der anonymen Veröffentlichung ist das polemische Subjekt auf Textebene eine Leerstelle, denn weder wird das polemische Subjekt im Text benannt, noch ein Verfasser im Paratext ${ }^{319}$ angegeben. Im Idealtypus ${ }^{320}$ einer anonymen Veröffentlichung wird bei der Publikation keinerlei Information über den Verfasser der Schrift gegeben, weder textintern noch -extern. ${ }^{32}$ Infolgedessen ist die Ebene der Text-Kontext-Verbindung gänzlich blank oder vage und bleibt so offen für Interpretationen der Leserschaft. Ein konkretes Vorwissen über den Autor, sein Anliegen, seine Vergangenheit, seine Handlungen etc. werden dabei mit Absicht verschleiert. Zum Beispiel veröffentlichte Melchior Hoffman I 529 zusammen mit Andreas Bodenstein von Karlstadt anonym die Schrift DJalogus vin gründtliche berichtung gehaltner disputation im land zu Holsten, ${ }^{322}$ die als (Reformations-)Dialog zwischen zwei fiktiven Figuren konzipiert ist. Da sich das Gespräch der beiden Figuren als Bericht über die Flensburger Disputation, in der Hoffman seine religiösen Lehren vor Bugenhagen u. a. zu verantworten hatte, entpuppt, versucht die anonyme Veröffentlichung eine objektive Position des Autors (zu Melchior Hoffman und den Geschehnissen) zu suggerieren. Für die Polemik, die im Dialogus gegen Hoffmans Kontrahenten geäußert wird, wirkt die Anonymität insofern unterstützend, weil sie Glaubwürdigkeit generiert.

319 Vgl. Genette, Gérard (200I): Paratexte. Das Buch vom Beiwerk des Buches. Frankfurt/Main: Suhrkamp.

${ }^{320}$ Unter ,Idealtypus‘ (ebenso, idealtypisch') wird eine potenziell mögliche Reinform verstanden, die als heuristisches Hilfsmittel zu Kategorisierungszwecken dient. Weder gibt der Begriff ,Idealtypus‘ eine Wertung ab, noch sagt er etwas über eine reale Existenz in der Wirklichkeit aus.

${ }^{321}$ Ein nachträgliches Autorbekenntnis oder ein Nachweis der Autorschaft durch Forschungen Dritter und andere Fälle, bei denen die Anonymität nachfolgend aufgehoben wird, sind zweifelsohne möglich. Solche Fälle sollen hier allerdings ausgeblendet werden, da es vorrangig darum geht, die bewusst angelegten Informationen im Zeitraum der Publikation zu betrachten, denn performative Handlungen haben nach Sibylle Krämer immer einen „Ereignischarakter“. D. h. trotz der im Akt und in der Wahrnehmung verwobenen „Elemente sowohl des Reproduktiven wie des Planvollen“, steht das singuläre „In-Szene-Setzen“, gebunden an eine bestimmte „Raum-Zeit-Stelle“ im Zentrum. Krämer (2004), S. 2 I (Hervorhebung im Original).

322 Anonymus [i. e. Melchior Hoffman und Andreas Rudolf Bodenstein von Karlstadt] ( I 529): DJalogus v $\bar{n}$ gründtliche berichtung gehaltner disputation im land zü Holsten vnderm Künig von Deñmarck vom hochwürdigen Sacrament oder Nachtmal des Herren. In gegenwertigkeit Kü.Ma.Sun Hertzog Kersten sampt Kü.Räten / vilen vom Adel / vnd grosser versamlung der Priesterschafft. Jetzt kurtzlich geschehen den andern Donderstag nach Ostern / im jar Christi. Als man zalt. M. D. xxix. Straßburg: Balthasar Beck, A2v. Kurztitel: Dialogus. 
Ist das polemische Subjekt auf der Textebene (inkl. der Paratexte) mit einem Pseudonym gekennzeichnet, entsteht eine andere Situation als bei der anonymen Veröffentlichung. Ein Pseudonym ist ein bewusst eingesetzter Deckname, der zwar vorgibt, einen ,realexistenten' Referenten zu besitzen, in Wirklichkeit aber ein selbstreferenzielles Zeichen ohne außersprachliches Pendant ist, d. h. das Pseudonym täuscht eine entsprechende Person auf Kontextebene vor, die es nicht gibt. ${ }^{323}$ Die Verbindung der Textebene mit der Kontextebene ist folglich eine Pseudoverbindung: Es wird zwar angedeutet, dass ein Autor auf der Kontextebene identifizierbar sei, aber der Name führt in eine referenzielle Leere. Diese Art der Suggestion eines Kontext-Bezugs im Text soll an dieser Stelle als ,Kontextfiktion' bezeichnet werden. Im Gegensatz zum ,Realkontext` erscheint die Kontextfiktion als eine dem Text eingeschriebene textexterne Referenz auf jemanden, der realiter nicht existiert - der Kontext wird lediglich fingiert. Die Verschleierung besteht insofern auf Text- und Kontextebene: Zum einen wird eine Autorrolle im Text fingiert, die den eigentlichen Autor verdeckt, zum anderen hat diese Autorrolle zudem einen fiktiven Referenten und kann auch auf der Kontextebene nicht identifiziert werden. Wie beim anonymen Veröffentlichen bedingen diese Umstände, dass die Leserschaft nur begrenzt ihr Vorwissen aktivieren kann. Zwar kann das Pseudonym eine Botschaft enthalten (der Nachname ,Bauer' z. B.), sie ist aber immer eine vom Autor angelegte Information und somit Teil der Inszenierung. ${ }^{324}$ Ein von der Inszenierung unabhängiges Vorwissen bzw. Vor-Urteil, das auf Kontextebene bereits besteht, ist nicht abrufbar, insbesondere nicht für den eigentlichen Urheber der Schrift, der sich hinter dem Pseudonym verbirgt.

Die dritte Form des Verschleierns der Autoridentität beim verdeckten Polemisieren ist die Veröffentlichung unter anderem Namen. In Abgrenzung zum Pseudonym wird bei dieser Variante unter dem Deckmantel einer anderen, im ,Realkontext ${ }^{`}$ existierenden Person veröffentlicht. Diese Person kann z. B. ein Herausgeber sein, der stellvertretend genannt wird. Möglich ist aber auch, dass der Name einer anderen

${ }^{323}$ Melchior Hoffman veröffentlichte Schriften unter dem Pseudonym Caspar Beck(er) und täuschte damit einen Autor vor, der in der Realität nicht existent war.

324 Ein berühmtes Beispiel für diese Art des Verdeckens der Autoridentität sind die sogenannten Dunkelmännerbriefe. Der oder die Autor/en bleiben unbekannt, auf der Textebene werden aber Dominikanermönche als Verfasser der Briefe inszeniert. 
Person als Autorname instrumentalisiert wird. ${ }^{325}$ Für das Wirken von Polemik kann das Publizieren unter anderem Namen legitimierende oder autorisierende Funktionen haben, wenn z. B. der vorgetäuschte Autor oder der Herausgeber mehr Prestige oder Berechtigung besitzen. Bei der Verwendung eines anderen Namens wird so in der Regel auf vorhandenes kontextuelles Vorwissen (über die genannte Person)

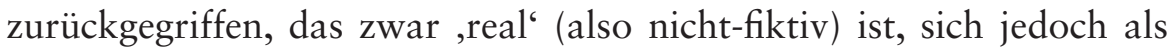
,falsch' in Bezug auf den ,realen'Autor erweist. ${ }^{326}$

Alle drei Formen des verdeckten Polemisierens haben den Effekt, dass der, reale' Autor unerkannt bleibt. Für die Vermittlung der Polemik bedeutet das, dass der Polemiker sich ungeachtet seines eigenen Images äußern kann. Er muss seine eigene Person, seinen Status und seine Handlungen nicht erklären, legitimieren oder rechtfertigen, wenn er den Gegner angreift. Beim anonymen Veröffentlichen entsteht in Bezug auf den Autor eine Leerstelle, bei Verwendung eines Pseudonyms eine ,Kontextfiktion“ an ebendieser Stelle und bei der Veröffentlichung unter anderem Namen füllt das Image des Anderen den Platz aus.

Ein extrem wichtiger Punkt ist, dass der Autor beim verdeckten Polemisieren über sich selbst in der 3. Person sprechen kann und so in der Schrift für sich die Perspektive entwerfen kann, die wie die eines Außenstehenden erscheint. Die so umgestaltete Bewertungssituation hat zur Folge, dass sich auch die Möglichkeiten der Konstruktion des Selbstimages grundlegend verändern.

325 Hoffman hat z. B. höchstwahrscheinlich Die Epistel des Apostell Sanct Judas, dessen Vorrede als von Cornelius Poldermann verfasst angegeben wird, geschrieben und publizieren lassen. Poldermann, Cornelis [i. e. Melchior Hoffman, Cornelius Poldermann (Hg.)] (I 534): Die Epistel des Apostell Sanct Judas erklert vnnd gantzs fleissig von wort zü worten / außgelegt zu eyner ernsten warnungen ia auch zu eynem kostlichen nutz und trost / allen Gotts forchtigen liebhabern der ewigen vnendlichen warheyt. [Hagenau: Valentin Kobian]. Abgedruckt in den TAE II, Nr. 479, S. 24I-245. Fritz Husner äußert wage den Verdacht, dass Melchior Hoffman der Autor dieser Schrift sei. Husner, Fritz (I946): „Zwei unbekannte Wiedertäuferdrucke“. Stultifera navis 3, S. 84-88. Peter Kawerau bestätigt diese Vermutung: Kawerau, Peter (1958): "Zwei unbekannte Wiedertäufer-Drucke“. Zeitschrift für Kirchengeschichte 69, S. I2 I-I26.

${ }^{326}$ Zur Verdeutlichung: $\mathrm{X}^{\text {Kontext }}$ (,reale' Person) ist der Autor, jedoch wird Y Yontext (,reale' Person) als polemisches Subjekt $\mathrm{Y}^{\text {Text }}$ eingesetzt. Durch die Inszenierung (Y für $\mathrm{X})$ kann ein eventuell vorhandenes Vorwissen über $\mathrm{Y}^{\text {Kontext }}$ aktiviert werden. Diese potenziellen Kenntnisse entsprechen jedoch nicht $\mathrm{X}^{\text {Kontext }}$, es wird insofern eine ,falsche“ Kontextreferenz evoziert. Diese falsche Referenz ist immer noch Teil der Inszenierung. 


\section{Konstruktion des Selbstimages}

Der Aufbau eines Images des polemischen Subjekts gehört generell ebenso zur polemischen Situation wie die Zerstörung oder Manipulation des Fremd- oder Feindimages des polemischen Objekts. ${ }^{327}$ Bei offenem Polemisieren erfolgt die Imagekonstruktion auf Seiten des polemischen Subjekts jedoch anders als bei verdecktem Polemisieren, da durch die Kongruenz von polemischem Subjekt und,realem' Autor bereits ein Image oder mehrere Images bestehen können, d. h. wenn das polemische Subjekt eine Selbstinszenierung des ,realen' Autors ist, bildet dessen bereits bestehendes Image eine potenzielle Deutungsgrundlage für die Rezeption der Inszenierung des polemischen Subjekts. ${ }^{328}$ Die Inszenierung im Text muss sich dementsprechend innerhalb der Grenzen befinden, die sowohl durch die mediale Vermittlung ${ }^{329}$ als auch durch die Identität (des, realen' Autors) im Spannungsfeld von produktiven „Acts of Identity “33० und rezeptiver Identitätskonstruktion (durch die Leserschaft) gesetzt werden. ${ }^{33}$ Bei der Produktion ist die soziale Wirklichkeit des Autors unvermeidlich präsent und wird folglich zu einem Teil der Selbstinszenierung, denn

[d]ie narrativen Strukturen sind keine Eigenschöpfung des Individuums, sondern im sozialen Kontext verankert und von ihm beeinflusst, so dass ihre Genese und ihre Veränderung in einem komplexen Prozess der Konstruktion sozialer Wirklichkeit stattfinden. Insofern präformieren sie

327 Vgl. dazu: „Polemische Texte bleiben jedoch bei der Konstruktion von Feindbildern nicht stehen; das Wesen jeder Polemik besteht darin, daß sie eben nicht nur den Gegner argumentativ vernichtet, sondern daß zugleich auch dem Leser ein positives Gegenbild angeboten wird." Paintner (20II), S. 457.

${ }_{328}$ Die Deutungsgrundlage muss als theoretische Größe verstanden werden, denn die konkrete Umsetzung in der Praxis ist immer an die jeweils rezipierende Person und deren individuelles Vorwissen gebunden.

329 Vgl. dazu: „[D]ie den Medien jeweils inhärente Struktur prägt die Art der individuellen Inszenierung in grundlegender Weise. Das Individuum ist also der Eigengesetzlichkeit des Mediums unterworfen, mittels dessen es sich inszeniert.“ Becker (2004), S. 4 I 6.

$33^{\circ}$ Gehrke (2004), S. I I-I9.

${ }^{33}$ Vgl. dazu: „Vielmehr erfasst ,Performativität" eine Dimension aller kulturellen Praktiken im Spannungsverhältnis zwischen einem Ereignis und seiner Wahrnehmung; und zwar soweit dieses Verhältnis so beschrieben werden kann, dass das, was ein Akteur hervorbringt, von Betrachtern auf eine Weise rezipiert wird, welche die Symbolizität und Ausdruckseigenschaften dieses Vollzugs gerade überschreitet." Krämer (2004), S. 2 I. 
die Art und Weise, in der eine Person sich erzählen kann, und damit auch ihr Verständnis von sich selbst. ${ }^{332}$

Die Verankerung des sozialen Kontexts kann sowohl unbewusst als auch bewusst geschehen. Sie zeigt sich bewusst beim offenen Polemisieren, wenn der Autor Überlegungen anstellen muss, wie er sich im Verhältnis zu dem bereits bestehenden Image glaubwürdig in Szene setzt, sich legitimiert und seine Person positiv gestaltet. Das eventuell bereits bestehende Image kann für die Rezeption des im Text konstruierten Images eine wichtige Rolle spielen, denn die Leserschaft mag schon ,VorUrteile' gefällt haben, die nicht Teil der Inszenierung selbst sind oder dadurch hervorgerufen werden. ${ }^{333}$ Im Idealtypus oder Denkmodell ${ }^{334}$ des offenen Polemisierens nimmt das Vorwissen der Leserschaft dabei implizit und explizit Einfluss auf die Imagebildung im Text: Zum einen wird das antizipierte Vorwissen der Leserschaft bei der Textproduktion vom Autor mitbedacht, zum anderen wirken sich die tatsächlichen Vorurteile und -kenntnisse auf Seiten der Leser auf die Textrezeption aus. Folglich entsteht das Image des Autors (beim offenen Polemisieren) in der Wechselwirkung von Produktion und Rezeption. Rückwirkend kann ein bereits bestehendes Image auf diese Weise bestärkt, verändert oder widerlegt werden. Die Inszenierung im Text trägt dementsprechend wiederum zum Image bei, denn

[i]n dieser Re-Zitation können wir uns vom Zitierten zugleich distanzieren und es eben dadurch auch um- und neuinterpretieren. Kraft dieser dem Sprechen impliziten Struktur von Theatralität kann Mechanismus

${ }_{332}$ Kraus, Wolfgang (2002): „Falsche Freunde. Radikale Pluralisierung und der Ansatz der narrativen Identität“. In: Straub, Jürgen \& Joachim Renn (Hg.): Transitorische Identität. Der Prozesscharakter des modernen Selbst. Frankfurt/Main: Campus, S. I 59-186, hier S. I6I.

333 Bei verdecktem Polemisieren können bestimmte Vorurteile als Teil der Inszenierung bewusst hervorgerufen werden. Da allerdings das Text-Kontext-Verhältnis unbekannt ist, funktioniert die Inszenierung unabhängig von einer ,realen' Kontextebene, die die skizzierte Situation als Kontext-Realität bestätigen oder als konstruiert entlarven würde.

334 Insbesondere im Hinblick auf die begrenzte Öffentlichkeit des I6. Jahrhunderts muss hier von einem Idealtypus oder Denkmodell gesprochen werden, dass sich nicht immer eins zu eins auf die frühneuzeitliche Realität übertragen lässt. Es ist dennoch auch für das I6. Jahrhundert möglich, von Potentialen auszugehen, die von Fall zu Fall auf ihre Ausschöpfung oder Umsetzung hin untersucht werden sollten. Es bleibt z. B. zu fragen, ob ein Schriftwechsel als solcher rezipiert wurde, ob eventuell mündliche Begegnungen (Predigt etc.) stattfanden oder ob andere Kenntnisse über die Funktion und Persönlichkeit einer Person durch Mundpropaganda kursierten. 
und Macht des Überkommenen und Gewohnten immer auch unterlaufen werden. 335

In dieser Hinsicht kann auch die Selbstimagebildung als andauernder Prozess betrachtet werden, in den ein Autor beim offenen Polemisieren mit der Selbstinszenierung im polemischen Text einzugreifen sucht.

Beim verdeckten Polemisieren hingegen funktionieren die Imagebildungen des polemischen Subjekts und des, realen' Autors getrennt voneinander. Da die Text-Kontext-Kongruenz verdeckt ist, wird von den Rezipienten nicht die Verbindung zum ,realen` Autor hergestellt. Der Autor kann unter der Maske des polemischen Subjekts sein Selbstimage demgemäß vom Standpunkt eines Dritten aus konstruieren, was z. B. Distanz und Objektivität vortäuschen kann. ${ }^{336}$ Zwar ist auch in solch einem Fall ein Image des Polemikers bereits vorhanden, da es beim Nennen des Namens des Polemikers ebenfalls zur Aktivierung des kontextuellen Vorwissens oder vorhandenen Vorurteilen kommen kann, aber als außenstehender Beobachter der eigenen Identität befindet sich das undefinierte, fiktive oder als alter Ego präsentierte polemische Subjekt auf vorgetäuschter Augenhöhe mit dem ebenfalls außenstehenden Rezipienten, was die Justierung oder Bestätigung eines Images im Text glaubwürdiger erscheinen lässt. Das Sprechen über sich selbst in der 3. Person hat somit durch die Maskierung des Selbst bzw. durch das Verdecken des eigentlichen Text-Kontext-Verhältnisses ein großes Funktionspotential in Bezug auf die Selbstimagekonstruktion.

Für die Kategorien offenes und verdecktes Polemisieren kann festgehalten werden, dass sie sich auf die Figur des Sprechers beziehen - und zwar sowohl auf das polemische Subjekt als auch auf die Repräsentation des ,realexistenten' Polemikers. Es gibt grundsätzlich zwei unterschiedliche Verhältnisse zwischen diesen beiden Sprecherfiguren: I. Kongruenz

335 Krämer (2004), S. I6.

${ }^{336}$ Vgl. dazu Joachim Fischers Aussagen über die Rolle des Dritten: „Ich und Du liegen im Kampf um die Geltung unserer Teilnehmerperspektiven auf die Wirklichkeit. Erst das Erscheinen des Dritten, mit seiner Beobachterperspektive, zwingt uns nun real, die Wirklichkeit als die Sache selbst, das Dritte, so in unserer Perspektive zur Sprache zu bringen, daß es gleichsam von selbst sprechen würde. [...] Erst die um den Dritten bereicherte Anthropologie der Intersubjektivität vermag das Phänomen des Objektiven zu rekonstruieren, soweit es intersubjektiv konstituiert ist. " Fischer, Joachim (2000): „Der Dritte. Zur Anthropologie der Intersubjektivität“. In: Eßbach, Wolfgang (Hg.): wir / ihr / sie. Identität und Alterität in Theorie und Methode (= Identitäten und Alteritäten 2). Würzburg: Ergon, S. I03-I36, hier S. I28f. 
oder 2. Inkongruenz durch eine Maskierung, die ihrerseits in drei Variationen (anonym, pseudonym und unter anderem Namen) vollzogen werden kann. Bei ersterem ist die Situation des Polemisierens offen, bei zweiterem verdeckt. Relevanz für die Vermittlung der Polemik ergibt sich insofern, dass die Frage „Wer spricht?“ bzw. „Wer äußert die Polemik?" Folgen für die Kommunikationssituation hat, die ihrerseits die Erscheinungsform der Polemik im Einzelnen beeinflusst: Insbesondere für die Konstruktion des Selbstimages des Autors stellt sich die Sprecherfrage als konstitutiv dar.

\subsubsection{Direktes und indirektes Polemisieren}

Während die Ermittlung des Sprechers die Grundlage der Unterscheidung zwischen offenem und verdecktem Polemisieren repräsentiert, steht bei der Differenzierung von direktem und indirektem Polemisieren die Frage „Wer wird angesprochen? “ im Vordergrund. Die Frage nach dem Adressaten der (An-)Rede bzw. nach dem polemischen Objekt ist nicht an die Gestaltung der Sprecherrolle gebunden, so dass die Kategorien ,direktes und indirektes Polemisieren' unabhängig von den bereits genannten Kategorien ,offenes und verdecktes Polemisieren' sind. $\mathrm{Ob}$ offen oder verdeckt polemisiert wird, setzt der Ausformung der Rede keinerlei Grenzen.

Die Beantwortung der Adressatenfrage ist im Gegensatz zur Ermittlung des Sprechers ausschließlich auf der Textebene zu beantworten, so dass ein Abgleich mit der Kontextebene zwar von analytischem Interesse für die Inszenierung, aber für die Kategorieneinteilung nicht erforderlich ist. Begutachtet werden allein die textinterne Kommunikationssituation und der dort konstruierte Adressat. Ob der Adressat der Textebene auch gleichzeitig der auf der Kontextebene intendierte oder tatsächliche Empfänger ist, ist zum einen schwer zu untersuchen und zum anderen irrelevant, da die polemische Instanz, wie bereits erörtert, grundsätzlich der implizite Hauptempfänger von Polemik ist: Sie ist die richterliche Instanz, die erreicht werden soll, d. h. der ,eigentliche', intendierte Adressat ist bei der Methode polemischen Schreibens vorbestimmt. Nicht die Anrede und Persuasion des Gegners (und damit Konsens) werden angestrebt, sondern der Entwurf und die Verstärkung antagonistischer Positionen (vor einem Publikum). Das polemische Objekt kann insofern nicht der Hauptadressat der polemischen Situation auf Kontextebene sein, sondern maximal ein Nebenadressat. Vielmehr als auf die Überredung des Kontrahenten zielt Polemik darauf ab, das polemische Objekt auf eine Weise in Szene zu 
setzen, dass es vom Publikum abgelehnt wird. ${ }^{337}$ Matt formuliert dieses polemische Primärziel überspitzter: Das Publikum soll „den Akt der sozialen Tötung selber vollziehen durch tätige Verachtung, durch die spontane Exkommunikation des andern im Urteil: Der gehört nicht mehr zu uns! " ${ }_{33}^{8}$ Wie das polemische Objekt inszeniert wird, ist u. a. auch davon abhängig, welchen Platz es in der Kommunikationssituation auf der Textebene einnimmt, denn für das Erreichen des Primärziels kann auch das Mittel der Adressierung in vielfacher Weise im Text strategisch eingesetzt werden. Diese textinterne Inszenierung ist jedoch nicht an die textexterne Kommunikationssituation der Polemik gebunden. ${ }^{339}$

Bei der Untersuchung von streitinszenierenden Schriften in Bezug auf die textinterne Polemikvermittlung lassen sich zwei Grundarten der Rede des polemischen Subjekts im Verhältnis zum polemischen Objekt identifizieren: Zum einen kann das polemische Subjekt in einen Dialog mit dem polemischen Objekt treten, zum anderen kann es über das polemische Objekt sprechen, während es sich direkt an das Publikum wenden oder einen Monolog halten kann, ohne ein Publikum zu adressieren. Das Sprecher-Ich kann dementsprechend erstens mit der direkten Anrede, mittels der grammatischen 2. Person, mit dem polemischen Objekt in ,Kontakt' treten oder zweitens das polemische Objekt in der grammatischen 3. Person gleichsam zum Thema machen - dabei ist es zunächst irrelevant, ob eine polemische Instanz direkt angesprochen wird oder nicht. Bremer erörtert die zwei möglichen Redeformen (in Bezug auf das polemische Objekt) ebenfalls als wichtiges Unterscheidungsmerkmal des reformatorischen Streitens:

Neben den bisher genannten Streittechniken ist die Anrede des Gegners bzw. die Form, in der über den Gegner berichtet wird, ein wesentliches Differenzierungsmerkmal. Es gibt im Hinblick auf die Anrede zwei grundlegende Typen von Streitschriften. Zunächst gibt es die Möglichkeit, vom Gegner in der 3. Person Singular zu sprechen, im zweiten Typ wird der Gegner direkt in der 2. Person Singular angesprochen. ${ }^{340}$

337 Stenzel (I984), S. 5-7. Dascals Separation von „staged polemics“ als diejenige Form von Polemik, die sich vornehmlich an das Publikum richtet, ist insofern zu widersprechen, dass jegliche Anwendung von Polemik „staged polemics“ ist bzw. dass es keine andere Form von Polemik als eben diese gibt. Dascal (2004), S. 7.

${ }_{338}$ Matt (I994), S. 35.

339 Vgl. dazu: „Wir halten also daran fest, dass der primäre Adressat polemischer Texte das Publikum ist und dass dieser Sachverhalt ein konstitutives Element der Realsituation ist, auch wenn er in der polemischen Konstellation durch andersartige textinterne Adressierungen verwischt wird.“ Dieckmann (2005), S. 4I.

$34 \circ$ Bremer (2005b), S. 39. 
Bremer spricht in diesem Zusammenhang sogar von ,zwei grundlegenden Typen von Streitschriften“, die durch die divergierenden Kommunikationssituationen hervorgebracht werden. Solch eine Differenzierung in zwei Typen von Streitschriften soll hier hingegen nicht vorgenommen werden, da es allzu selten möglich ist, die konstante Nutzung der einen oder anderen Redeform innerhalb einer ganzen Schrift zu erkennen. ${ }^{34 \mathrm{I}}$ Obgleich Bremers Einteilung verdeutlicht, dass die unterschiedlichen Redeformen (direkte Anrede des/der Kontrahenten oder Rede über ihn/sie) jeweils eine andere Kommunikationssituation mit sich bringen, wird hier jedoch Abstand davon genommen, diese Differenzierung auf den Text als Gesamteinheit zu beziehen. Anstatt von ganzen Schriften als Einheiten auszugehen, bietet es sich an, Texteinheiten und -abschnitte als kleinere Einheiten zur Grundlage der Untersuchung zu machen. Damit umgeht man gleichzeitig den Umstand, dass Gesamttexte selten durchgängig dem einen oder anderen Redeschema folgen. ${ }^{342}$

Die Kommunikationssituation der polemischen Situation, in der das polemische Objekt direkt angesprochen wird, wird in Analogie zur direkten Anredeform unter dem Begriff, direktes Polemisieren' gefasst. Das Sprechen über das polemische Objekt in der 3. Person wird hingegen ,indirektes Polemisieren' bezeichnet. ${ }^{343}$ Da der Einsatz beider Formen mit unterschiedlichen Funktionen verbunden ist und divergierende

${ }^{34 \mathrm{I}}$ Bremer konstatiert im Anschluss an seine Typenidentifikation selbst, dass der Wechsel zwischen direkter Anrede des Gegners und Rede über den Gegner in der 3. Person oftmals innerhalb eines Textes vollzogen wird. Ebd., S. 39.

${ }^{342}$ Dieckmann identifiziert in Bezug auf den "gemeinten Adressaten“ (jenseits der grammatischen 2. Person) vier verschiedene Texttypen: „Eine solche Analyse hätte voraussagbar das Ergebnis, dass in einem Teil der Texte das polemische Objekt angesprochen wird, in einem anderen das Publikum, die Leserschaft in ihrer Rolle als urteilende Instanz, dass in einer dritten Gruppe die Ansprache wechselt und in einer vierten ein Adressat sprachlich überhaupt nicht identifiziert wird. “ Dieckmann (2005), S. 40. Mit seiner potenziellen Einteilung räumt Dieckmann dem Wechsel der Anrede zwar einen sichtbaren Platz ein, er relativiert allerdings seine hypothetischen Vorüberlegungen nachfolgend, indem er zu dem Ergebnis kommt, dass als ,gemeinter Adressat" nur das Publikum gelten kann. Ebd., S. 4I. Damit widerspricht er seinem eigenen Vorschlag zur Kategorisierung von Texttypen. Die Einteilung von polemischen Texten nach dem Kriterium ,Adressat ${ }^{\star}$ eignet sich insofern nicht als Verfahren. Nichtsdestoweniger ist es relevant, wie sich das polemische Subjekt gegenüber dem polemischen Objekt kommunikativ positioniert, ob es direkt angesprochen wird oder nicht, ob es wechselt oder ob gar kein Empfänger konstruiert ist.

343 Wie bereits angedeutet wurde, kommen in der Regel weder die eine noch die andere Art des Polemisierens einförmig und konstant isoliert in einem Text vor, sondern werden realiter nebeneinander und mitunter sogar alternierend eingesetzt. 
rhetorische Strategien mit sich bringen, ist die Differenzierung zwischen beiden Arten trotzdem sinnvoll. Dies bestätigt Bremer, indem er hervorhebt, dass die direkte Anrede ein „Hinweis auf die Personalisierung des Konflikts “ darstelle und eine „emotionalisierende Streitschrift“ zur Folge habe. ${ }^{344}$ Die Unterscheidung der beiden Redeformen ist deshalb fruchtbar zu machen, weil die unterschiedlichen Kommunikationssituationen divergierende Funktionspotentiale in Bezug auf die Streitinszenierung beinhalten.

\section{Direktes Polemisieren}

Im Fall des direkten Polemisierens erfolgen die Diskreditierung des Gegners und die Widerlegung seiner Argumente bildlich gesprochen geradeaus ohne Umschweife. Die Kommunikationssituation ist formal gesehen ein lediglich einseitig geführter Dialog des polemischen Subjekts mit dem polemischen Objekt. Durch verschiedene Techniken kann das polemische Objekt jedoch so in den Text eingeschrieben werden, dass mitunter der Effekt eines Streitgesprächs unter vier Augen entsteht: Die Aussagen des Gegners werden mithilfe direkter oder indirekter Redewiedergabe eingeflochten, seine zukünftigen Reaktionen oder Antworten auf die eigenen Aussagen noch unmittelbar in derselben Schrift antizipiert und seine Person ausgiebig beschrieben, so dass der Gegner schließlich in der durch den Text konstruierten Form Gestalt annimmt:

Von einem Verfahren ist hier unabdingbar zu reden: von dem dringlichen Streben der Polemiker, den Gegner selber auftreten zu lassen. Das kann sich eigentlichen Bühnenszenen annähern. Was Abhandlung war, wird jäh zum Dialog. Der Widersacher spricht, der Polemiker antwortet, und siehe, er behält immer recht. Der Gegner steht da, oft genug in seines Leibes Schwäche; er darf Satz um Satz vorbringen und bekommt für jeden eins aufs Haupt, sorgsam gezielt und liebevoll gesetzt. ${ }^{345}$

Durch die eingesetzten Mittel wird der Text performativ. Er vermittelt dem Leser den Streit nicht bloß, sondern er stellt dem Leser den Streit vor Augen. Der Text wird somit zur Bühne, auf der ein Aufeinandertreffen des polemischen Subjekts und Objekts nahezu bildlich inszeniert wird. Die polemische Instanz ist im Idealtypus des direkten Polemisierens auf der Textebene nicht explizit vorhanden - in der Bühnenmetapher

\footnotetext{
344 Bremer (2005b), S. 39.
}

345 Matt (I994), S. 40. 
verbleibend sitzt das Publikum dementsprechend im Dunkeln, die Akteure hingegen treten auf der Bühne im Scheinwerferlicht auf.

Fasst man die erörterten Merkmale zusammen, kann als die idealtypische Situation des direkten Polemisierens jene bezeichnet werden, in der ein Zwigespräch zwischen polemischem Subjekt und Objekt vor einer nicht adressierten, aber als existent vorausgesetzten polemischen Instanz stattfindet. Das Publikum wird insofern immer mitgedacht und verbleibt Adressat der Polemik, wird aber nicht explizit angesprochen oder näher beschrieben. Anstatt des Publikums wird in diesem Fall das polemische Objekt als alleiniger Adressat inszeniert. ${ }^{346}$

\section{Indirektes Polemisieren}

Im Falle indirekten Polemisierens ist die Kommunikationssituation in der Weise konstruiert, dass das polemische Subjekt in der grammatischen 3. Person über das polemische Objekt spricht. Anstatt mit dem polemischen Objekt in den Dialog zu treten, wendet sich das polemische Subjekt entweder bewusst der polemischen Instanz zu - die direkte Anrede kann dort zum Einsatz kommen - oder sie hält eine Art Monolog, für den kein genauer Adressat identifizierbar ist. Das bedeutet, dass die polemische Instanz ebenso wie beim direkten Polemisieren auch eine textinterne Rolle einnehmen kann, es aber nicht muss. Auch beim indirekten Polemisieren bleibt sie in jedem Fall - präsent oder absent im Text - der Adressat, der jenseits des Textes erreicht werden soll. Im Unterschied zum direkten Polemisieren ermöglicht jedoch die Rede über das polemische Objekt in der 3. Person, dass der polemischen Instanz nicht nur implizit auf Kontextebene, sondern auch explizit auf der Textebene die Adressatenrolle zukommen kann. Das polemische Objekt wird im Idealtypus des indirekten Polemisierens hingegen als abwesende Kategorie behandelt und zu einem Thema ,degradiert', über das räsoniert wird.

Die Polemik, die so kommuniziert wird, ist jedoch ärmer an performativen Elementen, da mit der Rede über den Gegner in der 3. Person die Narrativität begünstigt wird. In Bezug auf die Streitinszenierung

${ }^{346}$ Erneut muss hinzugefügt werden, dass selten ein gesamter Text nach dem Muster des direkten Polemisierens gestaltet ist, sondern dass häufig nur einzelne Textabschnitte einheitlich sind. Es ist beispielsweise zu beobachten, dass viele polemische Schriften eine Rahmenstruktur besitzen: Gruß und Schluss sind dabei deutlich an ein Publikum adressiert (z. T. mit direkter Anrede), während die Kommunikationssituation innerhalb des Rahmens überwiegend einen Dialog mit dem polemischen Objekt darstellt. 
tritt das Erzählen vom Streit an die Stelle des Vor-Augen-Stellens des Streits. Die vorhandenen performativen Elemente der Inszenierung sind weniger bei der Streitaufführung zu verorten, als bei der Konstruktion des polemischen Antagonismus und des Selbst- und Fremdimages. Mit indirektem Polemisieren kann eine kommunikative Distanz geschaffen werden, der Gegner wird nicht adressiert, sondern als Ansprechpartner gemieden und aus der Kommunikationssituation gleichsam verbannt. Bildlich könnte man sagen, es wird mit dem Finger auf den Kontrahenten gezeigt, ohne dass dieser eine Stimme erhält. Bremer betont das Erzeugen einer solchen Distanz zum Gegner mittels der 3. Person und konstatiert in dem Zusammenhang: "Sie sprechen ihren Gegnern unausgesprochen die ,Ehre' der direkten Rede ab [...].“3477 Damit identifiziert Bremer kommunikative Strategien in den schriftlichen Streitigkeiten um Glaubensfragen, die Krämer für die menschliche Kommunikation im Allgemeinen konstatiert: Da die „Entwicklung unserer Identität [...] der Anerkennung durch die Anderen “ bedarf, nimmt das Angesprochenwerden eine zentrale Stellung für die „Verletzungsmacht der Rede“ ein. ${ }^{348}$ „Nicht mehr angesprochen zu werden, ist dann ein Kulminationspunkt sprachlicher Verletzbarkeit und kann kondensiert werden zur Chiffre vom ,sozialen Tod'. "Das Ignorieren einer Person ist demgemäß eine größere soziale Ächtung als die „AnVerkennung“ beleidigender Rede, da „jedwedes Ansprechen eines Anderen unausweichlich - und damit unabhängig von seinem Inhalt - einen Akt von Anerkennung vollzieht“..349

Die kommunikative Distanz zum Gegner kann zusätzlich mit gezielt eingesetzter Nähe zum Publikum kombiniert werden, indem mittels direkter Anrede der Dialog mit der polemischen Instanz eröffnet wird. Die Anrede der polemischen Instanz impliziert noch eindringlicher die gezielte kategorische Ausschließung des polemischen Objekts aus dem Kreise der Kommunikationsteilnehmer bzw. seine soziale Ächtung. Eine (auf die Leserschaft bezogene) persuasive oder eine die Gruppenzugehörigkeit stärkende Funktion wird in dem Fall auch im Text offen inszeniert und der Fokus auf die Bindung zum Publikum gelegt.

347 Bremer (2005b), S. 39. Mit „Sie“ sind bei Bremer zwar Martin Luther und Georg Scherer gemeint; das "Sie“ kann aber ebenso stellvertretend für viele andere Polemiker des I6. Jahrhunderts stehen.

$34^{8}$ Krämer (2010), S. 40.

349 Sämtliche vorangehenden Zitate in ebd. S. 4I. 
Ein Polemiker kann das indirekte Polemisieren auf unterschiedliche Weise einsetzen: Das narrative Element und die kommunikative Distanz können dafür genutzt werden, in einen berichtenden Stil zu wechseln, der emotionale Gleichgültigkeit zeigen soll, um auf diese Weise den Wahrheitsgehalt des Gesagten zu unterstützen. In solch einem Fall kann die Argumentation sehr sachlich ausgerichtet sein. Es können aber ebenfalls beleidigende Passagen eingebaut werden, wobei die kommunikative Distanz als bewusst ablehnende Haltung gegenüber dem Kontrahenten eingesetzt werden kann. Die Narrativität vermag auch hier die Objektivierung der eigenen Aussagen zu begünstigen. Das Sprechen über den Gegner in der 3. Person eröffnet insofern eine Fülle an möglichen Streittechniken, die sich stilistisch von der grobianischen Beleidigung bis zur sachlichen Abhandlung erstrecken. ${ }^{350}$

350 Vgl. Bremer (2005b): In den einzelnen Textanalysen identifiziert Bremer sehr unterschiedliche Funktionen für die Rede über den Gegner in der 3. Person: Sie zielt auf die „Isolierung“ (S. I60) des Gegners und wird eingesetzt, „um möglichst große Distanz zwischen sich und dem Gegner zu demonstrieren“ (S. I 50 ). Sie unterstützt den Wechsel hin zu einem „sachlichen Stil“ (S. I42), wirkt dann aber an anderer Stelle „besonders abschätzig“ (S. 93) und wiederum in einer anderen Schrift wird sie eingesetzt, um Streittechniken anzubringen, die dem „seelsorgerlichen Duktus [, der in direkter Anrede gehalten ist,] nicht angemessen sind“ (S. I3O). 